\title{
VARIAÇÃO DOS PARÂMETROS FÍSICOS DO CAMPO ULTRA-SÔNICO EM FONOFORESE COM DICLOFENACO GEL
}

\author{
Pedro Barco Cárnio
}

Dissertação apresentada ao Programa de Pós-Graduação Interinidades Bioengenharia - Escola de Engenharia de São Carlos I Faculdade de Medicina de Ribeirão Preto I Instituto de Química de São Carlos da Universidade de São Paulo, como parte dos requisitos para obtenção do título de Mestre em Bioengenharia.

ORIENTADOR: Prof. Dr. Nilton Mazzer

São Carlos 
Dedico este trabalho a toda minha família que me incentivou e auxiliou em todos os momentos da minha vida. Em especial aos meus pais Antonio Cárnio e Vanda Barco Cárnio que mesmo ausentes sempre se sacrificaram por mim, à Sonia minha esposa, e a minha filha Lívia pela compreensão e carinho. E a Deus por mais esta conquista. 


\section{AGRADECIMENTOS}

Ao meu orientador Prof. Dr. Nilton Mazzer, por sua capacidade, serenidade, amizade e empenho na realização deste trabalho.

Ao Prof. Dr. Carlos Dias Maciel, pela sua amizade e colaboração indispensável na realização deste trabalho.

Ao Prof. Dr. José Carlos Pereira, por seu carinho e atenção na elaboração deste trabalho.

A todos os funcionários da Bioengenharia que direta e indiretamente ajudaram na realização deste trabalho.

A Eliana Mello por sua ajuda na digitação e diagramação dos textos.

Aos meus professores de graduação da Universidade Federal de São Carlos, pelo incentivo constante na busca do conhecimento científico. 


\section{RESUMO}

CÁRNIO, PB. (2005). Variação dos parâmetros físicos do campo ultra-sônico em fonoforese com diclofenaco gel. Dissertação (Mestrado em Bioengenharia) - Escola de Engenharia de São Carlos, Faculdade de Medicina de Ribeirão Preto, Instituto de Química de São Carlos, Universidade de São Paulo.

O objetivo do presente trabalho foi de analisar, experimentalmente, a variação do índice de transmissão e o coeficiente de atenuação ultra-sônica no meio diclofenaco gel, bem como, a penetração do fármaco em amostras de gelatina semelhante a pele humana através da fonoforese. A variação destes parâmetros foi investigada em 120 amostras de agar-agar, (modo contínuo, $1 \mathrm{MHz}$ de freqüência, nas intensidades de 1,0 e 1,5 W/cm²), por 5 minutos. Os corpos de prova forma divididos em grupos referentes as intensidades de ultra-som utilizadas, e cada um destes grupos, foi subdividido em sub-grupos correspondendo aos diferentes meios utilizados para irradiação. A investigação da transmissão ultra-sônica foi medida a partir de um dosímetro de precisão ULTRASONIC POWER METER, modelo UPM-DT 10. O calculo do coeficiente de atenuação foi realizado a partir dos dados de leitura da transmissão ultrasônica. A penetração ou não da droga foi estudada por analise macroscópica e microscópica. Segundo os resultados obtidos não houve variação significativa nos índices de transmissão e nos coeficientes de atenuação do diclofenaco gel em comparação ao gel neutro. A penetração do medicamento foi de $3 \mathrm{~mm}$ para as amostras irradiadas com a intensidade de $1,0 \mathrm{~W} / \mathrm{cm}^{2}$ e de $5 \mathrm{~mm}$ para as amostras irradiadas com $1,5 \mathrm{~W} / \mathrm{cm}^{2}$, não houve evidencia de penetração do fármaco no grupo controle. Os resultados obtidos neste estudo sugerem que a fonoforese do diclofenaco gel é efetiva nas intensidades 1,0 e 1,5 W/cm².

Palavras-chave: atenuação ultra-sônica, fonoforese, penetração de drogas transdérmicas, ultra-som, transmissão ultra-sônica. 


\section{ABSTRACT}

CÀRNIO P.B. (2005) Variation of the Physical Parameters of the Ultrasonic field in Phonophoresis with Diclofenaco gel. Dissertation (Master's degree in Bioengenharia) - School of Engineering of São Carlos, University of Medicine of Ribeirão Preto, Institute of Chemistry of São Carlos, University of São Paulo.

I The objective of the present work was of analyzing, experimentally, the variation of the transmission index and the coefficient of ultrasonic reduction in the half diclofenaco gel, as well as, the penetration of the drug in samples of similar jelly the human skin through the phonophoresis. The variation of these parameters was investigated in 120 agar-agar samples, (continuous way, $1 \mathrm{MHz}$ of frequency, in the intensities of 1,0 and $1,5 \mathrm{~W} / \mathrm{cm}^{2}$ ), for 5 minutes. The proof bodies form divided in referring groups the ultrasound intensities used, and each one of these groups, it was subdivided in sub-groups corresponding to the different means used for irradiation. The investigation of the ultrasonic transmission was measured starting from a ULTRASONIC POWER to PUT, I model UPM-DT 10. The calculate it of the reduction coefficient was accomplished starting from the data of reading of the ultrasonic transmission. The penetration or not of the drug it was studied for it analyzes macroscopic and microscopic. According to the obtained results there was not significant variation in the transmission indexes and in the coefficients of reduction of the diclofenaco gel in comparison with the neutral gel. The penetration of the medicine went of $3 \mathrm{~mm}$ to the samples irradiated with the intensity of $1,0 \mathrm{~W} / \mathrm{cm}^{2}$ and of $5 \mathrm{~mm}$ for the samples irradiated with $1,5 \mathrm{~W} / \mathrm{cm}^{2}$, there was not evidences of penetration of the drug in the group control. The results obtained in this study suggest that the phonophoresis of the diclofenaco gel is effective in the intensities 1,0 and $1,5 \mathrm{~W} / \mathrm{cm}^{2}$.

Keywords: ultrasonic, phonophoresis, penetration of drugs, transdermal drug delivery, therapeutic ultrasound. 


\section{LISTA DE FIGURAS}

FIGURA 1 - Estrutura da pele - www.saudepravc.com.br/histologia .................. 16 FIGURA 2 - Vias Transdérmicas de Absorção Percutânea - PANCHAGNULA (1997) 21

FIGURA 3 - Iontoforese - CURRENT DRUG DELIVERY (2004)..................... 24

FIGURA 4 - Eletroporação - CURRENT DRUG DELIVERY (2004) ................... 25

FIGURA 5 - Ondas Fotomecânicas - CURRENT DRUG DELIVERY (2004).......26

FIGURA 6 - Fonoforese - CURRENT DRUG DELIVERY (2004) ......................27

FIGURA 7 - Ultra-som induzindo a cavitação na pele - ENCYCLOPEDIA OF

PHARMACEUTICAL THECNOLOGY (1997)............................... 28 


\section{LISTA DE GRÁFICOS}

GRÁFICO 1 - Variação da transmissão ultra-sônica (1,0 W/cm² Gel e Corante). 45 GRÁFICO 2 - Variação da transmissão ultra-sônica $\left(1,0 \mathrm{~W} / \mathrm{cm}^{2}\right.$ Diclofenaco

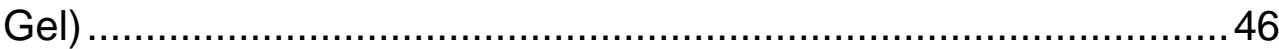

GRÁFICO 3 - Variação da transmissão ultra-sônica $(1,0$ W/cm² Diclofenaco Gel e Corante)

GRÁFICO 4 - Variação da transmissão ultra-sônica $(1,0$ W/cm² Diclofenaco Gel e Corante)

GRÁFICO 5 - Variação da transmissão ultra-sônica $\left(1,0 \mathrm{~W} / \mathrm{cm}^{2}\right.$ Diclofenaco Gel) 49

GRÁFICO 6 - Variação da transmissão ultra-sônica $(1,5$ W/cm² Diclofenaco Gel e Corante) 50

GRÁFICO 7 - Variação do Coeficiente de Atenuação $\left(1,0 \mathrm{~W} / \mathrm{cm}^{2}\right.$ Gel e Corante) ....51 GRÁFICO 8 - Variação do Coeficiente de Atenuação $\left(1,0 \mathrm{~W} / \mathrm{cm}^{2}\right.$ Diclofenaco

Gel) 52

GRÁFICO 9 - Variação do Coeficiente de Atenuação $\left(1,0 \mathrm{~W} / \mathrm{cm}^{2}\right.$ Diclofenaco

Gel e Corante) 53

GRÁFICO 10 - Variação do Coeficiente de Atenuação $\left(1,5 \mathrm{~W} / \mathrm{cm}^{2}\right.$ Gel e Corante) 54

GRÁFICO 11 - Variação do Coeficiente de Atenuação $\left(1,5 \mathrm{~W} / \mathrm{cm}^{2}\right.$ Diclofenaco Gel) 55

GRÁFICO 12 - Variação do Coeficiente de Atenuação $\left(1,5 \mathrm{~W} / \mathrm{cm}^{2}\right.$ Diclofenaco

Gel e Corante) 56 


\section{LISTA DE FOTOS}

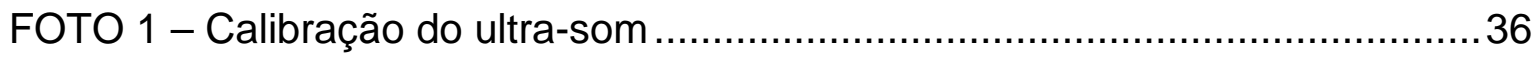

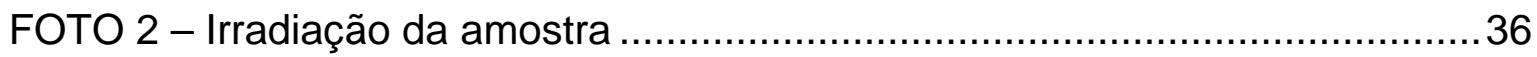

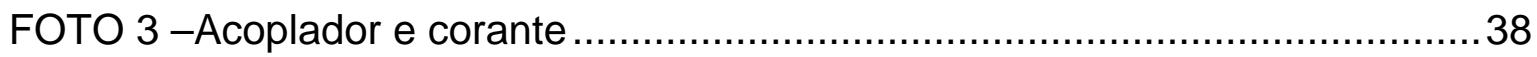

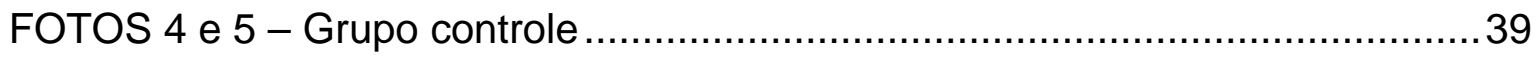

FOTO 6 - Análise macroscópica das amostras................................................40

FOTO 6 - Análise macroscópica das amostras................................................ 41

FOTO 8 - Lâminas das amostras ................................................................ 41

FOTO 9 e 10 - Análise microscópica das amostras ........................................... 42

FOTO 11 - Grupo controle - análise macroscópica ............................................57

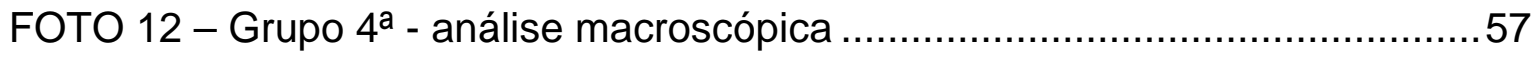

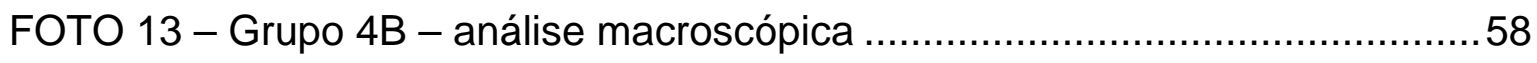

FOTO 14 - Grupo controle - análise microscópica ………………...................58

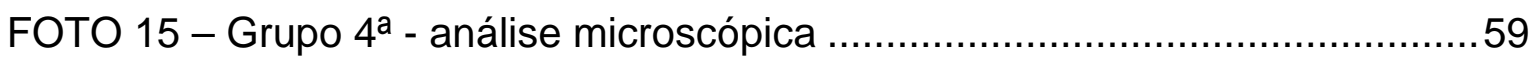

FOTO 16 - Grupo 4B - análise microscópica ……….........................................59 


\section{LISTA DE TABELAS}

TABELA 1 - Níveis de intensidade utilizados em fonoforese 29

TABELA 2 - Transmissão relativa de antiinflamatórios tópicos em relação à água deionizada 32

TABELA 3 - Teste t: duas amostras presumindo variâncias diferentes:

Gel Neutro e Corante $1,0 \mathrm{~W} / \mathrm{cm}^{2}$ 44

TABELA 4 - Teste-t: duas amostras presumindo variâncias diferentes:

Gel Neutro e Diclofenaco $1,0 \mathrm{~W} / \mathrm{cm}^{2}$ 45

TABELA 5 - Teste-t: duas amostras presumindo variâncias diferentes: Gel Neutro e Diclofenaco Corante $1 \mathrm{~W}$ 46

TABELA 6 - Teste-t: duas amostras presumindo variâncias diferentes: Gel Neutro e Corante $1,5 \mathrm{~W} / \mathrm{cm}^{2}$

TABELA 7 - Teste-t: duas amostras presumindo variâncias diferentes: Gel Neutro e Diclofenaco $1,5 \mathrm{~W} / \mathrm{cm}^{2}$

TABELA 8 - Teste-t: duas amostras presumindo variâncias diferentes: Gel Neutro e Diclofenaco Corante $1,5 \mathrm{~W} / \mathrm{cm}^{2}$

TABELA 9 - Teste-t: duas amostras presumindo variâncias diferentes: Gel e Corante $1,0 \mathrm{~W} / \mathrm{cm}^{2}$

TABELA 10 - Teste-t: duas amostras presumindo variâncias diferentes:

Diclofenaco Gel 1,0 W/cm ${ }^{2}$ 52

TABELA 11 - Teste-t: duas amostras presumindo variâncias diferentes:

Diclofenaco Gel e Corante 1,0 W/cm ${ }^{2}$. 53

TABELA 12 - Teste-t: duas amostras presumindo variâncias: Gel e Corante 1,5 $\mathrm{W} / \mathrm{cm}^{2}$

TABELA 13 - Teste-t: duas amostras presumindo variâncias diferentes:

Diclofenaco Gel 1,5 W/cm ${ }^{2}$ 55

TABELA 14 - Teste-t: duas amostras presumindo variâncias diferentes:

Diclofenaco Gel e Corante 1,5 W/cm 2 . 56 


\title{
LISTA DE ABREVIATURAS E SIGLAS
}

\author{
$\mathrm{cm}^{2} \quad$ centímetro quadrado; \\ cm centímetro; \\ et al colaboradores; \\ $\mathrm{dB} / \mathrm{mm}$ decibéis por milímetros; \\ $\mathrm{Hz} \quad$ Hertz; \\ MHZ Mega Hertz; \\ KHz Kilo Hertz; \\ W/cm² Watts por centímetro quadrado; \\ Nm nanômetro; \\ MI mililitros; \\ Mm milímetros; \\ $\mathrm{m}^{2} \quad$ metro quadrado; \\ ms mili segundo; \\ $\mu$ micro segundo; \\ g grama; \\ UPM Ultrasound Power Metter; \\ HCFMRP Hospital das Clínicas de Ribeirão Preto; \\ USP Universidade de São Paulo; \\ EESC Escola de Engenharia de São Carlos;
}


$\mu \mathrm{m} \quad$ Micrometro;

$\mathrm{pH} \quad$ Potencial de Hidrogênio;

$\mathrm{J} / \mathrm{cm}^{2} \quad$ Joule por centímetro quadrado;

Ln Logaritmo Neperiano. 


\section{LISTA DE SÍMBOLOS}

\begin{tabular}{|c|c|}
\hline$\%$ & Porcentagem; \\
\hline$\circ$ & Graus; \\
\hline${ }^{\circ} \mathrm{C}$ & Graus Celsius; \\
\hline$\alpha$ & Coeficiente de Atenuação; \\
\hline $\mid \alpha$ & Valor da Intensidade de Irradiação; \\
\hline lo & Valor da Intensidade Obtida; \\
\hline L & Espessura da Amostra; \\
\hline$\beta$ & Beta; \\
\hline$>$ & Maior; \\
\hline$<$ & Menor; \\
\hline$=$ & Igual; \\
\hline$p$ & Valor ou nível de significância; \\
\hline & Menos. \\
\hline
\end{tabular}




\section{SUMÁRIO}

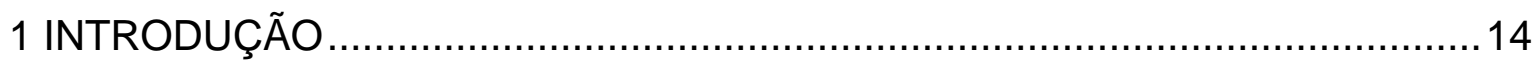

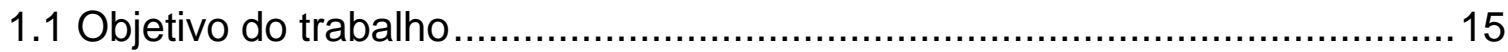

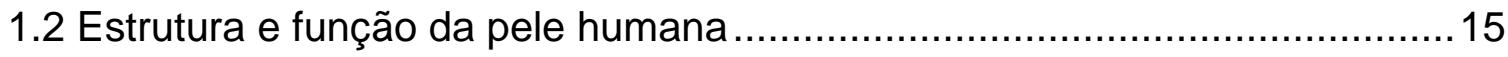

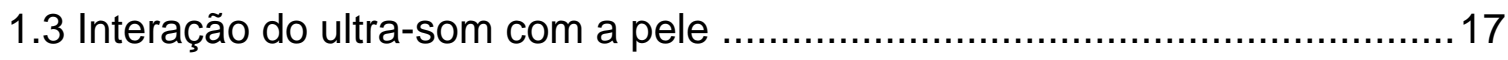

1.4 Aplicação de drogas transdérmicas e sua associação com agentes físicos. 20

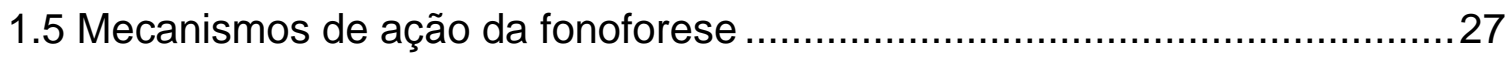

1.6 Revisão dos estudos sobre a influência dos meios acoplantes

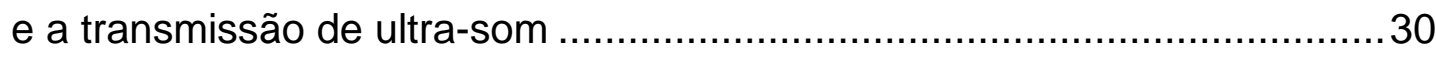

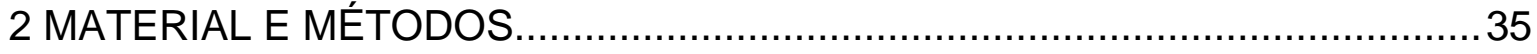

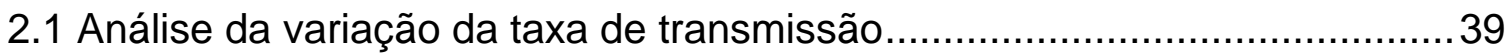

2.2 Análise do coeficiente de atenuação ......................................................... 40

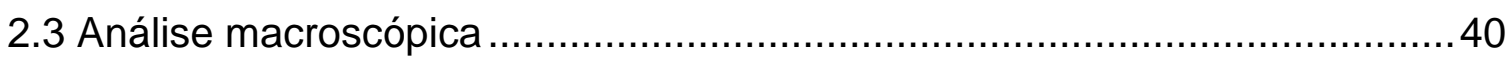

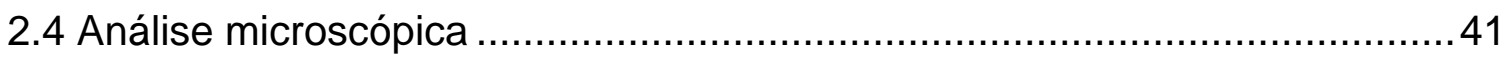

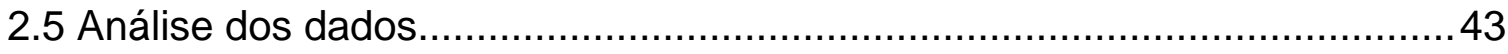

3 RESULTADOS

3.1 Variação da transmissão ultra-sônica dos meios...........................................44

3.2 Variação do coeficiente de atenuação dos meios..........................................50

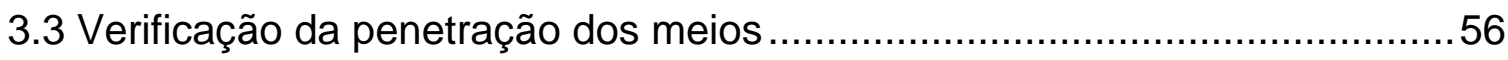

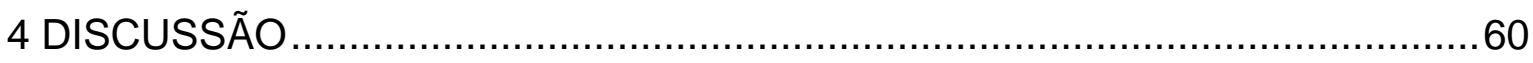

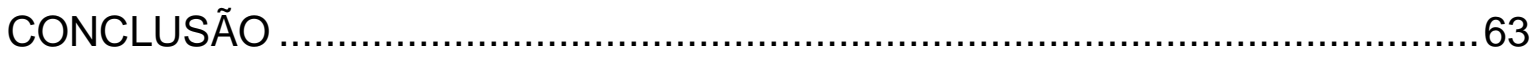

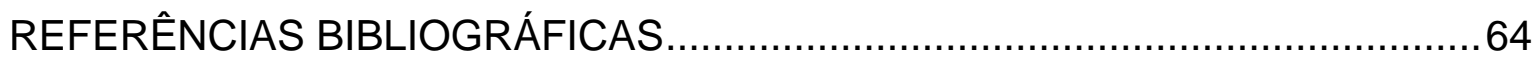

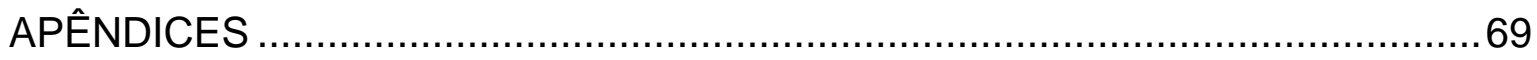




\section{INTRODUÇÃO}

O desenvolvimento de métodos alternativos para administração de medicamentos vem sendo estudado com o objetivo de diminuir o desconforto relatado por alguns indivíduos em relação aos métodos tradicionais como, injeções e comprimidos.

A opção de utilizar a pele como via de administração medicamentosa está encontrando várias vantagens em relação aos métodos tradicionais, no entanto, devido a vários fatores que podem interferir no uso desta técnica, faz com seja necessário à criação de um novo campo de estudo na área da biotecnologia.

O desenvolvimento de sistemas de transporte medicamentoso através da pele é um tema atual no meio científico e a cada dia que passa se torna um campo amplo de estudo para os pesquisadores.

Devido à utilização de vários tipos de tecnologia, o assunto é abordado de forma interdisciplinar e complexa envolvendo várias especialidades tais como; engenharia farmacêutica, engenharia química, bioengenharia, farmácia bioquímica e medicina.

A utilização de ondas ultra-sônicas para o transporte de medicamentos vem sendo relatada desde 1950, denominada fonoforese, ultra-sonoforese ou sonoforese seus mecanismos de atuação ainda não estão totalmente esclarecidos sendo necessários mais estudo nesta área (PANCHAGNULA, 1997; LOW \& REED, 2001).

O meio intermediário para o acoplamento do ultra-som é um dos fatores que podem afetar a eficiência da técnica de fonoforese (PANCHAGNULA, 1997).

O agente acoplador deve apresentar um coeficiente de atenuação apropriado para técnica, sendo que, um meio com baixa qualidade de transmissão ultra-sônica pode diminuir a intensidade da irradiação incidente no tecido, alterando assim, a interação do ultra-som na penetração do 
medicamento (REID \& CUMMINGS, 1977; DOCKER et al., 1982; LOW \& REED, 2001).

\subsection{Objetivo do trabalho}

Foi objetivo do presente estudo verificar os índices de transmissão, atenuação e penetração de um agente acoplador na forma de gel, (diclofenaco dietilamônio), em corpos de prova com estrutura similar a pele humana, durante a irradiação ultra-sônica com a freqüência de $1 \mathrm{MHz}$, e nas intensidades de 1,0 e 1,5 W/cm², com o tempo de aplicação de 5 minutos.

\subsection{Estrutura e função da pele humana}

A pele é um órgão complexo e mais extenso do corpo humano, cobre uma área de aproximadamente $1,73 \mathrm{~m}^{2}$ recebe aproximadamente 1/3 do sangue circulante do corpo, tem como funções de proteção, regulação da temperatura, produção de suor, sensação e pode também permitir a passagem de medicamentos pela sua camada externa (PANCHAGNULA, 1997).

O tecido epitelial compõe-se quase exclusivamente de células, apresenta pouca substancia intersticial, tem como característica uma grande coesão celular.

Basicamente composta de duas camadas, a epiderme com $100 \mu \mathrm{m}$ de profundidade, mais superficial e sem vascularização e a derme, subjacente a ela, com cerca de 500 a 3,000 $\mu \mathrm{m}$ de profundidade e altamente vascularizada, ambas apresentam uma estrutura microscópica complexa (FIGURA 1). 


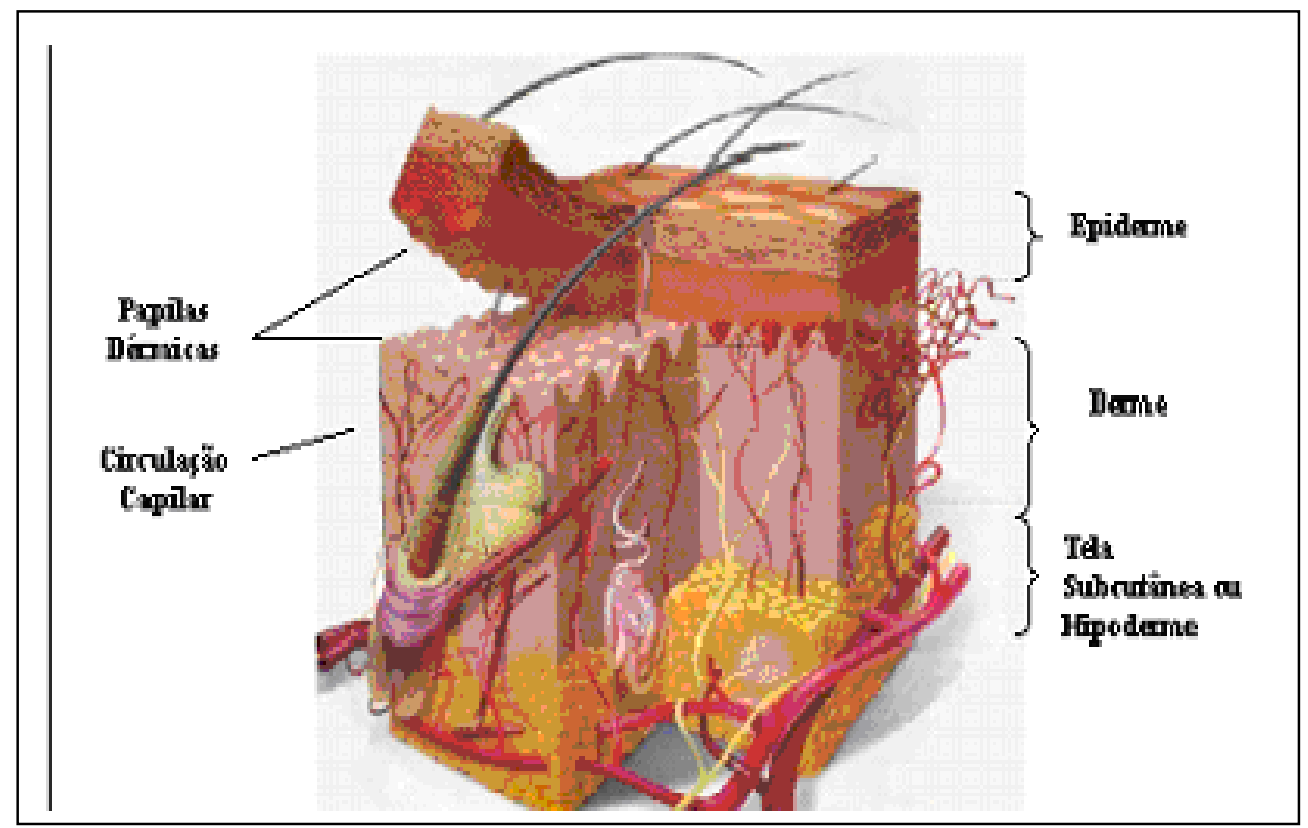

Figura 1- Estrutura da pele: corte histológico com as várias camadas que compõe o tecido epitelial; Epiderme, derme papilas dérmicas, circulação capilar e tela subcutânea.

Fonte - www.saudepravc.com.br/pintanapele/histologia.htm (figura modificada)

$\mathrm{Na}$ epiderme as camadas que a compõe estão continuamente sendo substituídas, sendo que as células de superfície morrem e são convertidas em escamas de queratina que se desprendem da epidérmica, a epiderme regenerada contém enzimas que metabolizam algumas substâncias penetradoras, estas enzimas podem estar presentes também no stratum corneum (MARZULLI et al., 1962).

O stratum corneum é a camada mais externa da epiderme, e é formado por uma estrutura heterogênea na qual se encontra $40 \%$ de proteínas (principalmente queratina), 15 a 20\% de gordura e $40 \%$ de água (MICHAELS et al., 1975).

A derme é rica em fibras colágenas e elásticas que conferem a pele sua capacidade de distender-se quando tracionada (DANGELO \& FATTINI, 1988).

Entre estas duas camadas temos um tecido hidratado de colágeno, com extensas redes de capilares, esta camada mostra elevações ditas papilas dérmicas, que se projetam na epiderme fazendo com que esta estrutura apresente uma série de cristas separadas por sulcos, estes ocupam cerca de 
$1 \%$ do total da superfície da pele e acredita -se que são responsáveis pelo transporte de substâncias do meio externo para a circulação capilar (SCHEUPLIEN \& BLANK, 1971; DANGELO \& FATTINI, 1988).

As células do tecido dérmico repousam sobre o tecido hipodérmico ou tela subcutânea que é rica em gordura, entretanto a quantidade de gordura varia nas diferentes partes do corpo, não estando presentes em algumas regiões como as pálpebras e o prepúcio, tem como função evitar a perda de calor e constitui reserva de material nutritivo (DANGELO \& FATTINI, 1988).

\subsection{Interação do ultra-som com a pele}

A interação das ondas ultra-sônicas com a pele é atribuída aos diferentes mecanismos produzidos por este tipo de irradiação como; aumento da microcirculação, promoção da reparação tecidual, indução de um campo elétrico ao nível da membrana celular e modificação da posição de partículas intra e extracelulares (LOW \& REED, 2001; OKUNO, 1986; GONÇALVES \& PARIZOTTO, 1998; SILVA, 1987).

A utilização do ultra-som na terapia de reparação cutânea tem ação importante sobre as diversas fases do processo inflamatório. Sua ação na fase inflamatória inicial da reparação é uma aceleração do processo, aumentando a liberação de fatores de crescimento pela desgranulação dos mastócitos, plaquetas e macrófagos. O ultra-som atuaria como um acelerador do processo inflamatório, portanto não como antiinflamatório. Segundo os autores, que o que se pode definir como efeitos já confirmados do ultra-som sobre o processo inflamatório e a reparação tecidual é a possibilidade de potencializar ou inibir a atividade inflamatória dependendo da geração de radicais livres nos tecidos, ou por ação direta ou por meio da circulação sanguínea, existe mediação do ultrasom sobre a inflamação, alterações na migração e função leucocitárias, aumento na angiogênese, na síntese e maturação de colágeno e também na formação do tecido cicatricial (GONÇALVES \& PARIZOTTO, 1998). 
Movimentos unidirecionais que ocorrem em fluidos submetidos a um campo ultra-sônico são denominados de fluxo e microfluxo, este fenômeno origina o aparecimento de forças e tensões que podem modificar a posição de partículas intra e extracelulares ou mesmo afetar a atividade celular (OKUNO, 1986). Vários estudos têm sugerido que o microfluxo causado pela irradiação do ultra-som terapêutico é um dos mecanismos responsáveis pela regeneração de tecidos lesados (HADDAD, 1992).

Silva (1987), afirmou que a aplicação de ondas de ultra-sônicas sobre a membrana celular de tecidos colágenos, pode determinar a ação de um campo elétrico o que pode ser uma explicação para o efeito reparador do ultra-som sobre a pele.

Shaoxia et al (2004), conclui que a irradiação do ultra-som pulsado induz a proliferação de fibroblastos primários da pele e conseqüentemente promove a regeneração tecidual.

Gonçalves (2003), estudou o efeito da aplicação do ultra-som terapêutico em enxertos de pele total em coelhos, sendo o tratamento iniciado no $3^{\circ}$ dia pós -operatório e aplicado diariamente por 7 dias. A intensidade utilizada foi de $0,5 \mathrm{~W} / \mathrm{cm}^{2}$, com uma freqüência de $3 \mathrm{MHz}$, por um tempo de 5 minutos. Os resultados demonstraram que houve um significativo aumento no número de células em proliferação na epiderme e vasos neoformados na camada reticular da derme, mas isto não implicou em uma diferença entre as áreas da epiderme e derme, nos enxertos irradiados e não irradiados.

Outro efeito que vem sendo amplamente estudo pelos pesquisadores atualmente, é a promoção do aumento da permeabilidade cutânea através da aplicação de ultra-som sobre a pele.

Os mecanismos pelos quais o ultra-som aumenta a permeabilidade cutânea ainda não são totalmente esclarecidos, uma das teorias mais difundidas atualmente é que a irradiação ultra-sônica provoca pequenas rupturas no tecido epitelial, em uma intensidade superior a $0,75 \mathrm{~W} / \mathrm{cm}^{2}$, após alguns segundos de aplicação (FRENKEL et al, 1999). 
A aplicação de ondas ultra-sônicas em freqüências e intensidades mais baixas também é estudada com o objetivo de não promover danos teciduais à pele.

Estudos realizados com ultra-som pulsado de baixa freqüência e baixa intensidade têm demonstrado grande efetividade no aumento da permeabilidade percutânea sem que ocorram rupturas no tecido epitelial (MITRAGOTRI, 1995). A teoria em que se fundamenta o efeito do aumento da permeabilidade nestas condições, é que ocorre a formação de microbolhas gasosas entre a barreira lipídica das células da pele, proporcionado assim uma desestruturação histológica local (PANCHAGNULHA, 1997).

A comparação da utilização do ultra-som terapêutico e do ultra-som de baixa freqüência, também foi realizada.

Mitragrotri (1996), comparou a aplicação do ultra-som terapêutico na freqüência de 1-3 MHz, com intensidade de $0-2 \mathrm{~W} / \mathrm{cm}^{2}$, com a utilização do ultra-som pulsado de baixa freqüência $(20 \mathrm{KHz})$ e baixa intensidade (125 $\mathrm{mW} / \mathrm{cm}^{2}$ ), na facilitação do transporte transdérmico de drogas na pele de cadáveres (in vitro). Os resultados obtidos demonstraram que, o ultra-som de baixa freqüência proporcionou um aumento significativo na absorção de substâncias de grande peso molecular como; estradiol, acido acetil-salicílico, cortisona, sacarose, solução de adestosterona e butanol em relação ao ultrasom terapêutico. As análises histológicas do tecido não evidenciaram lesões estruturais nas células epiteliais. Diante os seus resultados o autor concluiu que apesar de serem necessários maiores estudos futuros, o processo de indução de cavitação estável na barreira lipídica da pele promove um aumento da permeabilidade cutânea com uma maior eficiência nestas condições e que o transporte transdérmico de medicamentos por agentes físicos é uma alternativa viável em comparação a administração oral ou através de injeções. 


\subsection{Aplicação de drogas transdérmicas e sua associação com agentes físicos}

A aplicação de drogas através da pele é uma opção terapêutica que apresenta algumas vantagens em relação à administração oral e injetável de medicamentos tais como: liberação contínua de medicamentos com uma taxa premeditada, evita altas concentrações ou valores sub-terapêuticos, diminui sensivelmente à agressão ao trato gastrointestinal, proporciona menor perda inicial da concentração dos princípios ativos pela não metabolização primária dos mesmos, promove a diminuição dos efeitos colaterais sistêmicos associados ao medicamento, pois as concentrações dos fármacos podem ser menores que as utilizadas nos outros métodos, bem como, em alguns casos uma maior atuação terapêutica devido a sua aplicação local (MITRAGOTRI et al., 1995; WU et al.,1998; PANCHAGNULA, 1997).

O mecanismo fisiológico utilizado pelo corpo humano para a captação de medicamentos através da pele é denominado absorção percutânea. A absorção percutânea pode ser definida como, a penetração de substâncias nas várias camadas da pele com conseqüente infiltração na circulação sistêmica, e é divida em fases; A primeira é à entrada da substância em uma camada específica da pela e é denominada Penetração, a segunda fase é caracterizada pela passagem da substância a outra camada da pele com função e estrutura diferente da primeira, esta fase é denominada Infiltração. E finalmente a passagem desta substância a circulação sistêmica dita Absorção (PANCHAGNULA, 1997).

Várias vias são utilizadas para que ocorra a absorção percutânea de substâncias pela pele, denominadas de macro-rotas, estes caminhos se diferenciam pela polaridade ou não polaridade iônica das substâncias, sendo que, o transporte através das pequenas glândulas existentes na pele, é uma via comum para ambas, no entanto é considerada uma via de menor importância devido a sua pequena área, $1 \%$ do total da superfície da pele. 
As vias trans-celular e intercelular são amplamente utilizadas, porém, ocorre uma seletividade de acordo com as características iônicas das moléculas (FIGURA 2).

Substâncias polares tendem a se difundir por um processo de hidratação do stratum corneum, via transcelular, enquanto as moléculas não polarizadas se dissolvem e difundem-se através da matriz lipídica do mesmo, via intercelular (BARRY, 1991).

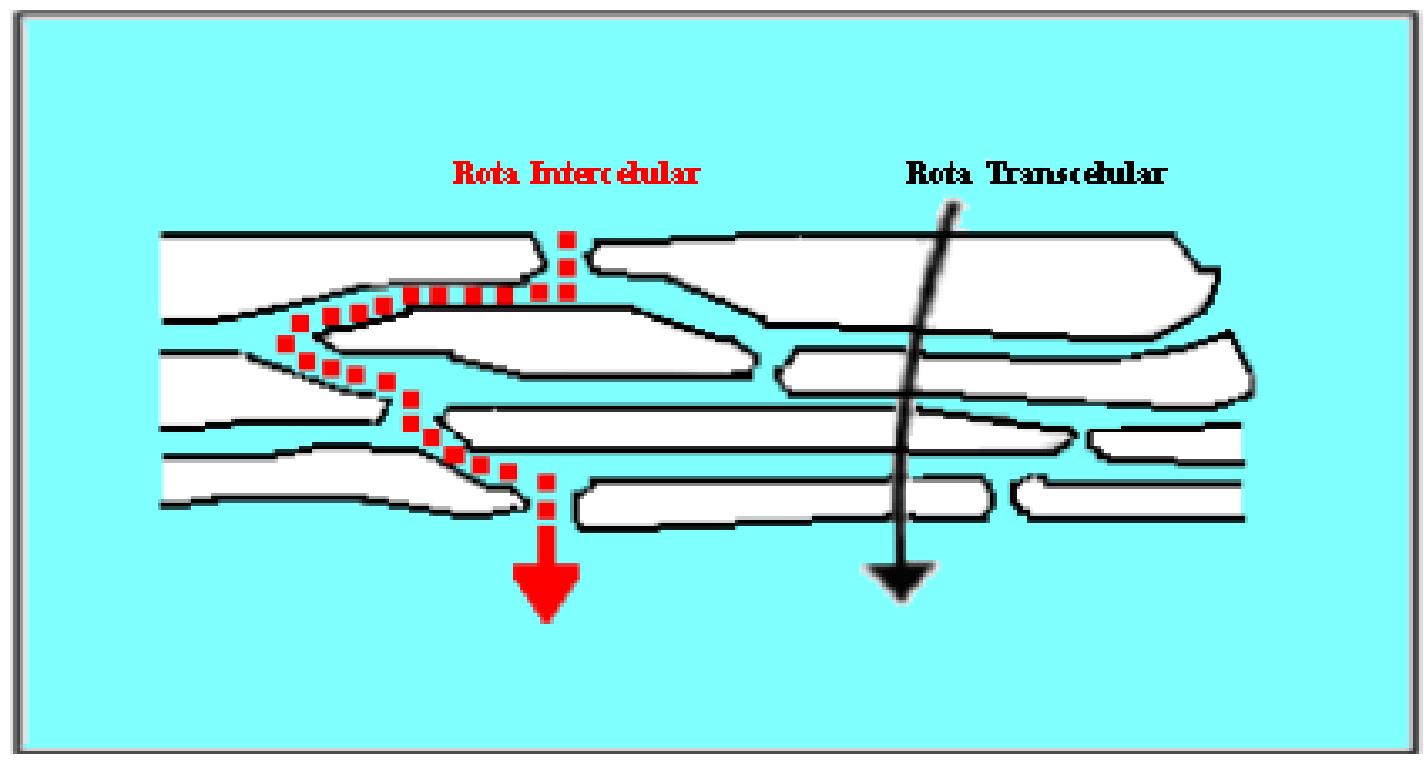

Figura 2 -Vias transdérmicas de absorção percutânea, via intercelular em vermelho e via transcelular em preto. A utilização seletiva destas vias ocorre de acordo com as características iônicas das moléculas.

Fonte - PANCHAGNULA, 1997 (figura modificada)

As aplicações transdérmicas podem ser limitadas por variáveis biológicas, referentes à estrutura da pele, bem como, por variáveis físico químicas referentes à propriedade da droga.

A região da aplicação transdérmica é um fator biológico de fundamental importância, o percentual da absorção percutânea é variável nas diferentes regiões anatômicas, sendo que, as superfícies axilares, testa frontal, canal auditivo tem um percentual de absorção maior do que outras áreas como o dorso da mão, abdome e coluna dorsal (FELDMANN \& MAIBACH, 1967). 
A idade, tal como, as condições patológicas da pele são outros determinantes que devem ser observados, animais com idade mais avançada tendem a ter um percentual de absorção menor que animais jovens (BEHL et al., 1985). Este fenômeno pode estar relacionado com o fato de que haja uma diminuição da superfície lipídica com o avanço da idade e, assim sendo, ocorra um aumento da resistência à penetração de substancias compostas por substâncias hidrolipídicas (ROSKOS et al., 1989).

Doenças ou lesões na pele também interferem na absorção percutânea, patologias como psoríase, dermatites, ferimentos podem aumentar a absorção, pois não existe integridade do stratum corneum (BROWN et al., 1984).

Outros fatores biológicos que interferem na absorção percutânea são: Circulação sanguínea, que quando aumentada melhora a difusão dos medicamentos, e a temperatura ambiente da pele, que caso seja elevada artificialmente também pode melhorar a perfusão de medicamentos (ENGSTROM et al., 1997, JETZER et al., 1988).

As variáveis químicas se constituem na propriedade da formulação dos medicamentos transdérmicos, estes fatores incluem peso molecular do medicamento, veículos utilizados na composição da droga, pH, da solução, coeficiente de partição e concentração da droga na superfície da pele. O desenvolvimento destes fatores individuais e sua interferência na permeação e penetração transcutânea é um campo de estudo importante no desenvolvimento de sistemas transdérmicos (PANCHAGNULA, 1997).

Para que a aplicação transdérmica permaneça viável, em muitos casos podemos utilizar a associação de outros recursos para aumentar a permeabilidade cutânea.

A utilização de agentes físicos para o aumento da absorção percutânea consiste na técnica de irradiação de campos eletromagnéticos como correntes elétricas, denominada lontoforese (FIGURA 3), ou de pulsos elétricos de alta 
voltagem com duração entre $10 \mu \mathrm{s}$ à $100 \mathrm{~ms}$, chamada de Eletroporação (FIGURA 4), na aplicação de ondas fotomecânicas produzidas por geradores de laser pulsado de baixa intensidade (FIGURA 5) com o comprimento de onda de $694.3 \mathrm{~nm}$, na intensidade de 2 a $8 \mathrm{~J} / \mathrm{cm} 2$, com a duração de 30 a $60 \mathrm{~ns}$, ou ainda na utilização de geradores ultra-sônicos de baixa intensidade (FIGURA 6), dita Fonoforese (NELSON \& CURRIER, 1993; CROOS \& ROBERTS, 2004; LOW \& REED, 2001).

A técnica da iontoforese foi descrita pela primeira vez em 1747 por Pivati. A administração de drogas farmacêuticas tornou - se mais difundida no século XX, a partir do estudo de LeDuc em 1900 que introduziu o termo iontoterapia e postulou a teoria básica que rege este processo (NELSON \& CURRIER, 1993).

A iontoforese pode ser definida como o movimento de íons através das membranas biológicas por meio de uma corrente elétrica contínua com fins terapêuticos (SIMITH \& MAIBACH, 1995).

Por definição iontoforese é o aumento da movimentação iônica, em um meio eletrolítico, durante a aplicação de uma corrente elétrica contínua, se uma droga encontra-se em uma forma iônica, ou seja, tem uma carga, pode-se fazer com que ela percorra qualquer direção. Através de um processo de divisão iônica do fármaco ocorre a condução de íons para os tecidos biológicos, por meio de um efeito de repulsão iônica, temos um desvio constante das cargas para os pólos opostos do campo elétrico, ou seja, as cargas positivas tendem a migrar para o pólo negativo e as cargas negativas para o pólo positivo (LOW \& REED, 2001). 


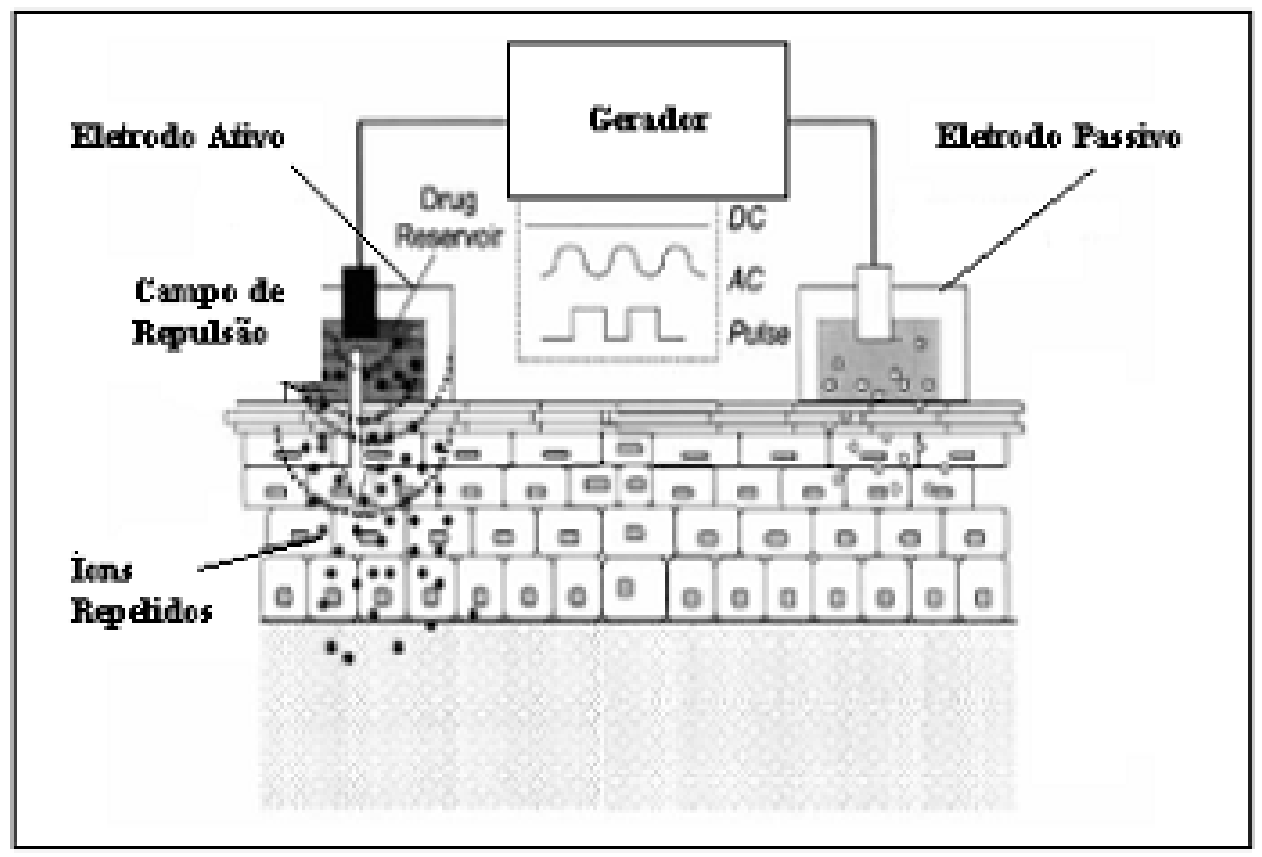

Figura 3 - Iontoforese

Fonte - Current Drug Delivery, 2004 (figura modificada)

A eletroporação é uma técnica que foi inicialmente desenvolvida para o transporte de macromoléculas através das membranas biológicas de culturas celulares isoladas, e se expandiu para utilização de sistemas transdérmicos in vivo (ORLOWSKI \& MIR, 1993; WEAVER, 1993).

Seu processo envolve a aplicação de pulsos elétricos de alta voltagem,

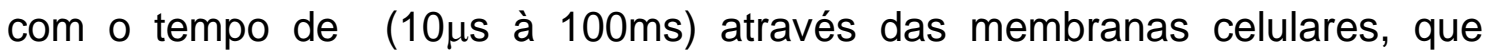
ocasionam a abertura transitória dos poros, permitindo a passagem de macromoléculas para o interior do espaço celular, através de uma combinação de processos que envolvem a difusão celular, eletroforese local e eletroosmose (WEAVER, 1993; PRAUSNITZ, 1999). 
A teoria da eletroporação é baseada no princípio que os lipídios biliares da pele, bem como, as membranas celulares são susceptíveis a abertura de seus poros durante a aplicação de pulsas de alta voltagem (EDWARDS et al., 1995).

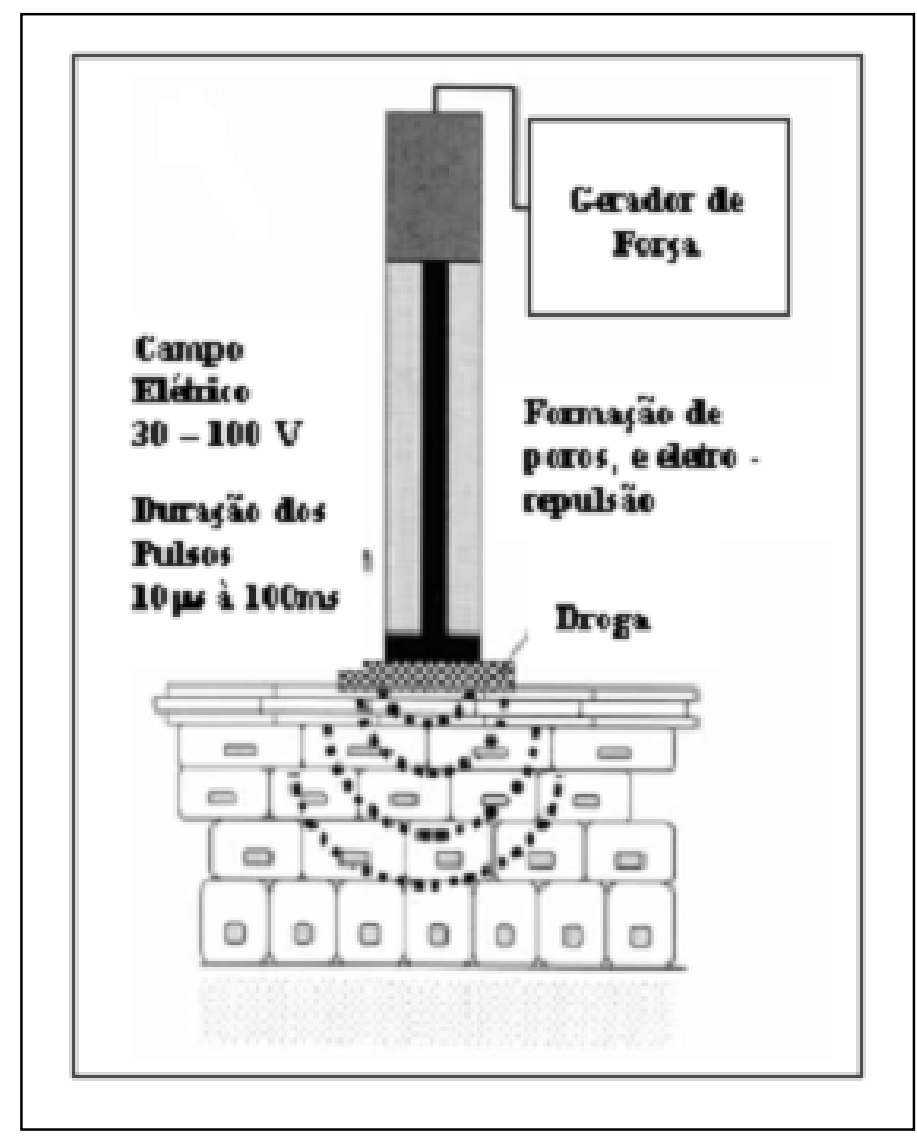

Figura 4 - Eletroporação

Fonte - Current Drug Delivery, 2004 (figura modificada) 
O mecanismo pelo qual o laser aumenta a permeabilidade cutânea ainda não está totalmente esclarecido, porém estudos microscópicos indicam que haja uma formação de canais transientes de transporte através da pele, durante a irradiação laser (MENON et al., 2000).

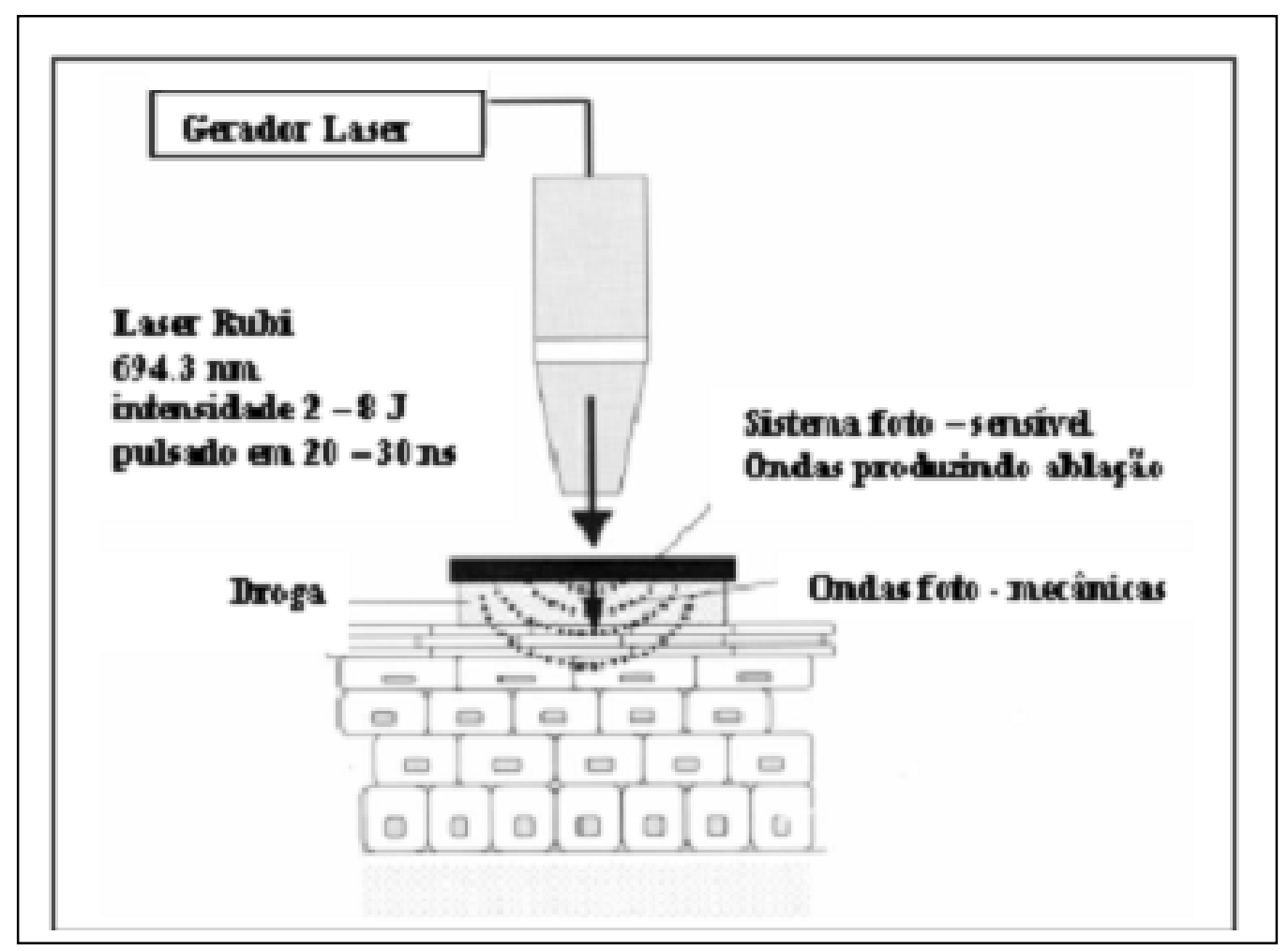

Figura 5 - Ondas Fotomecânicas

Fonte - Current Drug Delivery, 2004 (figura modificada)

A fonoforese é a utilização de um campo de energia ultra-sônica, com a freqüência entre $20 \mathrm{KHz}$ a $3 \mathrm{MHz}$ e intensidade variável, para a facilitação da penetração cutânea de medicamentos (PANCHAGNULA, 1997; LOW \& REED, 2001).

O aumento da permeação cutânea se dá através da desestruturação da barreira lipídica da camada mais externa da pele. A aplicação da técnica envolve a utilização de um gel ou creme medicamentoso como meio acoplador entre o cabeçote ultra-sônico e a área de aplicação (LOW \& REED, 2001). 


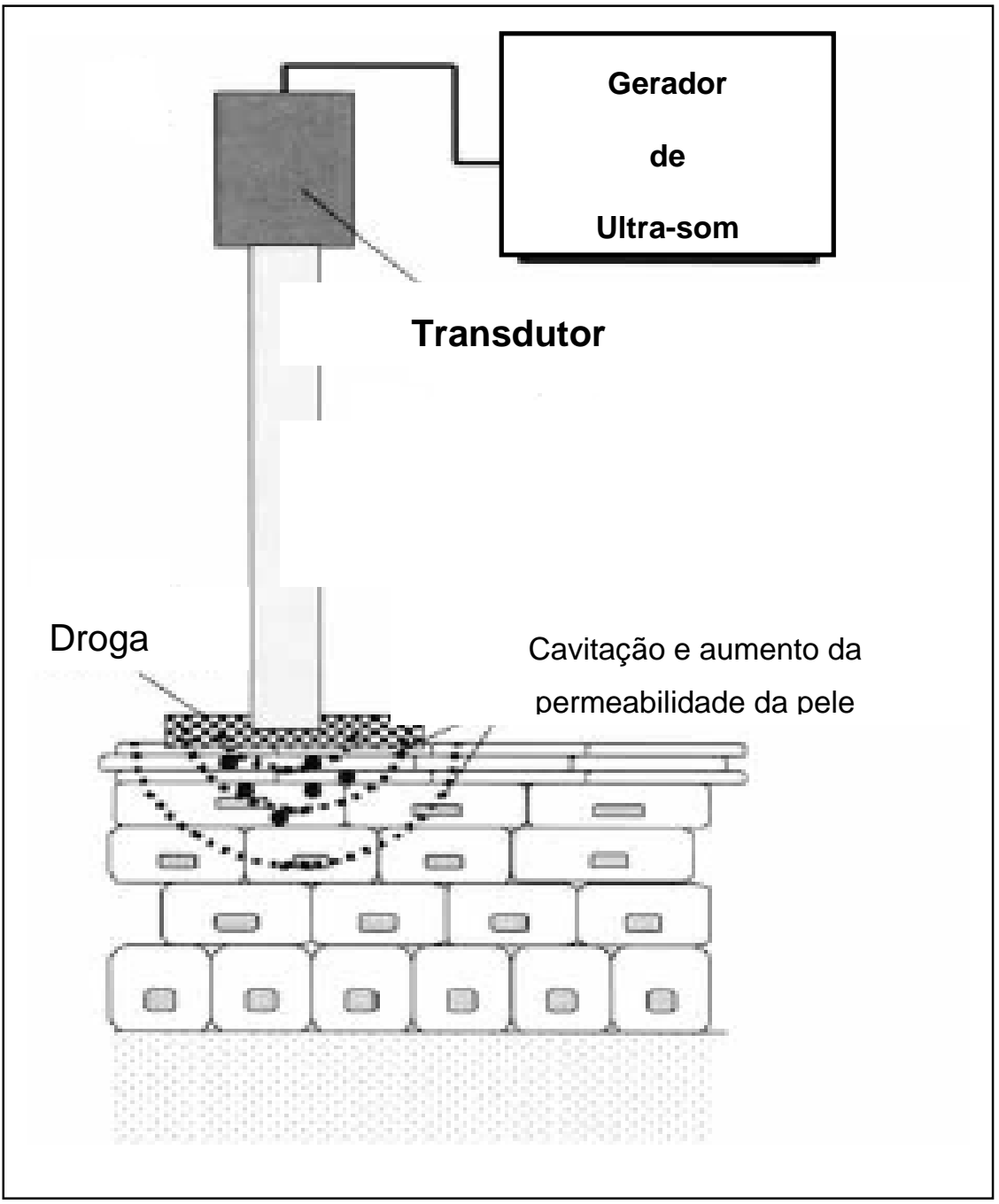

Figura 6 - Fonoforese

Fonte - Current Drug Delivery, 2004 (figura modificada)

\subsection{Mecanismos de ação da fonoforese}

Fellingner Schmid (1954), descreveram o primeiro estudo sobre a associação de ultra-som com a associação de hidrocortisona para o tratamento de poliartrite para os dedos da mão. A partir deste estudo várias pesquisas têm sido realizadas para se esclarecer quais são os mecanismos de ação da fonoforese.

O processo de aumento da permeação cutânea, obtido através da aplicação de correntes acústicas se dá pela formação de bolhas gasosas microscópicas denominada cavitação (FIGURA 7). A cavitação se forma na 
camada mais externa da pele e momentaneamente proporciona uma desestruturação molecular facilitando assim a penetração de medicamentos (MITRAGOTRI, 1995; PANCHAGNULA, 1997).

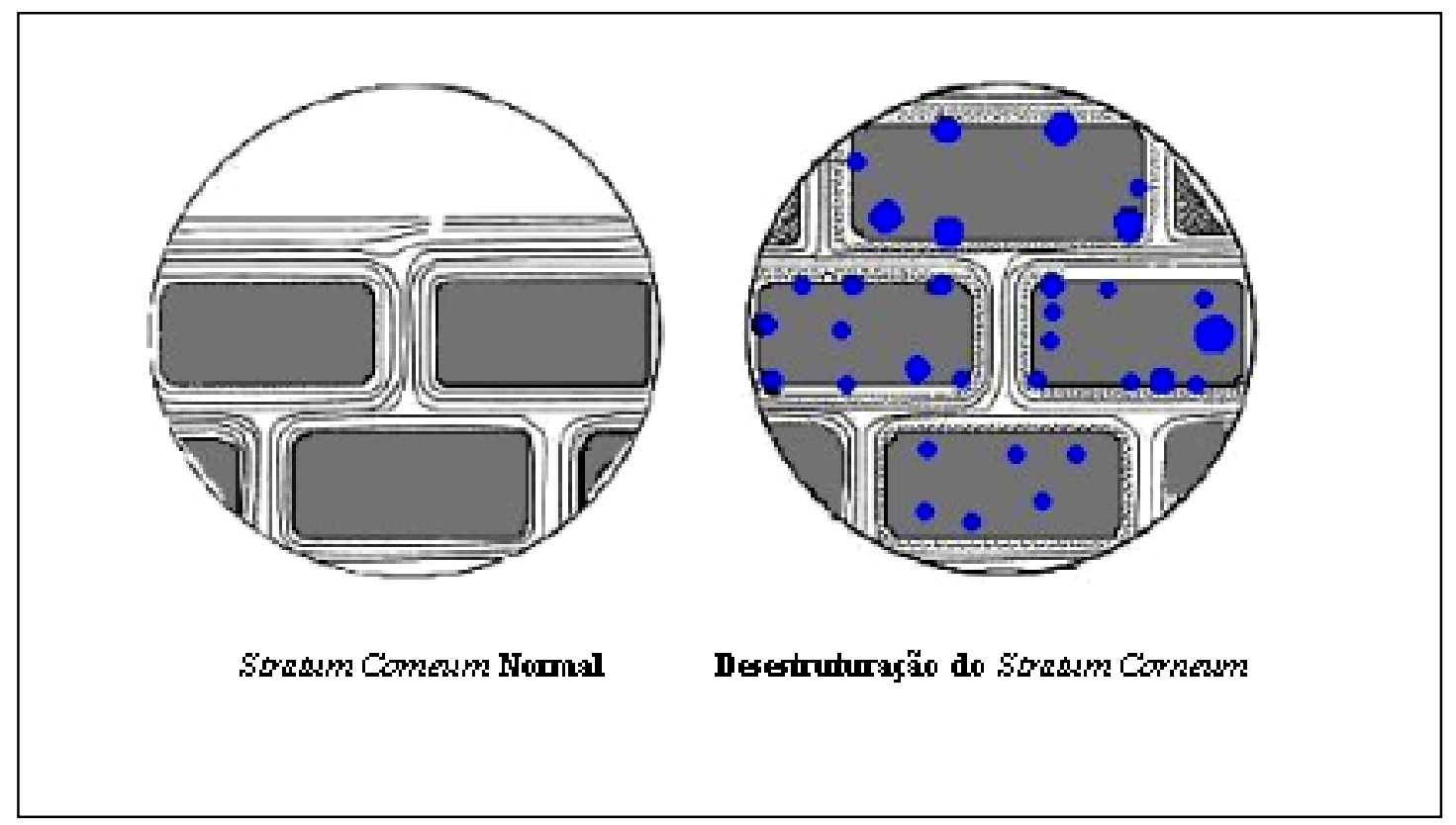

Figura 7 - Ultra-som induzindo a cavitação na pele: formação de microbolhas na camada superficial da pele através da aplicação de ultra-som. À esquerda a representação esquemática do tecido antes da aplicação de ultra-som, e a direita a formação das bolhas gasosas em azul.

Fonte - Encyclopedia of Pharmaceutical Thecnology, 1997 (figura modificada)

A freqüência da irradiação ultra-sônica é outro fator fundamental na aplicação da fonoforese. Podemos classificar as freqüências de irradiação em 3 grupos: Terapêutica (1-3MHz), alta freqüência (acima de $3 \mathrm{MHz}$ ) e baixa freqüência (abaixo de 1MHz) (MITRAGOTRI et al., 1995).

Quanto maior a freqüência, maior será a absorção de energia, no entanto, a penetração mais profunda não interfere necessariamente em maior efetividade da técnica. Alguns autores concluem que o fato das freqüências mais baixas se mostrarem mais efetivas na penetração de medicamentos é devido ao aumento da cavitação nos tecidos mais superficiais da pele (SKAUEN \& ZENTNER, 1984; MITRAGOTRI et al., 1995; PANCHAGNULA, 1997). 
O ultra-som pode ser aplicado tanto no modo contínuo como no modo pulsado, e isto pode ser decisivo para a deposição da droga pretendida. Para fonoforese se preconiza o regime contínuo de ondas, em razão da otimização do tempo de interação do ultra-som com a droga e o tecido. Porém é muito mais freqüente na rotina clínica o equipamento atuar no regime pulsado com freqüência fixa de repetições de $100 \mathrm{~Hz}$, os quais permitem que o processo de reparação tecidual seja associado à técnica (PARIZOTTO et al., 2003).

Como podemos observar na Tabela 1, vários níveis de intensidade têm sido utilizados nas aplicações para fonoforese, à deposição de drogas aplicadas topicamente pode ser acentuada por uma variedade de parâmetros incluindo a intensidade. A faixa de 0.1 a $2 \mathrm{~W} / \mathrm{cm} 2$ é encontrada com maior freqüência nos trabalhos científicos. Se o limiar de dose existe, ele ainda não é conhecido (MITRAGOTI, 1995; PARIZOTTO et al., 2003).

Tabela 1 - Níveis de intensidade utilizados em fonoforese

\begin{tabular}{|lcll|}
\hline Droga & Peso Molecular & \multicolumn{1}{c}{ Sistema Experimental } & Intensidade Ultra-sônica \\
\hline Cortisona & 346 & Pele Humana (in vitro) & $1 \mathrm{MHz}, 2,0 \mathrm{~W} / \mathrm{cm}^{2}$ \\
\hline Dexametasona & 392 & Pele Suina (in vitro) & $1 \mathrm{MHz}, 2,0 \mathrm{~W} / \mathrm{cm}^{2}$ \\
\hline Estradiol & 272 & Pele Humana (in vitro) & $1 \mathrm{MHz}, 2,0 \mathrm{~W} / \mathrm{cm}^{2}$ \\
\hline Hidrocortisona & 362 & Pele Humana (in vivo) & $1 \mathrm{MHz}, 3,0 \mathrm{~W} / \mathrm{cm}^{2}$ \\
& & Pele Humana (in vivo) & $1 \mathrm{MHz}, 1,5 \mathrm{~W} / \mathrm{cm}^{2}$ \\
& & Pele Suina (in vitro) & $1 \mathrm{MHz}, 1,5 \mathrm{~W} / \mathrm{cm}^{2}$ \\
\hline Indometacina & 357 & Ratos (in vivo) & $1 \mathrm{MHz}, 0,75 \mathrm{~W} / \mathrm{cm}^{2}$ \\
\hline Lidocaína & 234 & Pele Humana (in vitro) & $1 \mathrm{MHz}, 0,25 \mathrm{~W} / \mathrm{cm}^{2}$ \\
\hline & & Pele Humana (in vivo) & $1 \mathrm{MHz}, 1,5 \mathrm{~W} / \mathrm{cm}^{2}$ \\
\hline Progesterona & 274 & Pele Humana (in vivo) & $1 \mathrm{MHz}, 2,0 \mathrm{~W} / \mathrm{cm}^{2}$ \\
Salicilato & 138 & Pele Humana (in vivo) & $1 \mathrm{MHz}, 1,5 \mathrm{~W} / \mathrm{cm}^{2}$ \\
\hline & & Pele Humana (in vivo) & $1 \mathrm{MHz} 15 \mathrm{~W} / \mathrm{cm}^{2}$ \\
\hline Testosterona & 288 & Pele Humana (in vitro) & $1 \mathrm{MHz}, 2,0 \mathrm{~W} / \mathrm{cm}^{2}$ \\
\hline
\end{tabular}

Fonte - Encyclopedia of Pharmaceutical Thecnology, 1997 (tabela modificada)

À distância entre o transdutor e a pele também é um parâmetro a ser observado, a pressão ultra-sônica ou intensidade do campo ao redor do transdutor é uma medida complexa. Em muitos estudos encontrados na literatura, com a aplicação de ultra-som na freqüência de $1 \mathrm{MHz}$, essa distância foi menos que 1,66 cm (MITRAGOTRI et al., 1995). 
Outro fator que influi diretamente na aplicação da fonoforese é a capacidade de absorção ultra-sônica dos acopladores. Esta característica depende da viscosidade e do tempo de relaxação do meio, ou seja a propriedade que um material possui de se expandir e contrair durante a passagem do ultra-som. Viscosidades maiores aumentam a fricção interna. $O$ tempo de relaxação representa o tempo necessário para uma molécula voltar a sua posição de equilíbrio antes de ser atingida pela próxima compressão. Freqüências maiores aumentam as perdas causadas pela viscosidade e 0 tempo de relaxação do meio (OHMIC INSTRUMENTS, 1988).

\subsection{Revisão dos estudos sobre a influência dos meios acoplantes e a transmissão de ultra-som}

Warren et al. (1976) estudou a transmissão relativa de ultra-som através de vários meios acopladores, com o objetivo de determinar a existência de diferenças de transmissão entre os meios. Foram utilizados dois transdutores de ultra-som, o primeiro que irradiava as ondas através de uma película na qual era colocado o meio acoplador, e o segundo, que funcionava como um receptor a fim de mensurar a quantidade de irradiação obtida. Os resultados demonstraram que não houve diferença entre os meios acopladores na forma de gel, entretanto, cremes ou compostos com hidrocortisona apresentaram baixo poder de transmissão de ultra-som.

Estudo realizado por Balmaseda et al. (1986) avaliou a eficiência da transmissão de ultra-som através da água, óleo mineral, gel e silicone. O fenômeno de atenuação provocado pelos acopladores também foi estudado experimentalmente, bem como, o grau de impedância dos meios. Os resultados obtidos mostraram que, a água e o óleo mineral tem um alto grau de atenuação associado a um alto valor de impedância. O gel apresentou um menor grau de atenuação e um baixo grau de impedância. O silicone parecia oferecer pouca atenuação, porém o material demonstrou um baixo poder de transmissão ultra-sônica. 
A transmissão relativa de ultra-som através de acopladores utilizados em fonoforese foi estuda por CAMERON \& MONROE (1992). Inicialmente foi aplicado um questionário para evidenciar quais as formulações eram utilizadas com freqüência na clinica fisioterápica. Para se avaliar a transmissão média os acopladores foram dispostos sobre uma balança ultra-sônica e em seguida eram irradiados por um gerador de ultra-som com a freqüência de $1 \mathrm{Mhz}$. Foi observado que, os acopladores eram divididos em 3 grupos distintos com porcentagens de transmissão diferentes em relação à água: $\mathrm{O}$ primeiro com excelente poder de transmissão (acima de $80 \%$ ), o segundo com um bom poder de transmissão (acima de 40\%) e o terceiro com baixo poder de transmissão (abaixo de 40\%).

Importante ressaltar que neste experimento alguns produtos não transmitiram o ultra-som.

Estes resultados foram também encontrados no estudo de BENSON \& McELNAY (1994), aonde foram avaliados vários produtos tópicos com características antiinflamatórias utilizados na fonoforese. Utilizando um método muito similar a pesquisa anterior, a transmissividade de cada produto foi dada a partir da porcentagem de transmissão em relação à água deionizada.

Neste estudo foi concluído que a capacidade de transmissão ultra-sônica é uma característica particular de cada formulação, e pode aumentar com a elevação da freqüência ultra-sônica de aplicação, no entanto o aumento da freqüência pode ocasionar alterações na composição destas formulações.

Observando a Tabela 2 podemos notar que alguns produtos apresentaram um baixo poder de transmissão ultra-sônica. 
Tabela 2 - Transmissão relativa de antiinflamatórios tópicos em relação à água deionizada

\begin{tabular}{|c|c|c|c|c|c|}
\hline \multirow[t]{2}{*}{ Product } & \multirow[t]{2}{*}{ Active ingredient } & \multirow{2}{*}{$\begin{array}{l}\text { Uitrasound } \\
\text { output: intensity } \\
\text { (watts: Wicm }{ }^{2} \text { ) }\end{array}$} & \multicolumn{3}{|c|}{ \% Transmission relative to water ( \pm SD) } \\
\hline & & & $0.65 \mathrm{MHz}$ & $1.5 \mathrm{MHz}$ & $3.0 \mathrm{MHz}$ \\
\hline Feldene gel & $0.5 \%$ piroxicam & $\begin{array}{l}1.5: 0.3 \\
5.0: 1.0\end{array}$ & $\begin{array}{l}74.67 \pm 5.33 \\
52.85 \pm 2.44\end{array}$ & $\begin{array}{l}108.00 \pm 2.67 \\
100.80 \pm 3.40\end{array}$ & $\begin{array}{l}108.00 \pm 5.33 \\
118.40 \pm 7.40\end{array}$ \\
\hline |bugel & $5 \%$ lbuproten & $\begin{array}{l}1.5: 0.3 \\
5.0: 1.0\end{array}$ & $\begin{array}{l}56.00 \pm 3.30 \\
48.40 \pm 1.60\end{array}$ & $\begin{array}{r}94.67 \pm 2.67 \\
101.99 \pm 0.79\end{array}$ & $\begin{array}{l}113.33 \pm 4.67 \\
116.06 \pm 3.82\end{array}$ \\
\hline Oruvail gel & $2.5 \%$ ketoprolen & $\begin{array}{l}1.5: 0.3 \\
5.0: 1.0\end{array}$ & $\begin{array}{l}110.67 \pm 0.33 \\
111.55 \pm 0.00\end{array}$ & $\begin{array}{r}98.67 \pm 2.67 \\
105.93 \pm 1.78\end{array}$ & $\begin{array}{l}108.00=5.33 \\
122.22 \pm 2.98\end{array}$ \\
\hline Proflex cream & $5 \%$ ibuprofen & $\begin{array}{l}1.5: 0.3 \\
5.0: 1.0\end{array}$ & $\begin{array}{l}60.00 \pm 0.00 \\
49.00 \pm 5.78\end{array}$ & $\begin{array}{l}89.33 \pm 3.33 \\
89.56 \pm 1.00\end{array}$ & $\begin{array}{l}70.67 \pm 7.33 \\
85.34 \pm 3.95\end{array}$ \\
\hline Traxam gel & $3 \%$ felbinac & $\begin{array}{l}1.5: 0.3 \\
5.0: 1.0\end{array}$ & $\begin{array}{l}61.33 \pm 2.67 \\
94.30 \pm 7.98\end{array}$ & $\begin{array}{r}93.33 \pm 0.00 \\
105.45 \pm 1.56\end{array}$ & $\begin{array}{l}120.00 \pm 8.00 \\
112.06 \pm 2.92\end{array}$ \\
\hline Voltarol Emulgel & $\begin{array}{l}1.16 \% \text { diclofenac } \\
\text { ethylammonium sait } \\
\text { (equivalent to } 1 \% \\
\text { diclofenac sodium) }\end{array}$ & $\begin{array}{l}1.5: 0.3 \\
5.0: 1.0\end{array}$ & $\begin{array}{r}106.67 \pm 0.00 \\
81.75 \pm 1.59\end{array}$ & $\begin{array}{r}98.67 \pm 2.67 \\
105.51 \pm 0.98\end{array}$ & $\begin{array}{r}92.00 \pm 8.67 \\
110.08 \pm 2.52\end{array}$ \\
\hline
\end{tabular}

Fonte - BENSON \& McELNAY (1994).

Guirro et al. (2001) estudou a efetividade dos colimadores cônico e cilíndrico, do balão e luva de látex na transmissão de energia ultra-sônica. Para tanto foram utilizados uma balança de pressão de irradiação e um aparelho de ultra-som previamente aferidos. Os testes foram realizados com o ultra-som na freqüência de $1 \mathrm{Mhz}$ em pulso contínuo, o acoplamento dos meios ao transdutor foi realizado por meio de gel hidrossolúvel. Os resultados uma transmissividade de $21 \%$ para a luva, $18 \%$ para o balão e $20 \%$ para o colimador cilíndrico em relação à água. No que se refere ao colimador cônico, a transmissão diferiu ( $p$ $<0,05)$ conforme a quantidade de gel utilizada, 21\% $(1,5 \mathrm{ml})$ e $33 \%(2,5 \mathrm{ml})$, independente das fixações. De acordo com estes resultados a conclusão foi que nenhum dos meios testados deve ser utilizado como meio intermediário entre o transdutor e a área a ser irradiada.

Brasileiro et al. (2003) estudou a transmissibilidade ultra-sônica em 14 medicamentos utilizados na prática de fonoforese por meio de análises quantitativas e qualitativas. A análise qualitativa foi realizada por meio da observação da movimentação de ondas ultra-sônicas na superfície da água, enquanto a análise quantitativa foi feita com o auxílio de uma balança semianalítica. $\mathrm{Na}$ análise qualitativa 3 medicamentos foram reprovados, enquanto 
que na analise quantitativa 2 medicamentos demonstraram transmissibilidade pobre e 1 medicamento transmissão moderada e os demais medicamentos, 8 no total, boa transmissão. Os dados finais demonstraram que dos 14 medicamentos pesquisados, apenas 8 revelaram-se próprios pra a pratica da fonoforese.

A utilização de amostras de agar-agar como corpos de prova para simular tecidos biológicos é freqüentemente utilizada em pesquisas com ultra-som, estes espectros são caracterizados por sua homogeneidade acústica (GOLDSTEIN, 2000).

O agar-agar é um hidrocolóide extraído de algas marinhas, entre as suas principais propriedades destacam-se seu alto poder gelificante, elevada força de gel a baixas concentrações, baixa viscosidade em solução, alta transparência, gel termo-reversível e temperaturas de fusão e gelificação bem definidas. Uma solução de agar-agar possui uma carga levemente negativa, e em sua forma seca, não esta sujeita a contaminação por microorganismos no entanto soluções e géis de agar-agar são meios férteis de contaminação por bactérias e fungos e as devidas precauções devem ser tomadas para evitar o crescimento dos mesmos (TESKE \&TRENTINI, 1997).

Haar et al. (1989) utilizou modelos de agar-gel para evidenciar o aumento de temperatura e a formação de microbolhas produzidas por transdutores clínicos de ultra-som.

Rickey et al. (1995) estudou a validação do uso de corpos de prova constituídos de agar-agar para simular estruturas como músculos e vasos sanguíneos, os resultados demonstraram que as amostras de agar-agar não distorcem as imagens produzidas por ultra-som doppler, podendo assim ser utilizadas para este tipo de simulação.

Goldstein (2000) relata que a velocidade de propagação da onda ultrasônica em amostras de agar-agar é similar à velocidade de propagação nos tecidos moles biológicos, não havendo assim nenhum tipo de atenuação significativa da onda. 
Beard (2002) utilizou várias amostras de agar-agar com diferentes espessuras para aferir a propagação e atenuação de ondas ultra-sônicas em meios heterogêneos.

Diante da literatura cientifica atual observa-se os seguintes aspectos: Embora muitos acopladores estejam sendo utilizados em fonoforese, existem muitas diferenças na capacidade de transmissão acústica destes meios, sendo que alguns sequer transmitem a energia ultra-sônica tornando o procedimento muito impreciso, logo, maiores estudos na área são necessários (BRASILEIRO et al., 2003; BALMASEDA et al., 1986; BENSON \& McELNAY, 1994: CAMERON \& MONROE, 1992; GUIRRO et al., 2001; WARREN et al., 1976). Podemos utilizar amostras de agar-agar para simular o tecido biológico, pois suas propriedades de condução e atenuação das ondas ultra-sônicas são similares às partes moles do corpo e humano, e sua constituição não interfere na irradiação do ultra-som (BEARD, 2002; GOLDSTEIN, 2000, HAAR et al., 1989; RICKEY et al., 1995). 


\section{MATERIAL E MÉTODOS}

Para realização do presente estudo foi examinado o nível de transmissão e atenuação ultra-sônica de cada agente acoplador em relação ao gel neutro, bem como, a profundidade de penetração do diclofenaco gel nas amostras.

Durante a verificação do nível de transmissão e do coeficiente de transmissão ultra-sônico, os corpos de prova forma divididos em dois grupos referentes as intensidades de ultra-som utilizadas, e cada um destes grupos, foi subdividido em sub-grupos, com 10 amostras cada, correspondendo aos diferentes meios utilizados para irradiação (QUADRO 1).

Quadro 1 - Grupos de intensidade

\begin{tabular}{|l|l|}
\hline \multicolumn{1}{|c|}{ GRUPO $1\left(1,0 \mathrm{~W} / \mathrm{cm}^{2}\right)$} & \multicolumn{1}{c|}{ GRUPO $2\left(1,5 \mathrm{~W} / \mathrm{cm}^{2}\right)$} \\
\hline 1 A- GEL NEUTRO & 2 A- GEL NEUTRO \\
\hline 1 B- GEL E CORANTE & 2 B- GEL E CORANTE \\
\hline 1 C- DICLOFENACO GEL & 2 C- DICLOFENACO GEL \\
\hline 1 D- DICLOFENACO GEL E & 2 D- DICLOFENACO GEL E \\
CORANTE & CORANTE \\
\hline
\end{tabular}

A confecção dos corpos de prova foi realizada a partir de um gelificante Agar-agar em pó, diluído em água quente na proporção de 20 g/ 600 ml, após esta diluição foi adicionado à solução cerca de $5 \mathrm{ml}$ de formol (2\%), a fim de se evitar a contaminação das amostras por fungos.

Distribuídas em 10 recipientes de acrílico com capacidade de $60 \mathrm{ml}$ cada, as amostras, foram posteriormente levadas a uma câmara fria na temperatura de 5 a 10 graus, na qual permaneciam por um período de 8 horas para finalização do processo de gelidificação. 
A investigação do índice de transmissão ultra-sônica, foi realizada a partir de um dosímetro de precisão ULTRASONIC POWER METER modelo UPM-DT 10. Inicialmente o cabeçote ultra-sônico foi calibrado para a intensidade referida de cada grupo a ser pesquisado (FOTO 1).

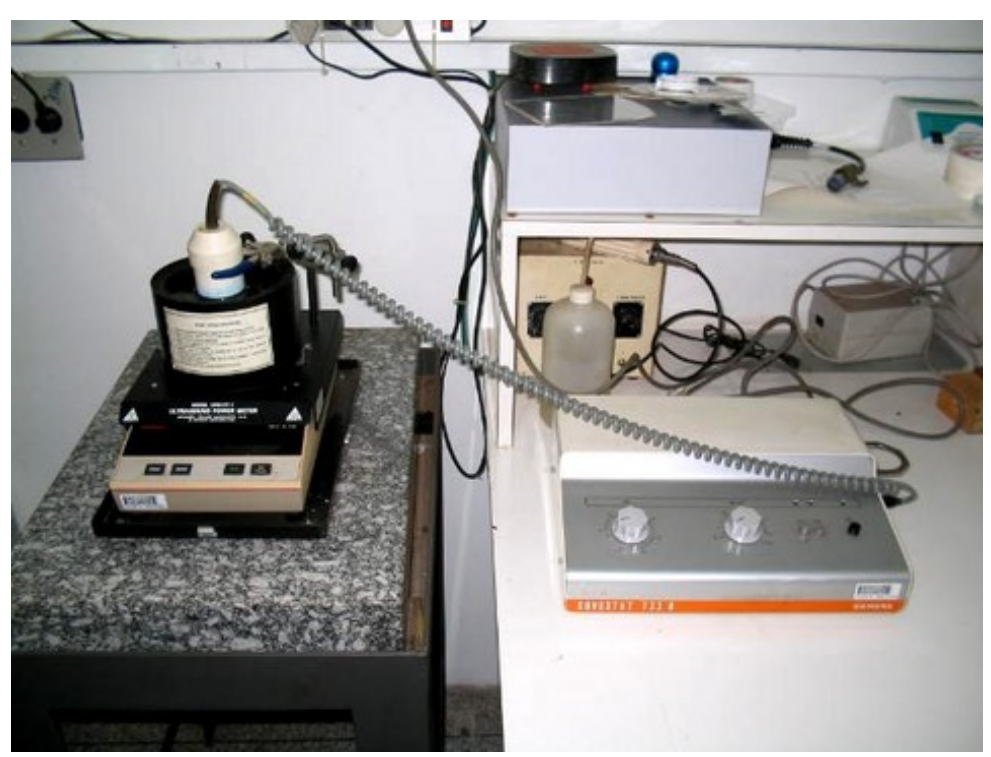

Foto 1 - Calibração do ultra-som

Depois de realizada a calibração a amostra foi adicionada ao sistema de irradiação com seu respectivo agente acoplador, este conjunto era fixado por meio de uma fita adesiva e em seguida disposto sobre o dosímetro através de um braço mecânico (FOTO 2).

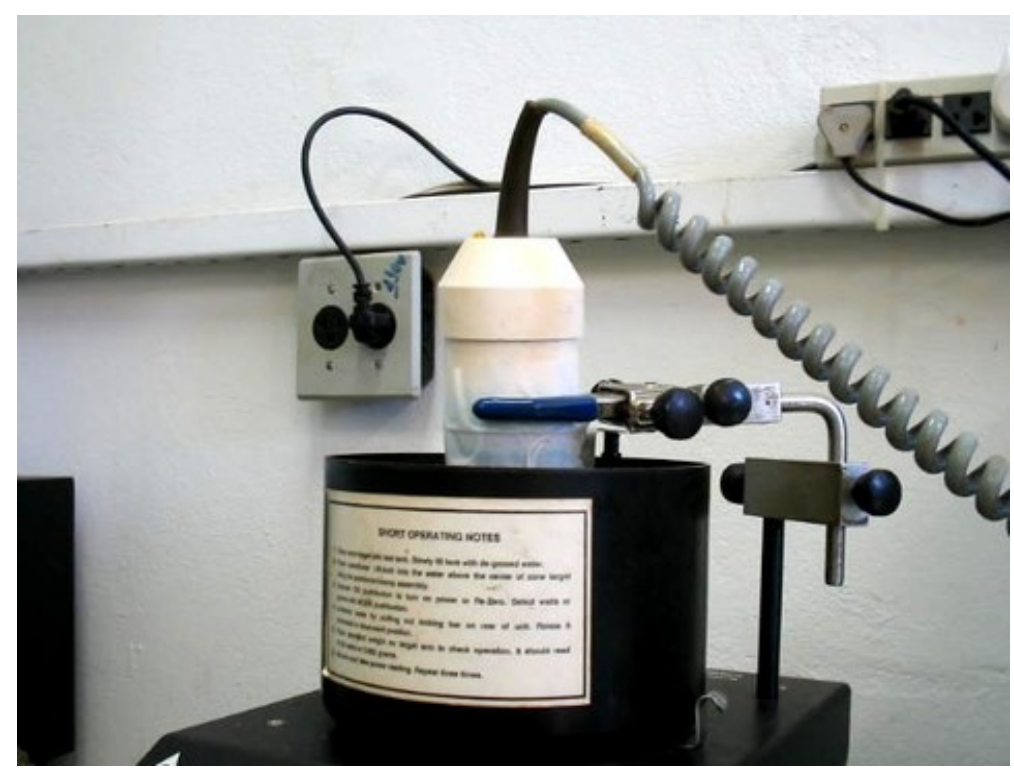

Foto 2 - Irradiação da amostra 
Antes de ocorrer à irradiação das amostras os acoplantes eram retirados da câmara fria e permaneciam a temperatura ambiente por 10 minutos, a fim de se evitar uma alteração nos valores de transmissão e penetração, devido à baixa temperatura dos mesmos.

A irradiação do ultra-som foi realizada de forma contínua e estacionária por um período de 5 minutos, com intensidade variável, conforme o grupo.

Durante o processo de irradiação foi observado um intervalo de 5 minutos entre uma amostra e outra, com a finalidade de minimizar um possível super-aquecimento do cabeçote ultra-sônico. O fundo do recipiente no qual residia o corpo de prova foi previamente retirado para uma melhor precisão na medida.

Para se medir a penetração do fármaco as amostras foram divididas em 3 grupos, referentes às intensidades e um grupo controle, todos constituídos de 10 corpos de prova cada. A adição do grupo controle teve como finalidade de se verificar a existência ou não da penetração passiva da droga (QUADRO 2).

Quadro 2 - Grupos de Penetração

\begin{tabular}{|l|l|l|}
\hline \multicolumn{1}{|c|}{ GRUPO $3\left(1,0 \mathrm{w} / \mathrm{cm}^{2}\right)$} & \multicolumn{1}{|c|}{ GRUPO $4\left(1,5 \mathrm{~W} / \mathrm{cm}^{2}\right)$} & \multicolumn{1}{c|}{ GRUPO CONTROLE } \\
\hline 3 A- DICLOFENACO & 4 A- DICLOFENACO & DICLOFENACO GEL E \\
GEL E CORANTE & GEL E CORANTE & CORANTE \\
\hline
\end{tabular}


Foi adicionado o corante químico azul de metileno na proporção de 10 $\mathrm{ml} / 60 \mathrm{~g}$ de substância acopladora para se medir a penetração da droga (FOTO 3).

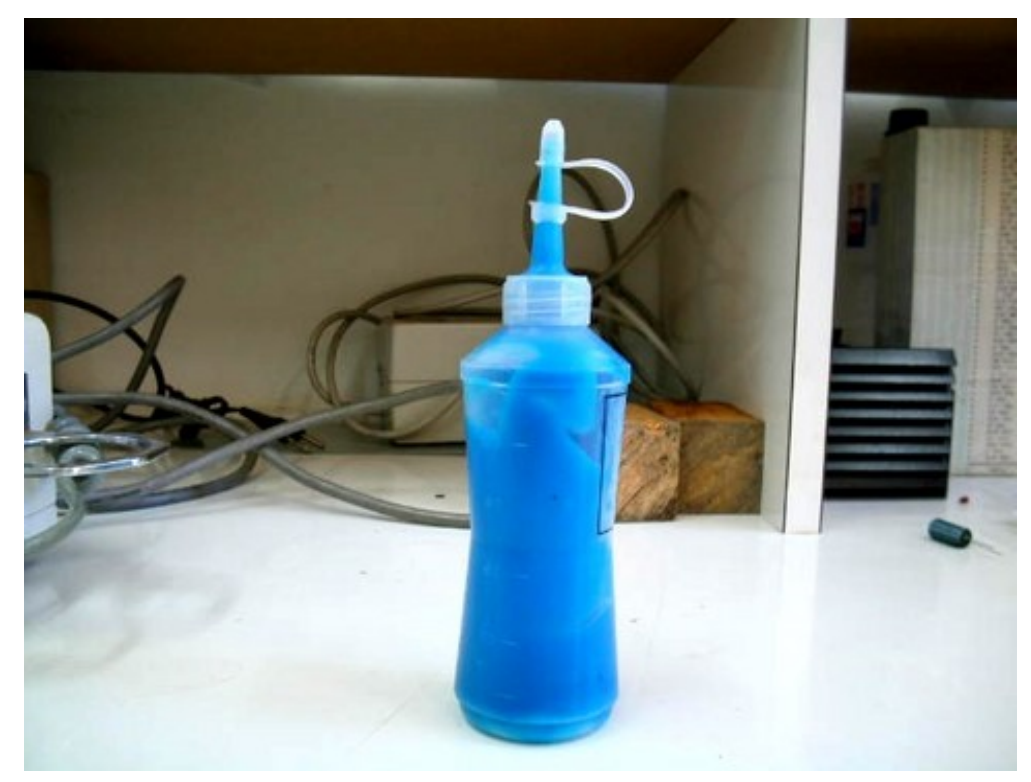

Foto 3 - Acoplador e corante

No grupo controle o agente acoplador marcado com o corante foi distribuído uniformemente sobre as amostras de Agar-agar, e permaneceu a temperatura ambiente por 5 minutos. Após este período os corpos de prova eram retirados de seus respectivos recipientes e lavados em água corrente, em seguida eram recondicionadas as câmaras frias, aonde permaneciam por no máximo 12 horas aguardando a analise microscópica, este mesmo procedimento ocorreu nos grupos irradiados com ultra-som (FOTOS 4 e 5). 

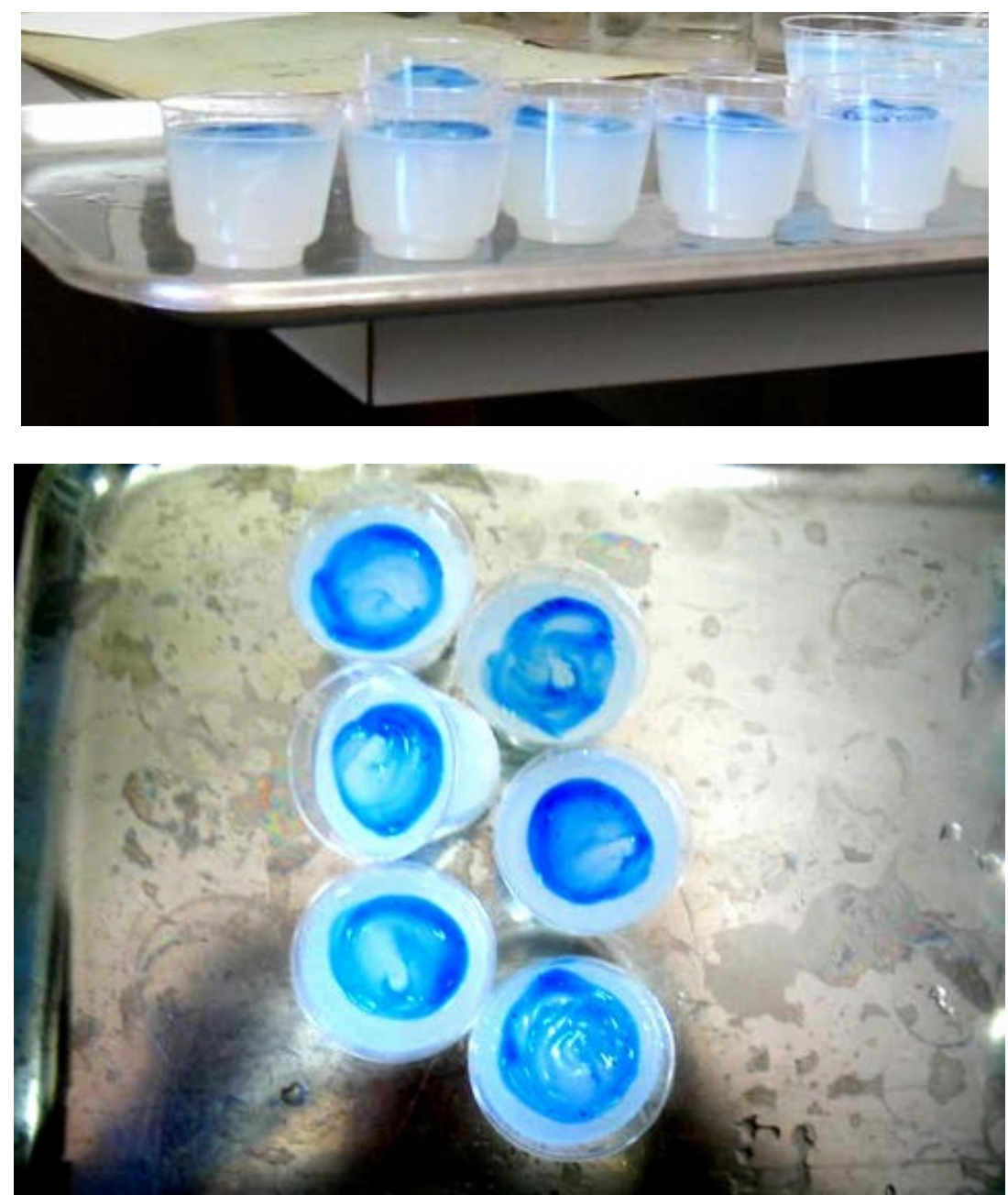

Foto 4 (a) e (b) - Grupo controle

\subsection{Análise da variação da taxa de transmissão}

Para analisar a variação de transmissão do campo ultra-sônico, foi considerado o valor da intensidade irradiada menos o valor da intensidade obtida pelo dosímetro de precisão durante 1 minuto de irradiação das amostras. Estes valores foram comparados posteriormente com os valores obtidos durante a irradiação de ultra-som em gel neutro. 


\subsection{Análise do coeficiente de atenuação}

O coeficiente de atenuação foi medido considerando-se o valor da intensidade irradiada, o valor da intensidade obtida e a espessura da amostra que era padronizada em $3,5 \mathrm{~cm}$. Para tanto utilizamos a formula: $\alpha=\underline{\ln (1 \alpha-10)}$

L aonde $\alpha$ é o coeficiente de atenuação, l $\alpha$ é o valor da intensidade de irradiação, lo é o valor da intensidade obtida e $L$ é a espessura da amostra. Estes valores foram comparados com os valores obtidos durante a irradiação em gel neutro.

\subsection{Análise macroscópica}

Para verificar a penetração do agente acoplador, as amostras foram cortadas ao meio no sentido transverso da irradiação e em seguida colocadas sobre um negatoscópio aonde, através de observação contra a luz, à penetração do corante foi aferida com uma régua métrica padrão e quantificada em milímetros (mm) (FOTOS 6 e 7).

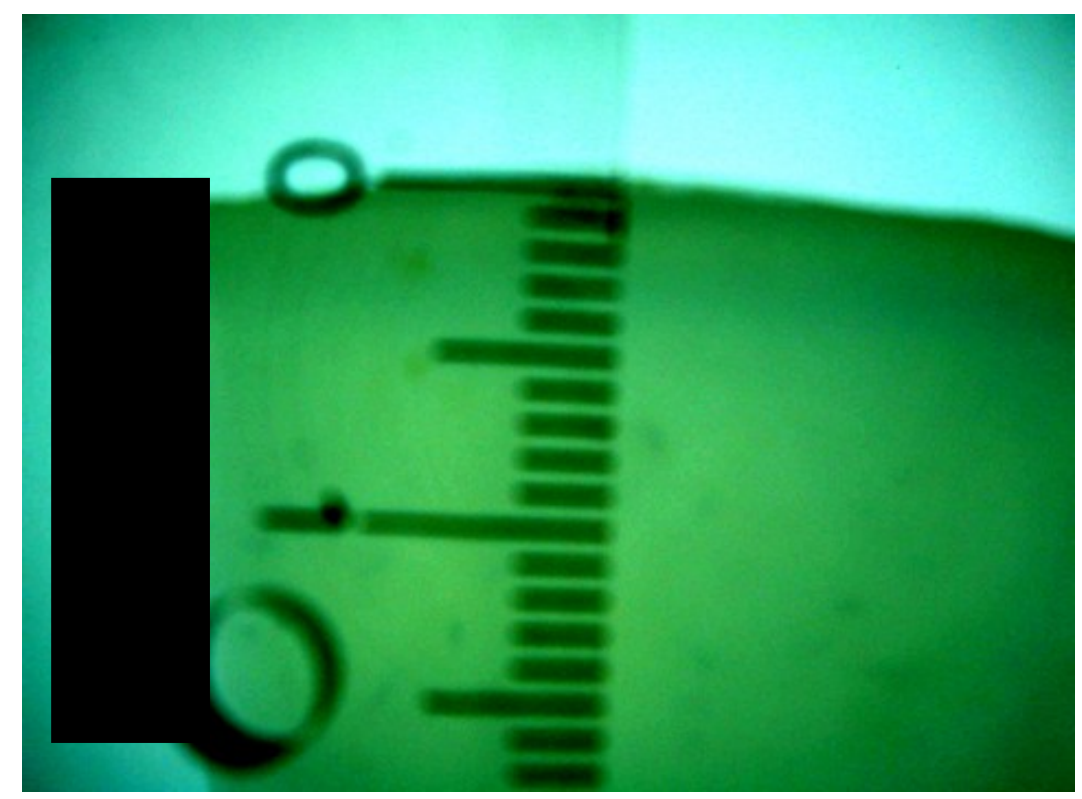




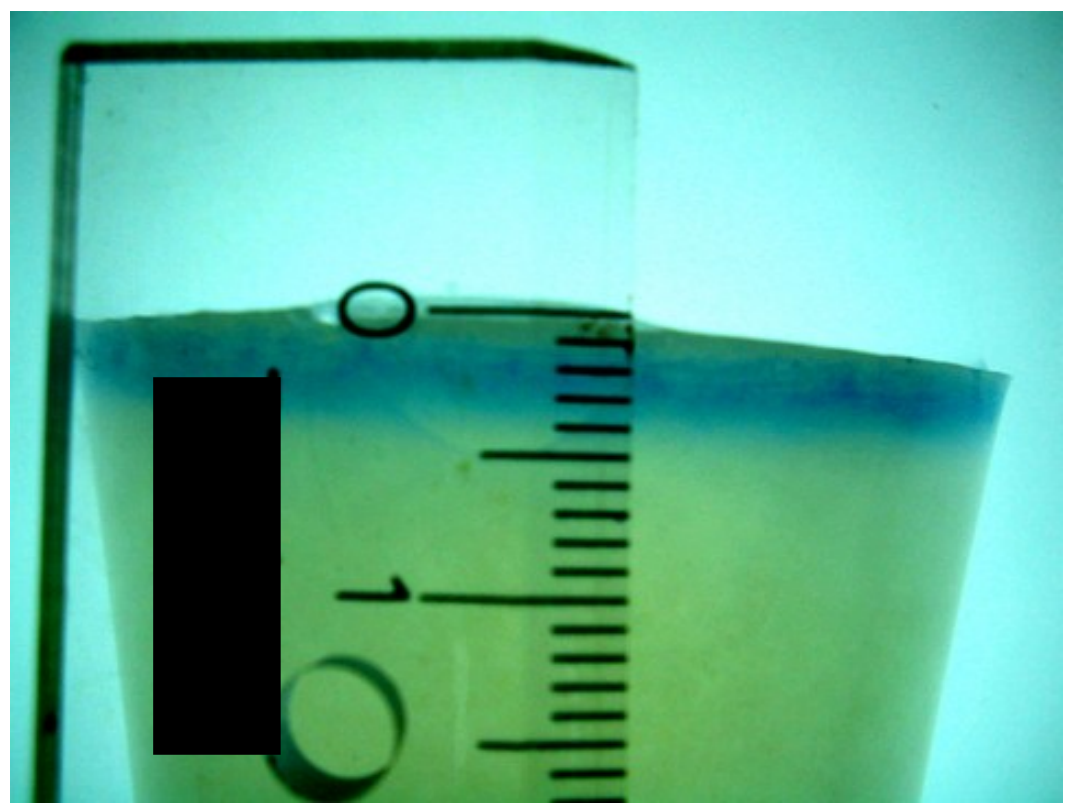

Fotos 6 e 7 - Análise macroscópica das amostras

\subsection{Análise microscópica}

Foram realizados cortes transversais em relação à irradiação do ultrasom com a espessura de $3 \mathrm{~mm}$. As amostras foram analisadas pela microscopia de luz com um aumento óptico de 10 vezes e os resultados registrados por analise semiquantitativa da presença ou não do corante de azul de metileno (FOTOS 8, 9 e 10).

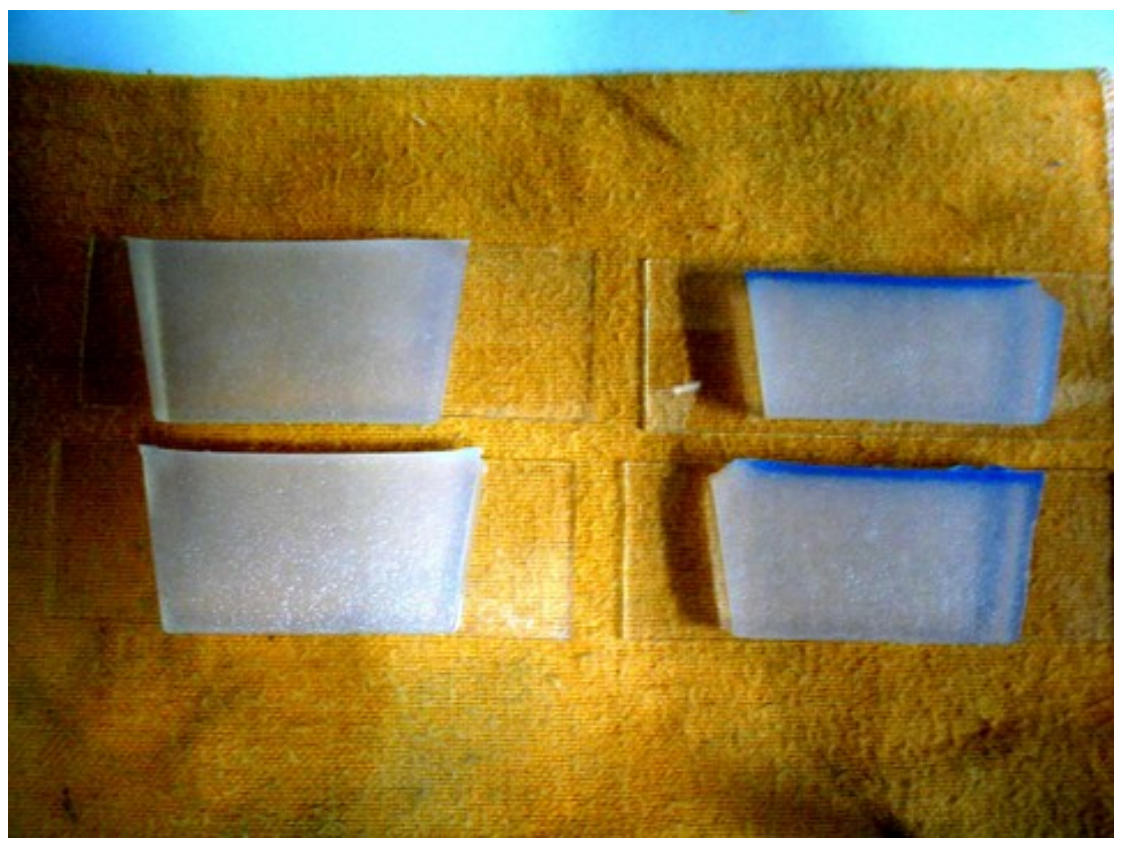

Foto 8 - Lâminas das amostras 

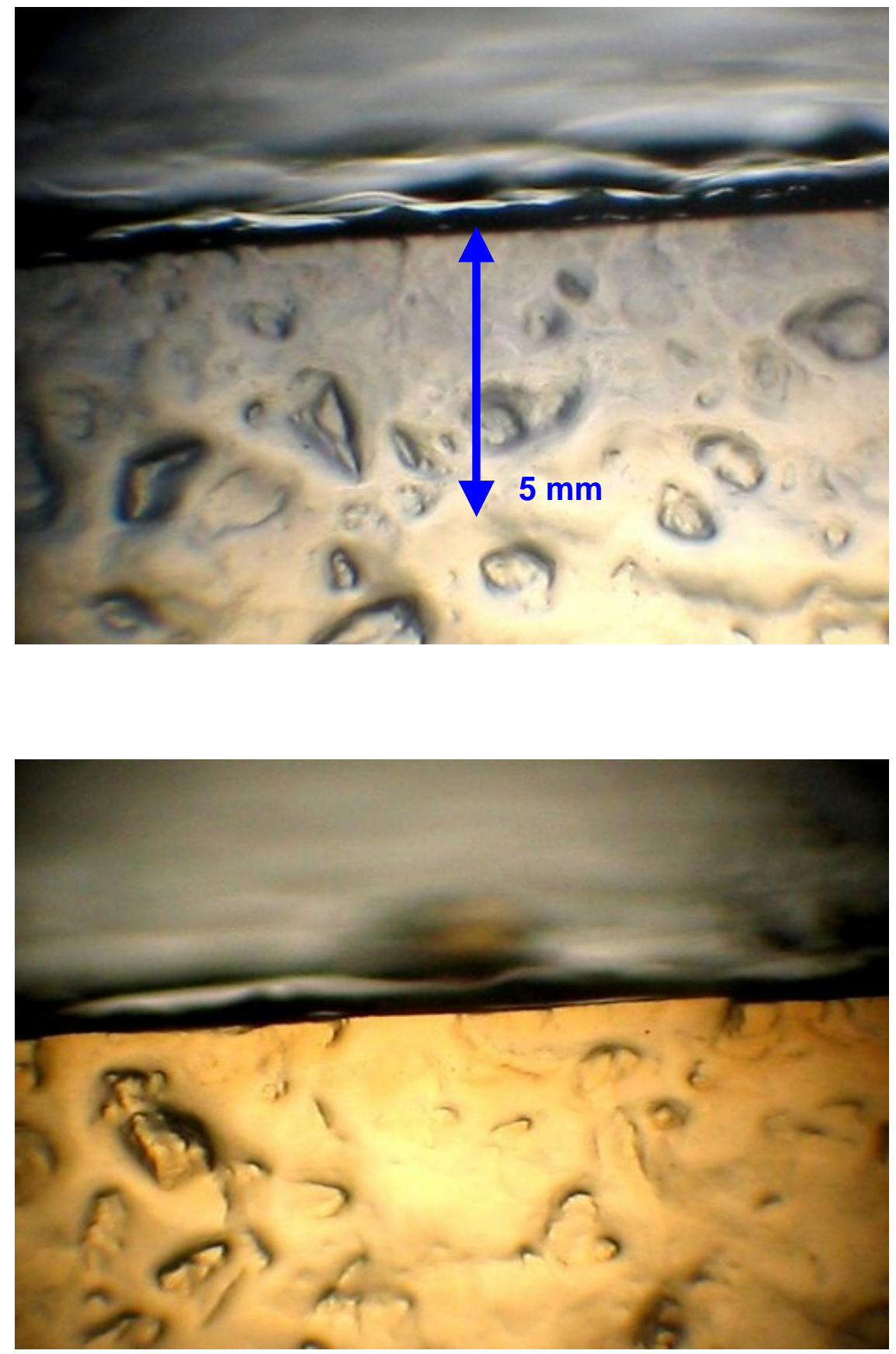

Fotos 9 e 10 - Análise microscópicas das amostras, aumento de 10 vezes. 


\subsection{Análise dos dados}

O teste $t$ student foi utilizado com um nível de significância $p<0,05$ sendo que 0,01 0,05 os valores são considerados significantes, $<0,01$ até 0,001 muito significantes e $<0,001$ extremamente significantes. 


\section{RESULTADOS}

Os resultados serão apresentados mediante a uma seqüência de tabelas e fotos ilustrativas dos dados colados referente a cada meio de transmissão estudado segundo a metodologia convencionada.

\subsection{Variação da transmissão ultra-sônica dos meios}

Neste teste foram verificados os índices de transmissão ultra-sônica em todos os meios estudados, através da medição da intensidade do campo de ultra-som irradiado nas amostras. Os dados obtidos foram comparados com os valores da transmissão realizada em gel neutro.

\section{a) Grupo 1 B - Gel e Corante Intensidade de 1,0 W/cm²}

Não houve diferença estatisticamente significante na transmissão do sinal em gel e corante em relação ao gel neutro, em valores médios observa-se uma redução do sinal de $0,10 \mathrm{~W} / \mathrm{cm}^{2}$.

Tabela 3 - Teste-t: duas amostras presumindo variâncias diferentes: Gel Neutro e Corante 1,0 W/cm ${ }^{2}$

\begin{tabular}{|c|c|c|}
\hline \multicolumn{3}{|c|}{ Gel Neutro e Corante $1,0 \mathrm{~W} / \mathrm{cm}^{2}$} \\
\hline & $\begin{array}{c}\text { Variável } \\
1\end{array}$ & $\begin{array}{c}\text { Variável } \\
2\end{array}$ \\
\hline Média & 0,47 & 0,37 \\
\hline Variância & 0,009 & 0,002333 \\
\hline Observações & 10 & 10 \\
\hline Hipótese da diferença de média & 0 & \\
\hline gl & 13 & \\
\hline Stat t & 2,970443 & \\
\hline$P(T<=t)$ uni-caudal & 0,005419 & \\
\hline t crítico uni-caudal & 1,770932 & \\
\hline$P(T<=t)$ bi-caudal & 0,010838 & \\
\hline t crítico bi-caudal & 2,160368 & \\
\hline
\end{tabular}


Gráfico 1 - Variação da transmissão ultra-sônica $(1,0$ W/cm² Gel e Corante)

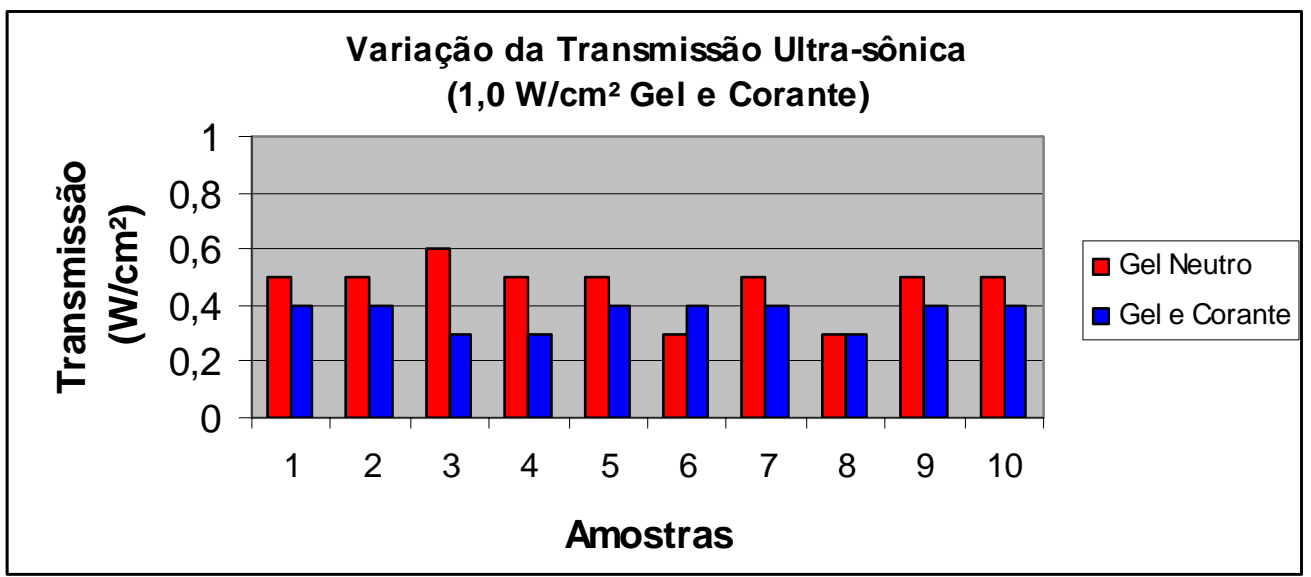

b) Grupo $1 \mathrm{C}$ - Diclofenaco Gel Intensidade de 1,0 W/cm²:

Não houve uma diferença estatisticamente significante na transmissão do sinal em diclofenaco gel em relação ao gel neutro, em valores médios observa-se uma redução de $0,15 \mathrm{~W} / \mathrm{cm}^{2}$.

Tabela 4 - Teste-t: duas amostras presumindo variâncias diferentes: Gel Neutro e Diclofenaco 1,0 W/cm²

Gel Neutro e Diclofenaco 1,0 W/cm²

\begin{tabular}{lrr}
\hline & Variável & Variável \\
& 1 & 2 \\
\hline Média & 0,47 & 0,32 \\
Variância & 0,009 & 0,001778 \\
Observações & 10 & 10 \\
Hipótese da diferença de média & 0 & \\
gl & 12 & \\
Stat $t$ & 4,569058 & \\
$\mathrm{P}(\mathrm{T}<=\mathrm{t})$ uni-caudal & 0,000322 & \\
t crítico uni-caudal & 1,782287 & \\
$\mathrm{P}(\mathrm{T}<=\mathrm{t})$ bi-caudal & 0,000645 & \\
$\mathrm{t}$ crítico bi-caudal & 2,178813 & \\
\hline
\end{tabular}


Gráfico 2 - Variação da transmissão ultra-sônica (1,0 W/cm² Diclofenaco Gel)

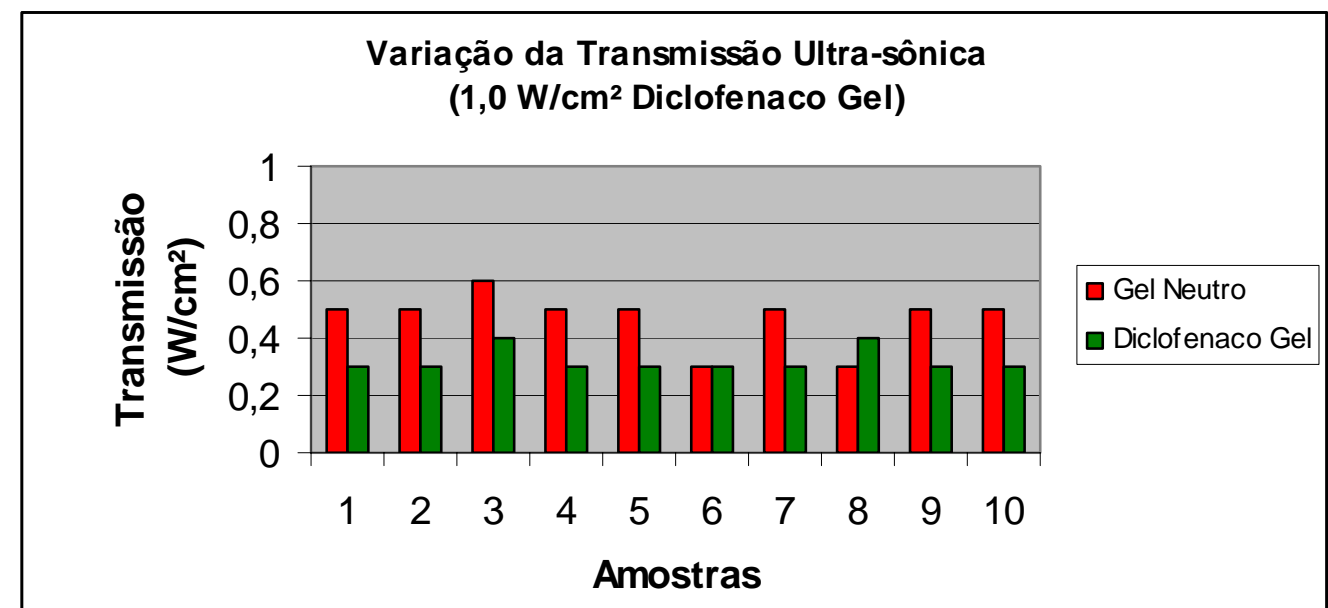

c) Grupo 1 D - Diclofenaco Gel e Corante Intensidade de 1,0 W/cm²

Não houve uma diferença estatisticamente significativa na transmissão do sinal no meio diclofenaco gel e corante em relação ao gel neutro, nos valores médios observa-se uma redução de 0,21 W/cm².

Tabela 5 - Teste-t: duas amostras presumindo variâncias diferentes: Gel Neutro e Diclofenaco Corante $1 \mathrm{~W}$

\section{Gel Neutro e Diclofenaco Corante 1W}

\begin{tabular}{lll}
\hline & Variável 1 & Variável 2 \\
\hline Média & 0,47 & 0,28 \\
Variância & 0,009 & 0,001778 \\
Observações & 10 & 10 \\
Hipótese da diferença de média & 0 & \\
gl & 12 & \\
Stat $\mathrm{t}$ & 5,787473 & \\
$\mathrm{P}(\mathrm{T}<=\mathrm{t})$ uni-caudal & $4,32 \mathrm{E}-05$ & \\
$\mathrm{t}$ crítico uni-caudal & 1,782287 & \\
$\mathrm{P}(\mathrm{T}<=\mathrm{t})$ bi-caudal & $8,64 \mathrm{E}-05$ & \\
$\mathrm{t}$ crítico bi-caudal & 2,178813 & \\
\hline
\end{tabular}


Gráfico 3 - Variação da transmissão ultra-sônica (1,0 W/cm² Diclofenaco Gel e Corante)

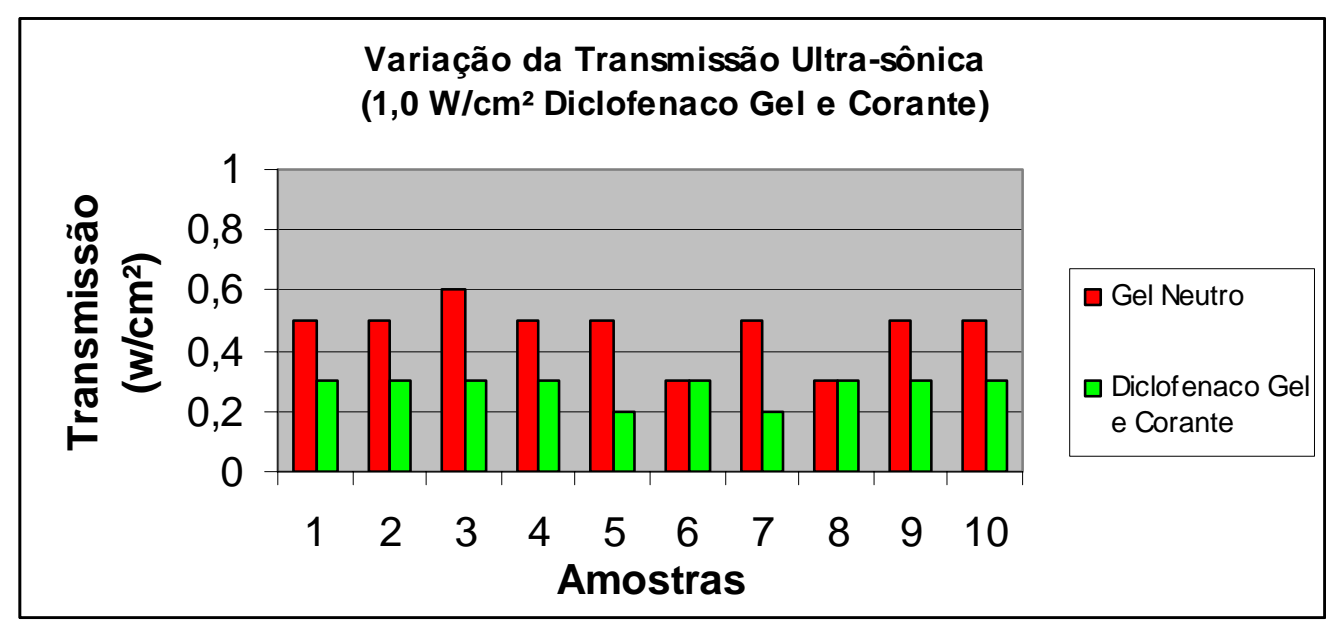

\section{d) Grupo 2 B - Gel e Corante Intensidade 1,5 W/cm²}

Não Houve diferença estatisticamente significativa na transmissão do sinal em gel e corante em relação ao gel neutro, em valores médios observamos uma redução do sinal de $0.08 \mathrm{~W} / \mathrm{cm}^{2}$.

Tabela 6 - Teste-t: duas amostras presumindo variâncias diferentes: Gel Neutro e Corante 1,5 W/cm

Gel Neutro e Corante $1,5 \mathrm{~W} / \mathrm{cm}^{2}$

\begin{tabular}{lll}
\hline & Variável 1 & Variável 2 \\
\hline Média & 0,76 & 0,68 \\
Variância & 0,004889 & 0,004 \\
Observações & 10 & 10 \\
Hipótese da diferença de média & 0 & \\
gl & 18 & \\
Stat $\mathrm{t}$ & 2,683282 & \\
$\mathrm{P}(\mathrm{T}<=\mathrm{t})$ uni-caudal & 0,00759 & \\
t crítico uni-caudal & 1,734063 & \\
$\mathrm{P}(\mathrm{T}<=\mathrm{t})$ bi-caudal & 0,015181 & \\
$\mathrm{t}$ crítico bi-caudal & 2,100924 & \\
\hline
\end{tabular}


Gráfico 4 - Variação da transmissão ultra-sônica (1,0 W/cm² Diclofenaco Gel e Corante)

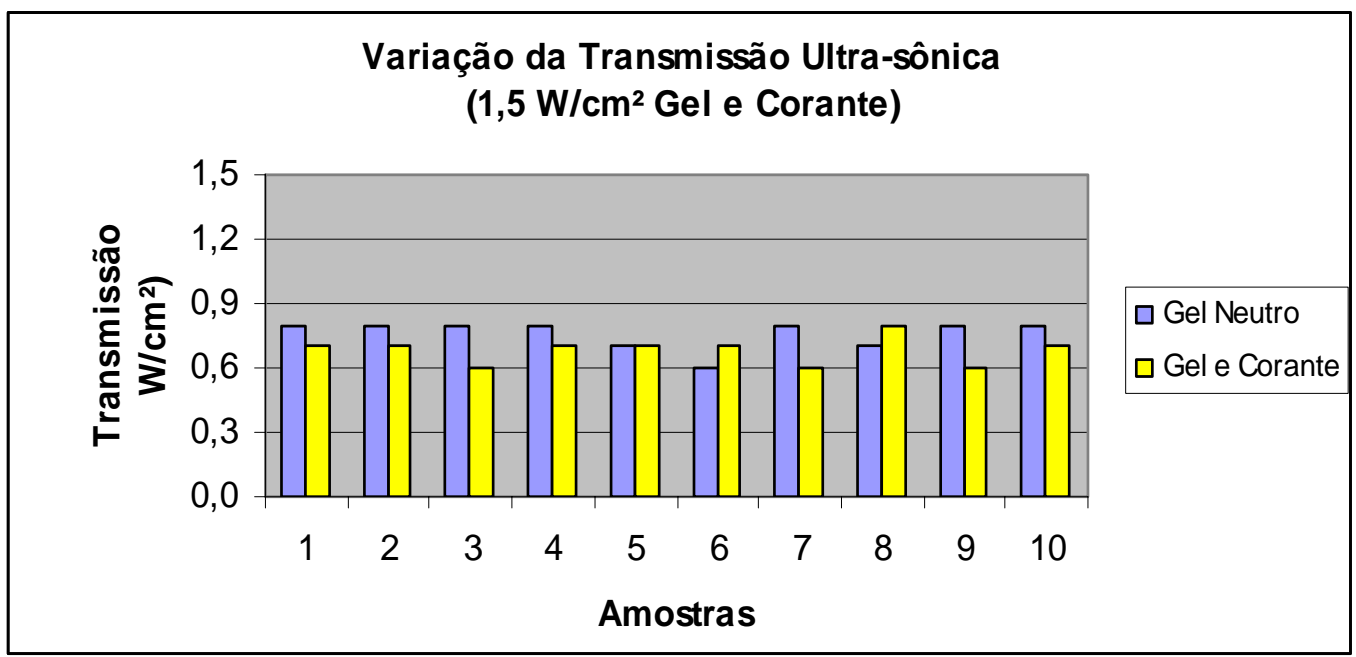

e) Grupo 2 C - Diclofenaco Gel Intensidade 1,5 W/cm²

Não houve diferença estatisticamente significativa na transmissão do sinal no meio diclofenaco gel em relação ao gel neutro, em valores médios observa uma redução do sinal de $0,11 \mathrm{~W} / \mathrm{cm}^{2}$.

Tabela 7 - Teste-t: duas amostras presumindo variâncias diferentes: Gel Neutro e Diclofenaco

$$
1,5 \mathrm{~W} / \mathrm{cm}^{2}
$$

Gel Neutro e Diclofenaco 1,5 W/cm ${ }^{2}$

\begin{tabular}{rrr}
\hline & Variável 1 & Variável 2 \\
Média & 0,76 & 0,65 \\
Variância & 0,004889 & 0,002778 \\
Observações & 10 & 10 \\
Hipótese da diferença de média & 0 & \\
Sl & 17 & \\
Stat $t$ & 3,972733 & \\
$\mathrm{P}(\mathrm{T}<=\mathrm{t})$ uni-caudal & 0,000492 & \\
$\mathrm{t}$ crítico uni-caudal & 1,739606 & \\
$\mathrm{P}(\mathrm{T}<=\mathrm{t})$ bi-caudal & 0,000984 & \\
$\mathrm{t}$ crítico bi-caudal & 2,109819 & \\
\hline
\end{tabular}


Gráfico 5 - Variação da transmissão ultra-sônica (1,0 W/cm² Diclofenaco Gel)

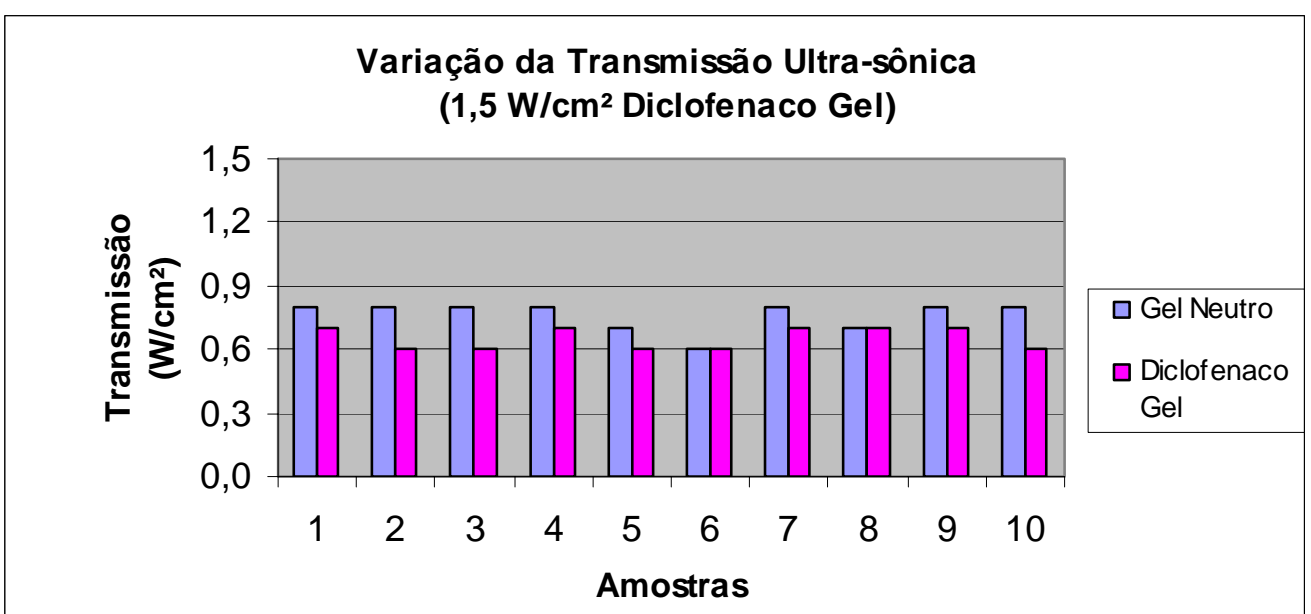

\section{f) Grupo 2 D - Diclofenaco Gel e Corante Intensidade 1,5 W/cm²}

Não houve diferença estatisticamente significativa na transmissão do sinal no meio diclofenaco gel e corante em relação ao gel neutro, em valores médios observamos uma redução do sinal em $0,14 \mathrm{~W} / \mathrm{cm}^{2}$.

Tabela 8 - Teste-t: duas amostras presumindo variâncias diferentes: Gel Neutro e Diclofenaco Corante $1,5 \mathrm{~W} / \mathrm{cm}^{2}$

Gel Neutro e Diclofenaco Corante 1,5 W/cm ${ }^{2}$

\begin{tabular}{lll}
\hline & Variável 1 & Variável 2 \\
\hline Média & 0,76 & 0,62 \\
Variância & 0,004889 & 0,004 \\
Observações & 10 & 10 \\
Hipótese da diferença de média & 0 & \\
gl & 18 & \\
Stat t & 4,695743 & \\
$\mathrm{P}(\mathrm{T}<=\mathrm{t})$ uni-caudal & $9,01 \mathrm{E}-05$ & \\
t crítico uni-caudal & 1,734063 & \\
$\mathrm{P}(\mathrm{T}<=\mathrm{t})$ bi-caudal & 0,00018 & \\
$\mathrm{t}$ crítico bi-caudal & 2,100924 &
\end{tabular}


Gráfico 6 - Variação da transmissão ultra-sônica $(1,5$ W/cm² Diclofenaco Gel e Corante)

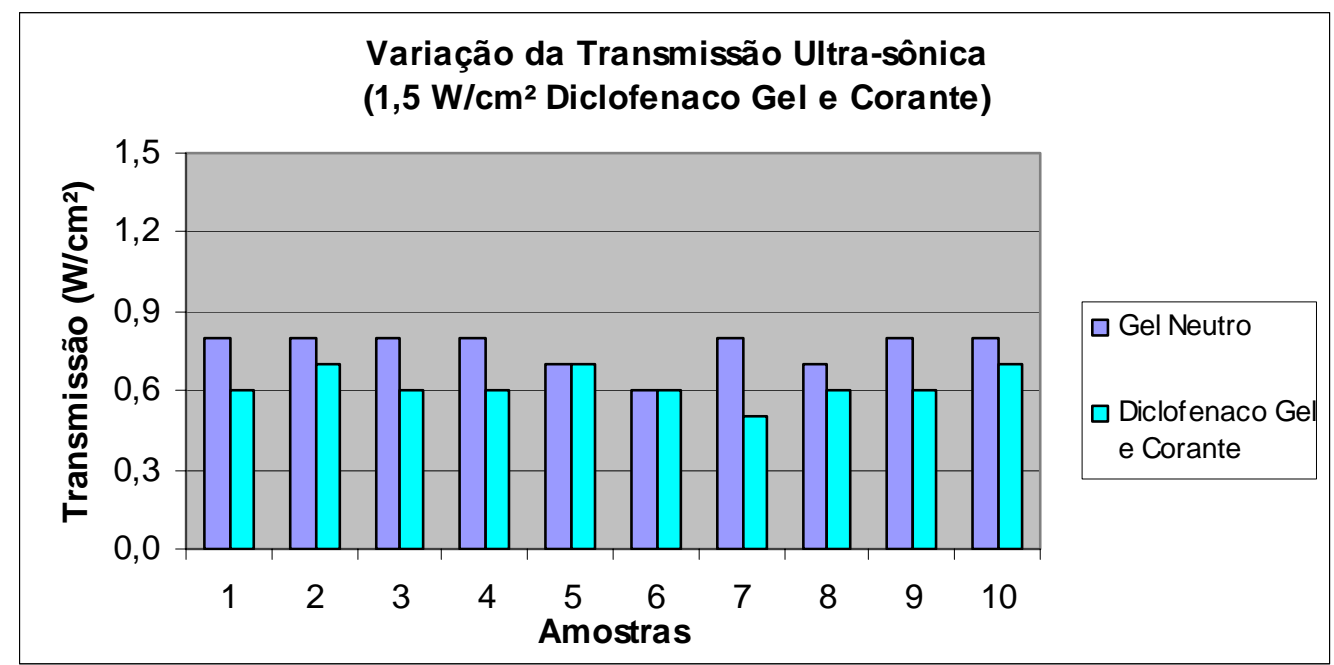

\subsection{Variação do coeficiente de atenuação dos meios}

Neste teste foram calculados os índices de atenuação ultra-sônica em todos os meios estudados, considerando o sinal de saída igual a 1,0 W/cm² para o grupo A e $1,5 \mathrm{~W} / \mathrm{cm}^{2}$ para o grupo B o sinal de chegada foi aferido através da medição da intensidade do campo de ultra-som irradiado nas amostras, por um dosímetro de precisão modelo UPM-DT 10.

\section{a) Grupo 1 B - Gel e Corante Intensidade de 1,0 W/cm²}

Não houve diferença estatisticamente significativa entre a atenuação do meio gel e corante em relação ao meio gel neutro, em valores médios observamos uma atenuação do sinal de 0,06 dB/mm. 
Tabela 9 - Teste-t: duas amostras presumindo variâncias diferentes: Gel e Corante 1,0 W/cm²

\begin{tabular}{lrr}
\multicolumn{3}{c}{ Gel e Corante $\mathbf{1 , 0}$ W/cm } \\
& Variável & Variável \\
& \multicolumn{1}{c}{1} & \multicolumn{1}{c}{2} \\
\hline Média & 0,222 & 0,28646 \\
Variância & 0,004397 & 0,001577 \\
Observações & 10 & 10 \\
Hipótese da diferença de média & 0 & \\
gl & 15 & \\
Stat t & $-2,6373$ & \\
$\mathrm{P}(\mathrm{T}<=\mathrm{t})$ uni-caudal & 0,009329 & \\
t crítico uni-caudal & 1,753051 & \\
$\mathrm{P}(\mathrm{T}<=\mathrm{t})$ bi-caudal & 0,018659 & \\
$\mathrm{t}$ crítico bi-caudal & 2,131451 & \\
\hline
\end{tabular}

Gráfico 7 - Variação do Coeficiente de Atenuação $\left(1,0 \mathrm{~W} / \mathrm{cm}^{2}\right.$ Gel e Corante)

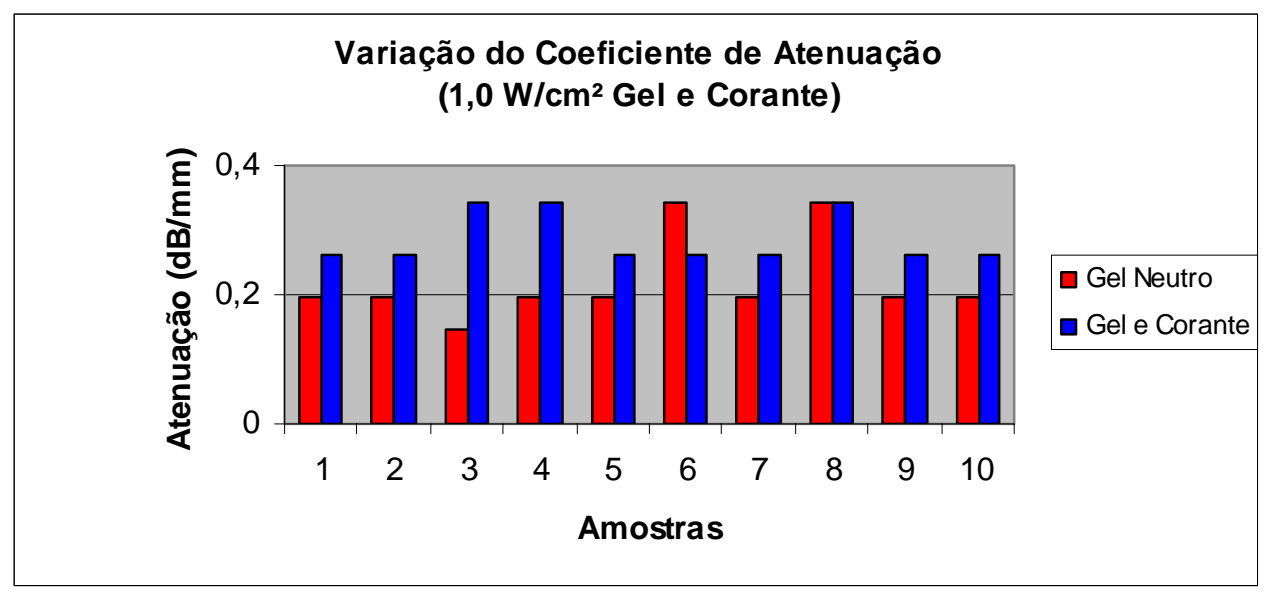

b) Grupo $1 \mathrm{C}$ - Diclofenaco Gel Intensidade de 1,0 W/cm²:

Não houve uma diferença estatisticamente na atenuação do sinal no meio diclofenaco gel em relação ao meio gel neutro, em valores médios observa uma atenuação da onda de $0,10 \mathrm{~dB} / \mathrm{mm}$. 
Tabela 10 - Teste-t: duas amostras presumindo variâncias diferentes: Diclofenaco Gel 1,0

$$
\mathrm{W} / \mathrm{cm}^{2}
$$

\begin{tabular}{lll}
\multicolumn{3}{c}{ Diclofenaco Gel $\mathbf{1 , 0}$ W/cm } \\
\hline & Variável 1 & Variável 2 \\
\hline Média & 0,222 & 0,32756 \\
Variância & 0,004397 & 0,001201 \\
Observações & 10 & 10 \\
Hipótese da diferença de & & \\
média & 0 & \\
gl & 14 & \\
Stat t & $-4,4613$ & \\
$\mathrm{P}(\mathrm{T}<=\mathrm{t})$ uni-caudal & 0,000269 & \\
t crítico uni-caudal & 1,761309 & \\
$\mathrm{P}(\mathrm{T}<=\mathrm{t})$ bi-caudal & 0,000538 & \\
$\mathrm{t}$ crítico bi-caudal & 2,144789 & \\
\hline
\end{tabular}

Gráfico 8 - Variação do Coeficiente de Atenuação $\left(1,0 \mathrm{~W} / \mathrm{cm}^{2}\right.$ Diclofenaco Gel)

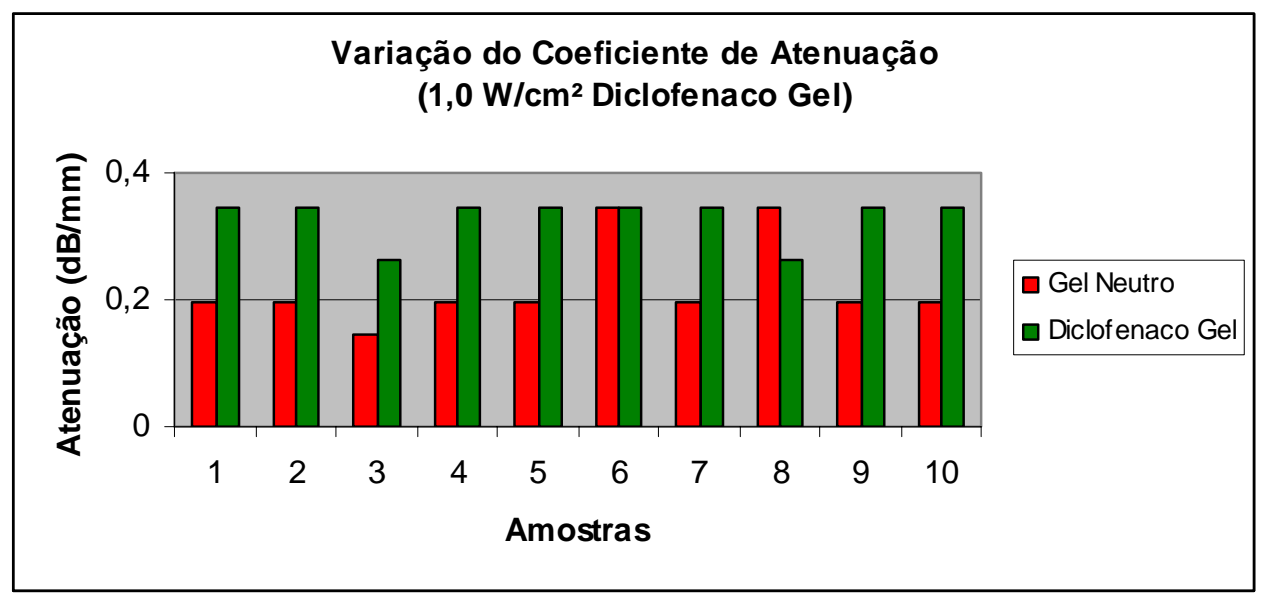

c) Grupo 1 D - Diclofenaco Gel e Corante Intensidade de 1,0 W/cm²:

Não houve uma diferença estatisticamente significativa na atenuação do sinal no meio diclofenaco gel e corante em relação ao gel neutro, em valores médios observamos uma atenuação da onda de 0,20 dB/mm. 
Tabela 11 - Teste-t: duas amostras presumindo variâncias diferentes: Diclofenaco Gel e Corante $1,0 \mathrm{~W} / \mathrm{cm}^{2}$

Diclofenaco Gel e Corante 1,0 W/cm²

\begin{tabular}{lrc}
\hline & Variável 1 & Variável 2 \\
\hline Média & 0,222 & 0,42506 \\
Variância & 0,004397 & 0,003129 \\
$\begin{array}{l}\text { Observações } \\
\text { Hipótese da diferença }\end{array}$ & 10 & 10 \\
média & & \\
gl & 0 & \\
Stat t & 18 & \\
$\mathrm{P}(\mathrm{T}<=\mathrm{t})$ uni-caudal & $-7,40176$ & \\
$\mathrm{t}$ crítico uni-caudal & $3,64 \mathrm{E}-07$ & \\
$\mathrm{P}(\mathrm{T}<=\mathrm{t})$ bi-caudal & 1,734063 & \\
$\mathrm{t}$ crítico bi-caudal & $7,28 \mathrm{E}-07$ & \\
\hline
\end{tabular}

Gráfico 9 - Variação do Coeficiente de Atenuação (1,0 W/cm² Diclofenaco Gel e Corante)

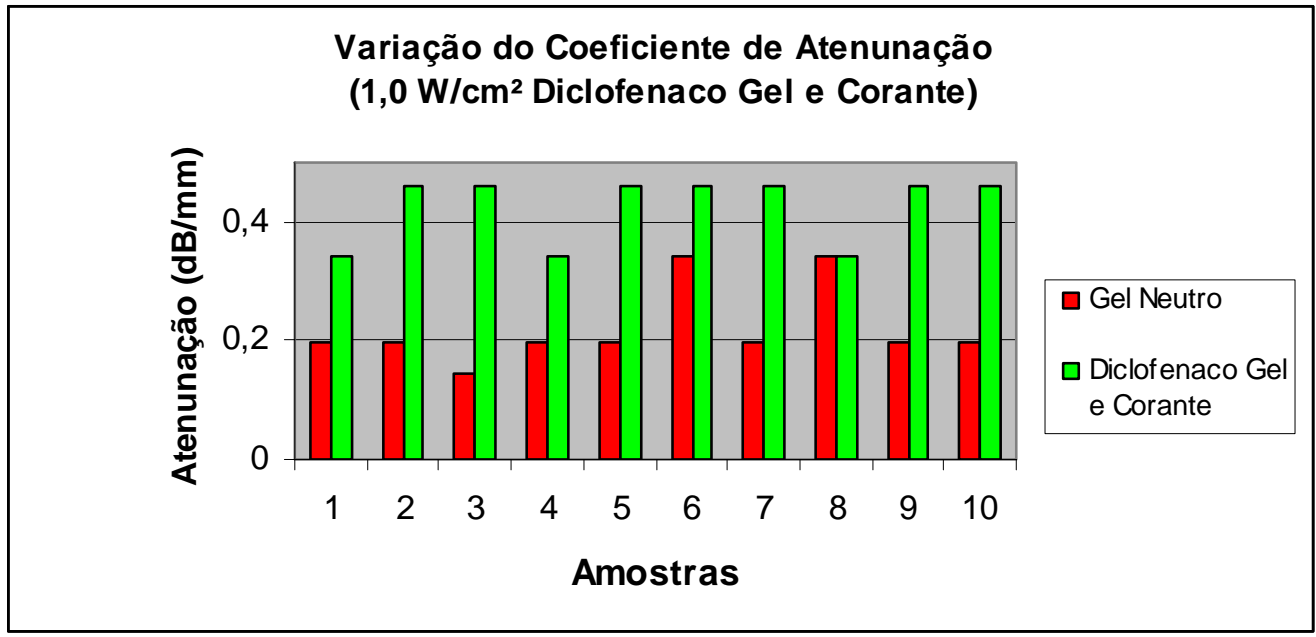

d) Grupo 2 B - Gel e Corante Intensidade 1,5 W/cm²:

Não Houve diferença estatisticamente significativa na atenuação do sinal no meio gel e corante em relação ao gel neutro, em valores médios observamos uma atenuação da onda de 0,08 dB/mm. 
Tabela 12 - Teste-t: duas amostras presumindo variâncias: Gel e Corante 1,5 W/cm

Gel e Corante 1,5 W/cm²

\begin{tabular}{lll}
\hline & Variável 1 & Variável 2 \\
\hline Média & 0,18723 & 0,272218 \\
Variância & 0,000259 & 0,000482 \\
Observações & 10 & 10 \\
Hipótese da diferença de & & \\
média & 0 & \\
gl & 16 & \\
Stat t & $-9,8722$ & \\
$\mathrm{P}(\mathrm{T}<=\mathrm{t})$ uni-caudal & $1,64 \mathrm{E}-08$ & \\
t crítico uni-caudal & 1,745884 & \\
$\mathrm{P}(\mathrm{T}<=\mathrm{t})$ bi-caudal & $3,28 \mathrm{E}-08$ & \\
t crítico bi-caudal & 2,119905 & \\
\hline
\end{tabular}

Gráfico 10 - Variação do Coeficiente de Atenuação $\left(1,5 \mathrm{~W} / \mathrm{cm}^{2}\right.$ Gel e Corante)

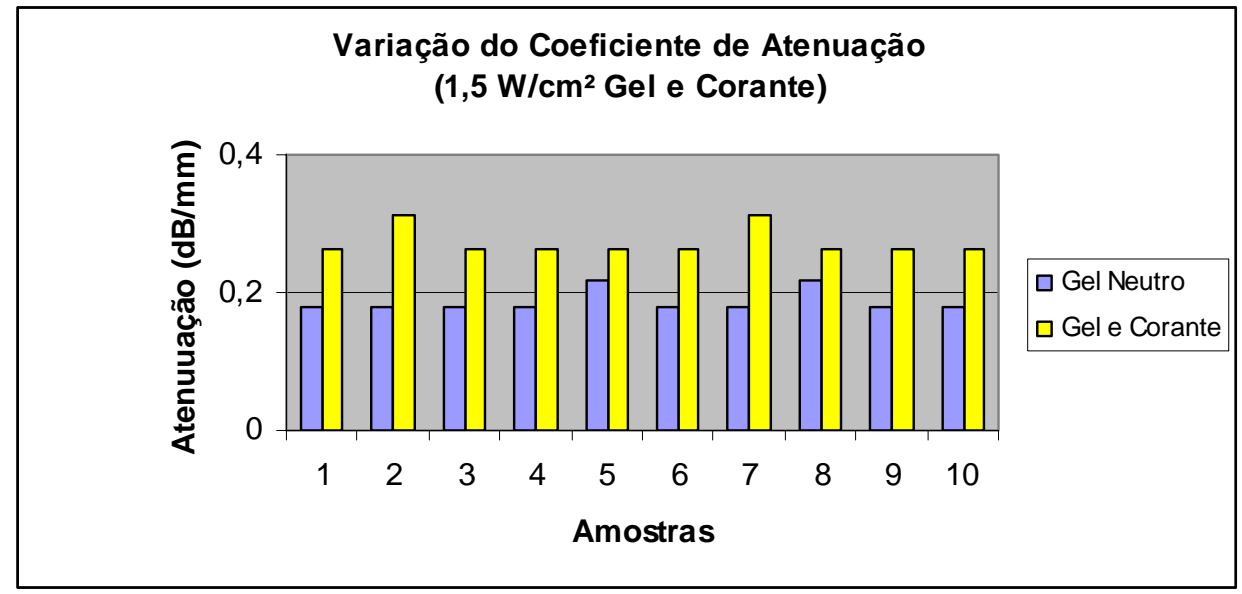

e) Grupo 2 C - Diclofenaco Gel Intensidade 1,5 W/cm²:

Não houve diferença estatisticamente significativa na atenuação do sinal no meio diclofenaco gel em relação ao gel neutro, em valores médios observa uma atenuação da onda de 0,01 dB/mm. 
Tabela 13 - Teste-t: duas amostras presumindo variâncias diferentes: Diclofenaco Gel 1,5 $\mathrm{W} / \mathrm{cm}^{2}$

Diclofenaco Gel 1,5 W/cm²

\begin{tabular}{lrr}
\hline & Variável 1 & \multicolumn{1}{c}{ Variável 2 } \\
\hline Média & 0,18723 & 0,20249 \\
Variância & 0,000259 & 0,000388 \\
Observações & 10 & 10 \\
Hipótese da diferença de média & 0 & \\
gl & 17 & \\
Stat $t$ & $-1,89737$ & \\
$\mathrm{P}(\mathrm{T}<=\mathrm{t})$ uni-caudal & 0,037449 & \\
$\mathrm{t}$ crítico uni-caudal & 1,739606 & \\
$\mathrm{P}(\mathrm{T}<=\mathrm{t})$ bi-caudal & 0,074898 & \\
$\mathrm{t}$ crítico bi-caudal & 2,109819 & \\
\hline
\end{tabular}

Gráfico 11 - Variação do Coeficiente de Atenuação (1,5 W/cm² Diclofenaco Gel)

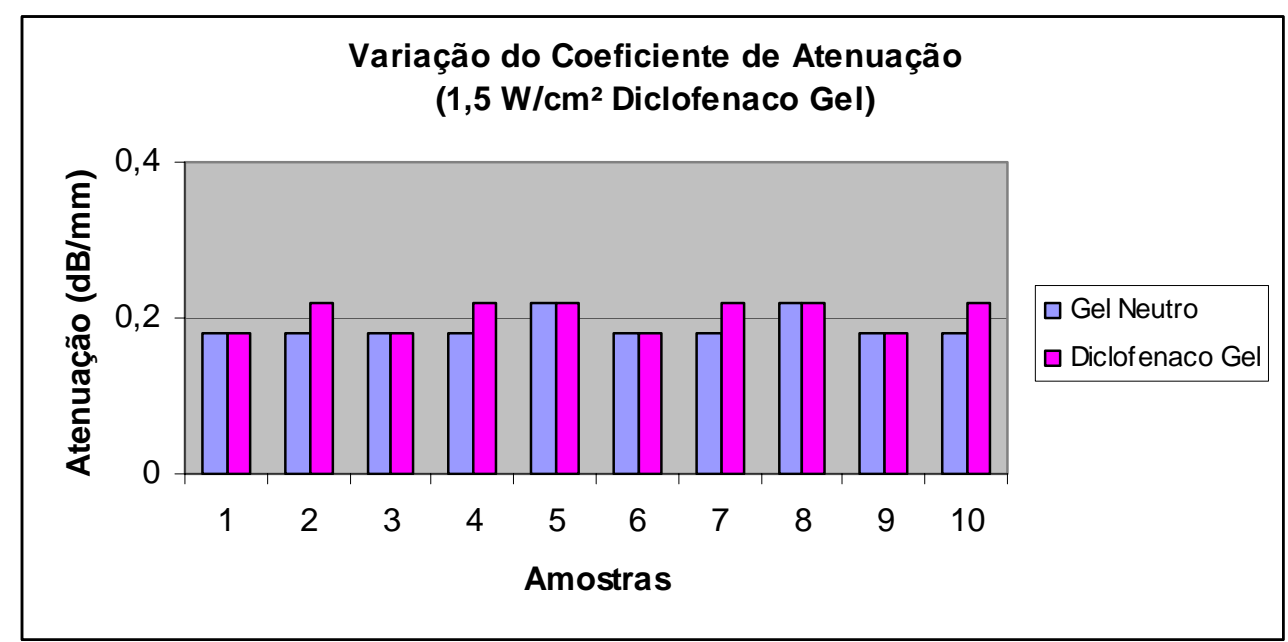

\section{f) Grupo 2 D - Diclofenaco Gel e Corante Intensidade 1,5 W/cm²:}

Não houve diferença estatisticamente significativa na atenuação do sinal no meio diclofenaco gel e corante em relação ao gel neutro, em valores médios observamos uma atenuação da onda de $0,05 \mathrm{~dB} / \mathrm{mm}$. 
Tabela 14 - Teste-t: duas amostras presumindo variâncias diferentes: Diclofenaco Gel e Corante $1,5 \mathrm{~W} / \mathrm{cm}^{2}$

Diclofenaco Gel e Corante 1,5 W/cm²

\begin{tabular}{lrr}
\hline & Variável 1 & \multicolumn{1}{c}{ Variável 2 } \\
\hline Média & 0,18723 & 0,239775 \\
Variância & 0,000259 & 0,000539 \\
Observações & 10 & 10 \\
Hipótese da diferença de média & 0 & \\
gl & 16 & \\
Stat $t$ & $-5,88302$ & \\
$\mathrm{P}(\mathrm{T}<=\mathrm{t})$ uni-caudal & $1,16 \mathrm{E}-05$ & \\
$\mathrm{t}$ crítico uni-caudal & 1,745884 & \\
$\mathrm{P}(\mathrm{T}<=\mathrm{t})$ bi-caudal & $2,31 \mathrm{E}-05$ & \\
$\mathrm{t}$ crítico bi-caudal & 2,119905 & \\
\hline
\end{tabular}

Gráfico 12 - Variação do Coeficiente de Atenuação (1,5 W/ $/ \mathrm{cm}^{2}$ Diclofenaco Gel e Corante)

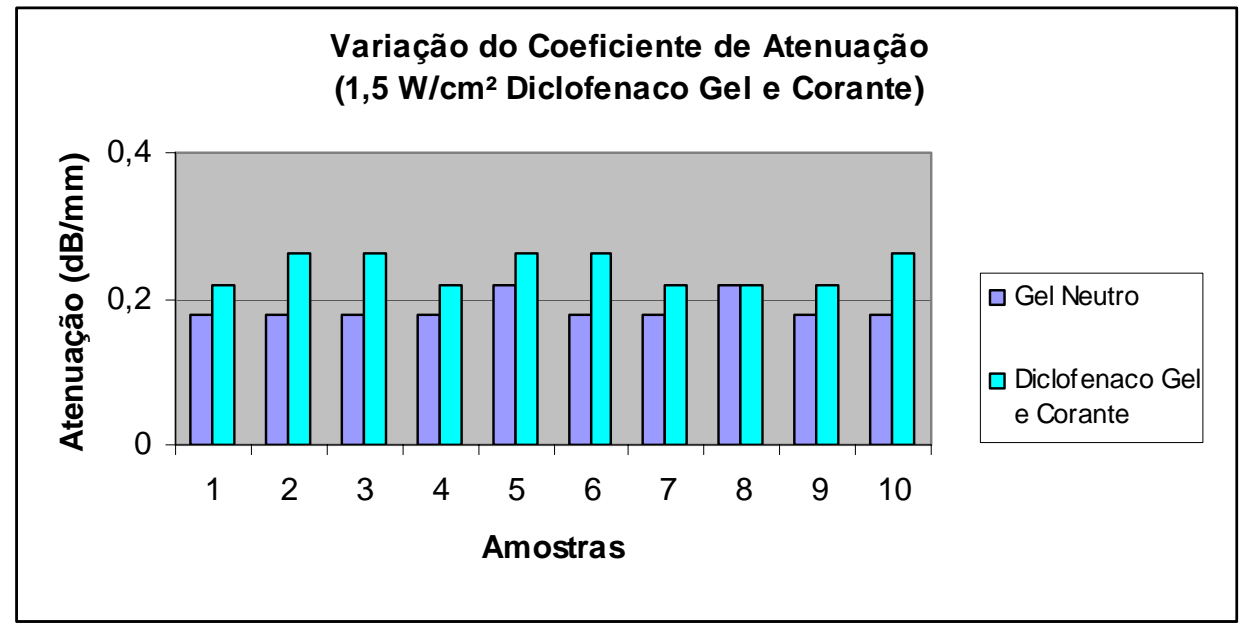

\subsection{Verificação da penetração dos meios}

Neste teste foi aferida a penetração dos meios previamente marcados com o corante, nas amostras, os dados foram comparados com um grupo controle no qual os acoplantes foram distribuídos uniformemente pela superfície dos corpos de prova porém sem a irradiação do ultra-som (APÊNDICE A, B,C). 
Análise Macroscópica:

Grupo Controle: Não houve evidência de penetração nas amostras destes grupos.

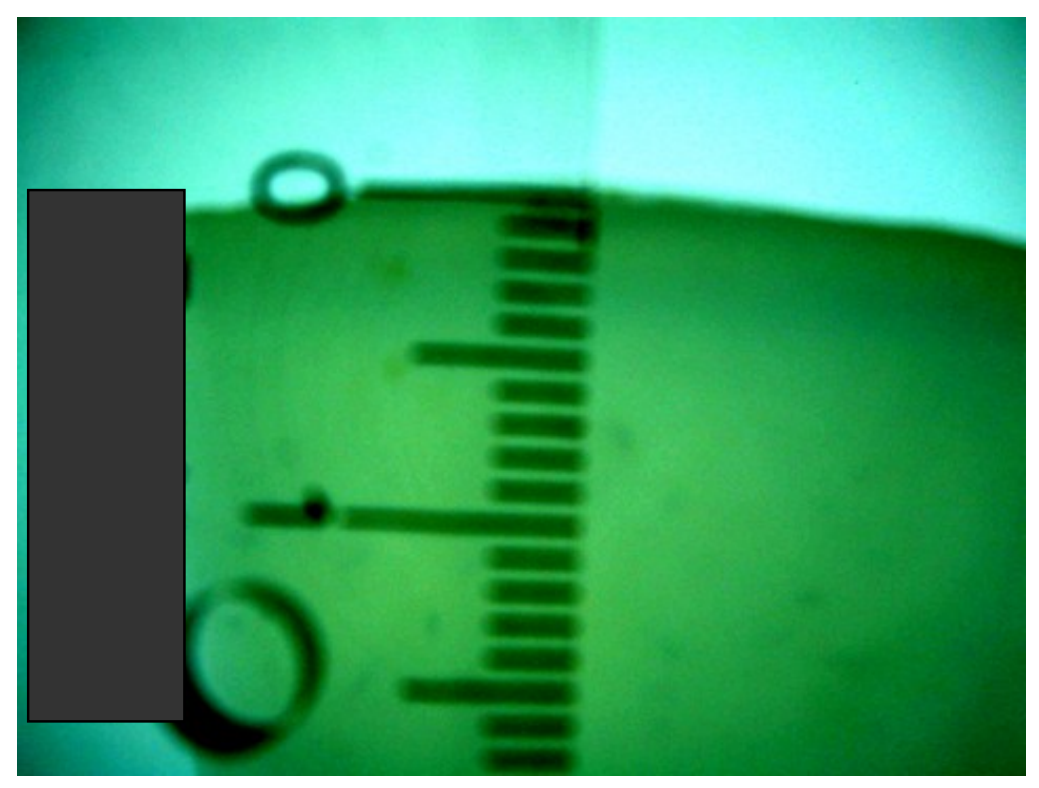

Foto 11 - Grupo controle - análise macroscópica

a) Grupo 4 A - Diclofenaco Gel e Corante Intensidade de 1,0 W/cm²:

Houve uma penetração de $3 \mathrm{~mm}$ evidenciada pelo corante em todas as amostras deste grupo.

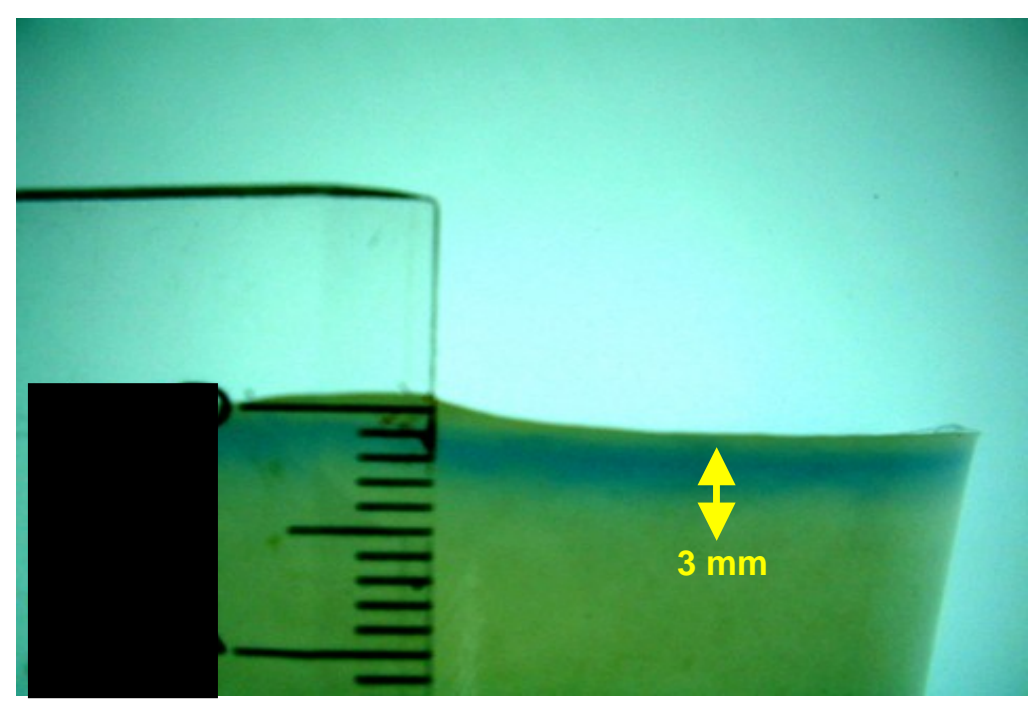

Foto 12 - Grupo 4 A - análise macroscópica 
b) Grupo 5 A - Diclofenaco Gel e Corante Intensidade 1,5 W/cm²:

Houve uma penetração de $5 \mathrm{~mm}$ evidenciada pelo corante em todas as amostras deste grupo.

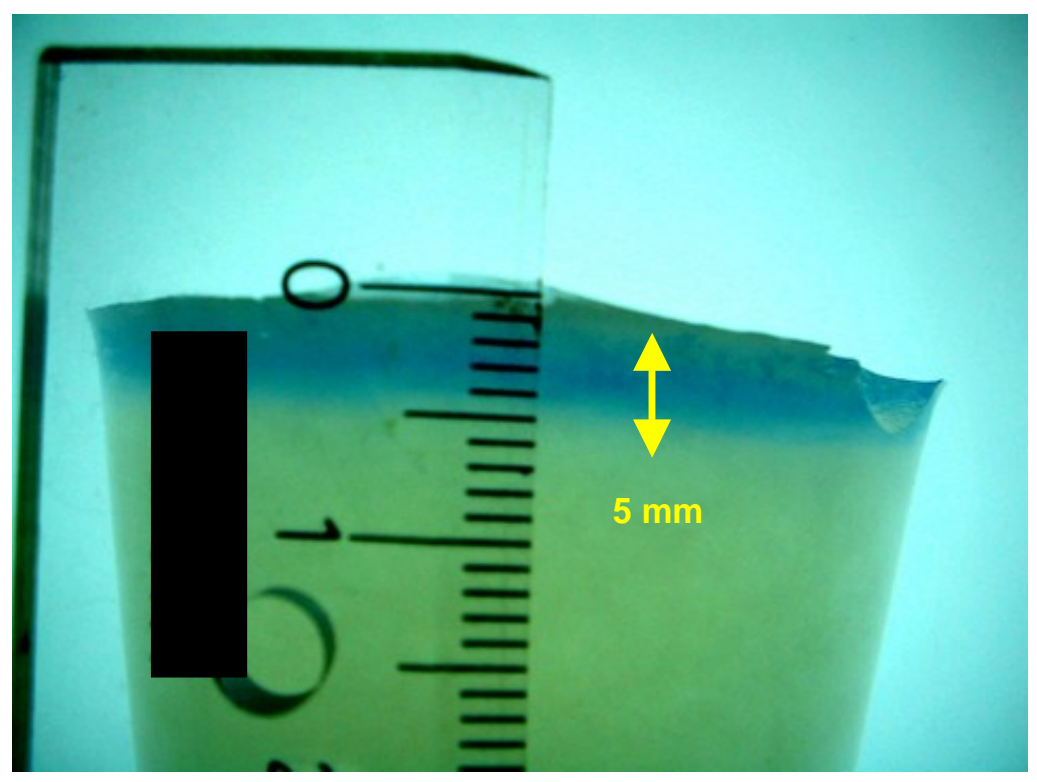

Foto 13 - Grupo 4 B - análise macroscópica

\section{Análise Microscópica:}

Grupo Controle: Não houve nenhuma evidencia de penetração do corante na superfície de todas as amostras deste grupo.

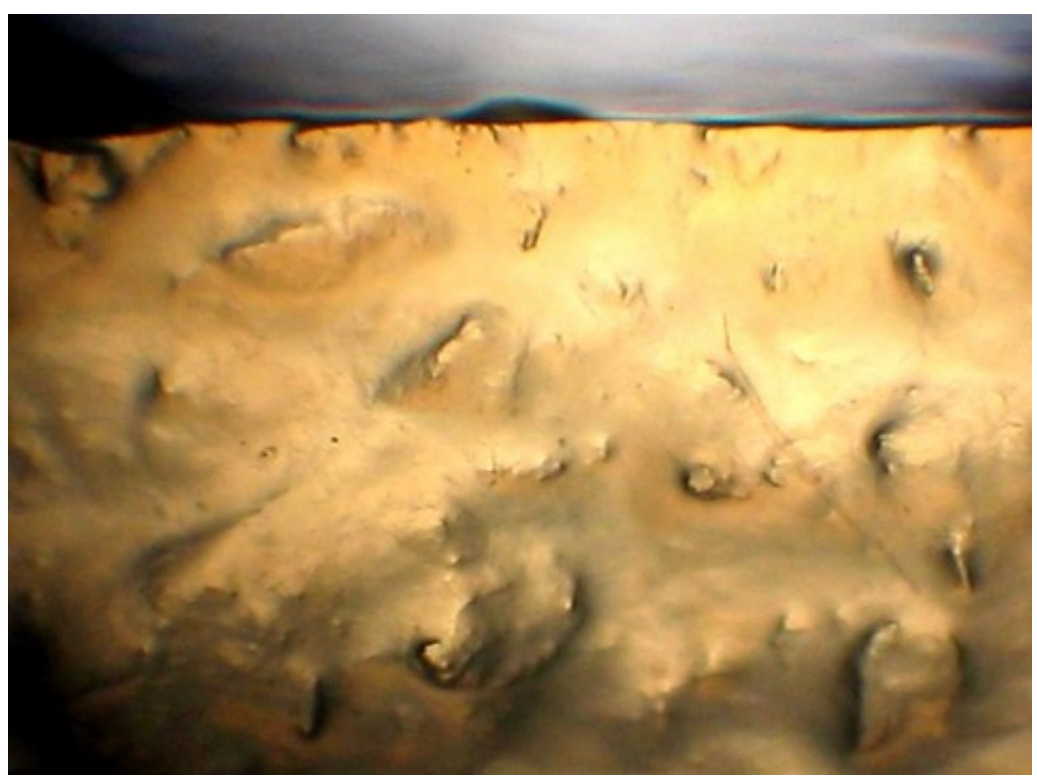

Foto 14 - Grupo controle - análise microscópica 
c) Grupo 4 A - Diclofenaco Gel e Corante Intensidade de 1,0 W/cm²:

Houve evidencia significativa da penetração do diclofenaco gel e corante na superfície irradiada de todas as amostras deste grupo.

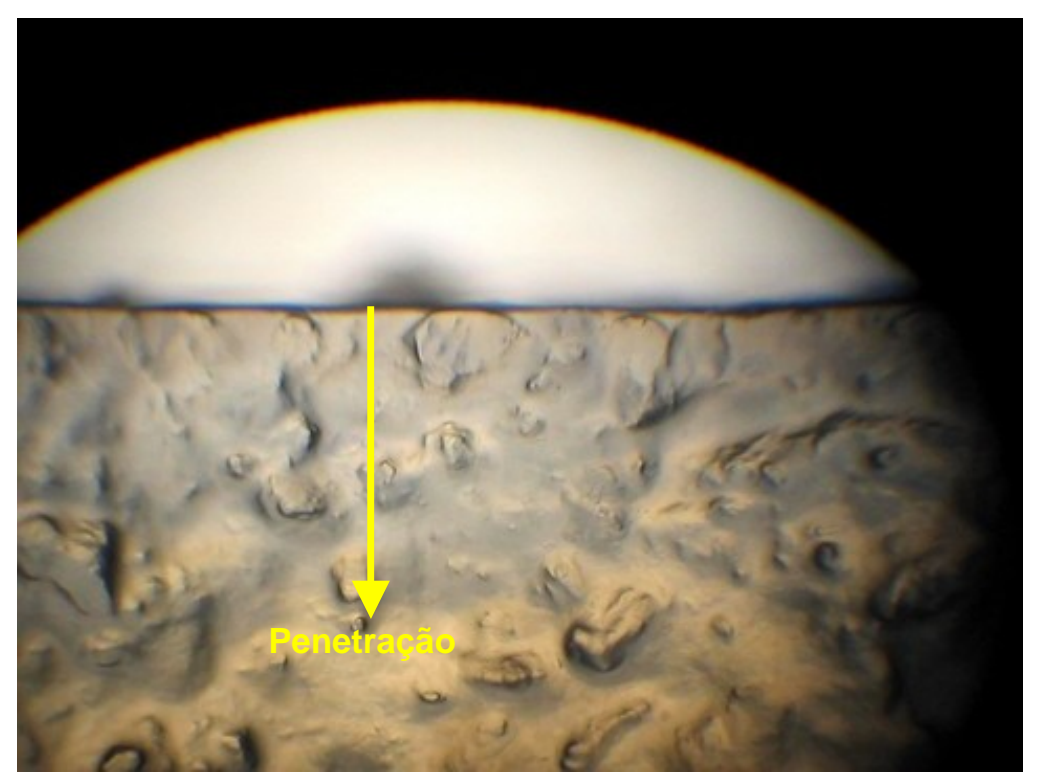

Foto 15 - Grupo 4 A - análise microscópica

\section{d) Grupo 5 A - Diclofenaco Gel e Corante Intensidade 1,5 W/cm²:}

Houve evidencia significativa da penetração do diclofenaco gel e corante na superfície irradiada de todas as amostras deste grupo.

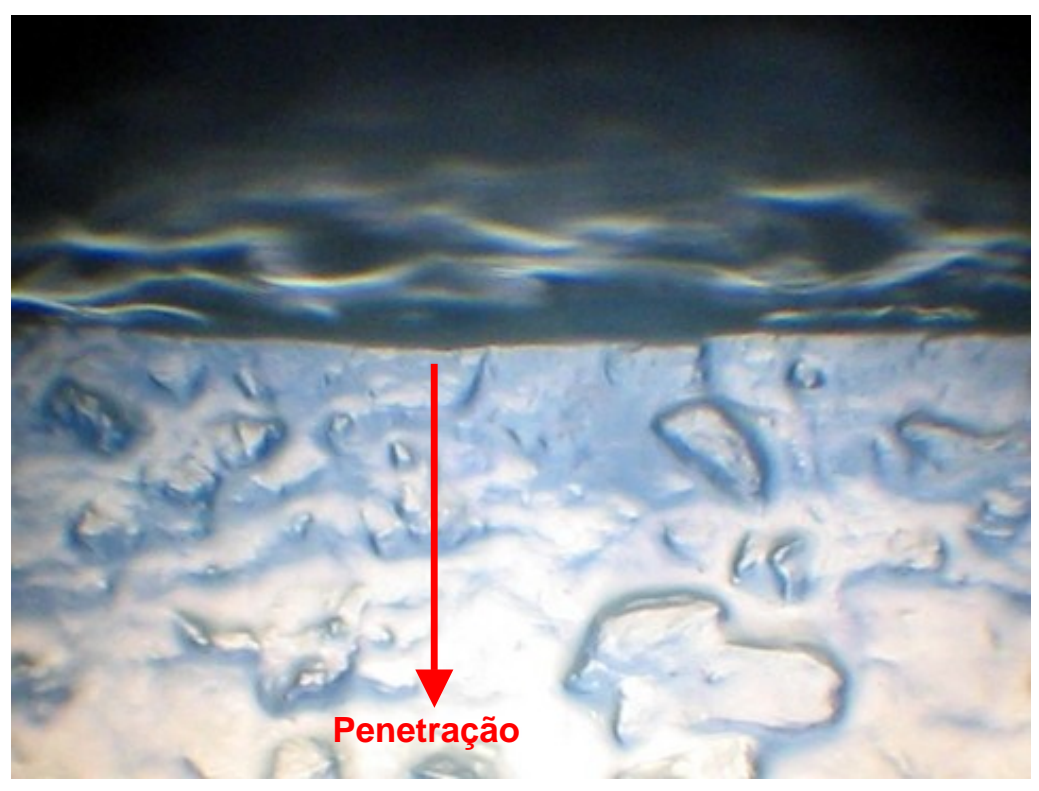

Foto 16 - Grupo 4 B - análise microscópica 


\section{DISCUSSÃO}

Embora o emprego do ultra-som associado a medicamentos tópicos esteja sendo estudado desde 1954, existem poucos trabalhos que descrevem a variação da transmissão ultra-sônica nos meios acopladores utilizados em fonoforese.

A maioria dos artigos e publicações encontradas sobre este tema, se referem à taxa de transmissão do ultra-som em acopladores do tipo gel, pomadas ou óleos minerais e como observamos uma repleta variação nos procedimentos metodológicos, ocorre uma grande dificuldade em obtermos um padrão para os meios acopladores (BALMASEDA et al., 1986; BENSON \& McELNAY, 1994: CAMERON \& MONROE, 1992).

Os estudos referentes à taxa de transmissão relativa de ultra-som em medicamentos tópicos, tem ainda, como referencia a transmissão do ultra-som em meio líquido, o que no nosso entender, não é o parâmetro mais adequado, pois a aplicação de ultra-som terapêutico ocorre por meios indiretos, no qual o acoplador mais utilizado é o hidrogel, logo se torna impreciso atribuir escalas de boa ou má transmissão tendo como referencia a água (BENSON \& MCELNAY, 1994; CAMERON \& MONROE, 1992; LOW \& REED, 2001).

A variação da intensidade e da freqüência do ultra-som utilizados em todos os estudos pesquisados, não permitem uma padronização efetiva da técnica, e dificultam a correlação da impedância do meio utilizado (MITRAGORI et al., 1995; PARIZOTTO et al., 2003).

Os estudos recentes sobre a técnica de fonoforese utilizam uma faixa muito baixa de freqüência de irradiação (20 a $48 \mathrm{Khz}$ ), e ainda em uma intensidade muito baixa na escala de $\mathrm{mW} / \mathrm{cm}^{2}$ por um tempo de aplicação muito longo que varia de 1 a 5 horas, o que descaracteriza esta forma de irradiação com a utilizada pela fisioterapia (MITRAGOTRI et al., 1996). 
Apesar destas recentes pesquisas apontarem uma maior efetividade da penetração dos medicamentos tópicos com esta metodologia, não existe no mercado um aparelho portátil de ultra-som, para aplicação clínica com esta finalidade (MITRAGOTRI et al., 1996).

O uso do ultra-som terapêutico dentro dos padrões clínicos adotados pela fisioterapia, tem sido investigado recentemente com o objetivo de fundamentar a técnica da fonoforese cientificamente, apesar de que a variação dos parâmetros físicos não tenha sido o objeto de estudo podemos observar que a utilização do ultra-som facilita a penetração de antinfalmatórios tópicos (ROSIM G. C, 2003; KOEKE PU, 2003).

Outro dado relevante a ser considerado é que nenhum estudo indica a profundidade de penetração da droga, não existe ainda, uma correlação exata de intensidade e penetração do medicamento, os pesquisadores pressupõem que quanto maior a intensidade, maior será a penetração, no entanto isso é embasado por postulados teóricos a respeito da irradiação ultra-sônica que relatam, quanto maior for à intensidade do campo ultra-sônico maior será sua ação,e não de achados científicos (LOW \& REED, 2001).

Portanto ainda não existem estudos, sobre o ultra-som terapêutico, que tentam correlacionar os índices de transmissão com outras variáveis como atenuação do campo ultra-sônico, e a relação da intensidade irradiada com a taxa de penetração do fármaco no sistema estudado.

Diante dos fatos encontrados na literatura científica atual, propô-se uma avaliação mais precisa dos coeficientes de atenuação e transmissão do ultrasom em um antiinflamatório tópico e correlacionou-se os parâmetros de intensidade com a penetração do medicamento.

Os dados aqui encontrados sugerem que alguns postulados teóricos largamente difundidos na fisioterapia sofrem uma mudança quando observados do ponto de vista físico e prático. 
Quando adotamos como referencia a transmissão do ultra-som em hidrogel, não observamos uma diferença estatisticamente significante do diclofenaco gel mesmo quando variamos a intensidade de irradiação.

A variação do coeficiente de atenuação não demonstrou uma redução significativa no meio diclofenaco gel em comparação ao hidrogel, portanto podemos concluir que a interação entre o fármaco e sua penetração não ocorre por meio da intensidade do campo ultra-sônico, mas sim por outros mecanismos que devem ser melhor esclarecidos.

A penetração do medicamento ocorre mesmo em intensidades consideradas mínimas para a prática da fonoforese, logo podemos adotar dosagens menores para as áreas de aplicação.

O ultra-som realmente facilitou a penetração do medicamento, fato este comprovado na comparação das analises histológica e macroscópica das amostras do grupo irradiado, com as do grupo controle, aonde não foi encontrada nenhuma evidência de penetração da droga.

Contudo, observamos que as etapas futuras para o desenvolvimento do conhecimento sobre a variação dos parâmetros físicos na associação do ultra-som terapêutico com medicamentos tópicos devem ter como objetivos esclarecer melhor o mecanismo pelo qual ocorre à facilitação da penetração de ions pela via transdérmica, se existe uma faixa de freqüência preferencial para a técnica, e se todos as drogas tópicas utilizadas atualmente na fonoforese têm o mesmo comportamento em relação a sua atenuação, transmissão e penetração. 


\section{CONCLUSÃO}

Os resultados obtidos nesta pesquisa permitem concluir que, não ocorre uma variação significativa dos coeficientes de atenuação e transmissão durante a irradiação de ultra-som terapêutico a $1 \mathrm{MHz}$ no meio diclofenaco gel, e que o ultra-som promove a penetração do fármaco em sistemas experimentais similares ao da pele humana.

Estudos futuros são necessários para um maior esclarecimento dos mecanismos biofísicos que compõem a facilitação da penetração de drogas através dos campos ultra-sônicos, assim como, se esta penetração ocorre em outra freqüência terapêutica como a de $3 \mathrm{MHz}$, que atualmente é preconizada para o tratamento das camadas mais superficiais da pele.

O sistema experimental utilizado neste estudo é de fácil reprodução e boa confiabilidade, podendo por tanto ser aproveitado nas aulas de graduação do curso de fisioterapia, na disciplina de eletroterapia, como uma ferramenta de ensino e estímulo à pesquisa. 


\section{REFERÊNCIAS BIBLIOGRÁFICAS}

ABRAHAM MH, CHADHA HS, MITCHELL RC. (1995). The factors that influence skin penetration of solutes. J Pharm Pharmacol., 47:8-16.

BALMASEDA JUNIOR MT, FATEHI MT, KOOZEKANANI SH, LEE AL. (1986). Ultrasound therapy: a comparative study of different coupling media. Arch Phys Med Rehabil, 67:14750.

BARRY BW. (1983). Dermatological formulations. Percutaneous Absorption. New York: Marcel Dekker.

. (1991). Lipid-protein-partition theory of skin penetration enhancement.

J Cont Rel., 15:237-48.

BEARD M. (2002). Guided wave inspection of embedded cylindrical structures, Mechanical Engineering Department. Imperial College London.

BEHL CR, BELLANTONE NH, FLYNN GL. (1985). Influence of age on percutaneous absorption of drug substances. In: BRONAUGH RL, MAIBACH HI. editors. Percutaneous Absorption. New York: Marcel Dekker, p. 183-212.

BENSON HAE, McELNAY JC. (1994). Topical non-steroidal antiinflammatory products as ultrasound couplants: their potential in phonophoresis. Physiotherapy, 80(2):74-6.

BLANK IH, SCHEUPLIEN RJ, MCFARLANE DJ. (1967). Mechanism of percutaneous absorption III. The effect of temperature on transport of non electrolytes across skin. J Invest Dermatol., 49:582-9.

BRASILEIRO J, ALVES TC, ESCÓSSIA CC. (2003). Análise da transmissibilidade ultra-sônica de medicamentos utilizados na prática da fonoforese. Revista Brasileira de Fisioterapia, 7(2):139-44.

BROWN HS, BISHOP DR, ROWAN CA. (1984). The role of skin absorption as a route of exposure for volatile organic compounds (VOCs) in drinking water. Am. J. Public Health, 74(5):479-84.

BUNGE AL, CLEECK RL. (1995). A new method for estimation of dermal absorption from chemical exposure: II, Effect of molecular weight and octonolwater partition coefficient. Pharm Res., 12:88-95.

CAMERON MH, MANROE LG. (1992). Relative transmission of ultrasound by media customarlly used of phonophoresis. Physical Therapy, 72:142-8.

CHEIN YW. (1988). Advances in transdermal systemic drug delivery. Drugs of Future, 13:343-62. 
CROOS SE, ROBERTS MS. (2004). Physical enhancement of transdermal drug application: is delivery technology keeping up with pharmaceutical development? Current Drug Delivery, 1:81-92.

DANGELO, FATTINI. (1988). Anatomia humana básica. 2.ed. Rio de Janeiro, Livraria Atheneu.

DOCKER MF, PATRICK MK, FOULKES DJ. (1982). Ultrasound couplants for physiotherapy. Physiotherapy, 68(4):124-5.

EDWARDS DA, PRAUSNITZ MR, LANGER R, WEAVER JC. (1995). J. Control. Release, 34:211-21.

ELIAS PM.(1981). Lipids and the epidermal permeability barrier. Arch Dermatol Res., 270:95-117.

ENGSTROM S.(1997). What is the time scale of magnetic field interaction in biological systems? Bioelectromagnetics, 18(3):244-9.

FELDMANN RJ, MAIBACH HI. (1967). Regional variation in percutaneous penetration of C-cortisol in man. J Invest Dermatol., 48:181-3.

FRENKEL V, KIMMEL E, IGER Y. (1999). Ultrasound-induced cavitation damage to external epithelia of fish skin. Ultrasound Med Biol., 25(8) 1295-303.

GOLDSTEIN A. (2000). The effect of acoustic velocity on phantom measurements. Ultrasound Med Biol., Sep; 26 (7):1133-43.

GONÇALVES AC. (2003). Efeitos do ultra-som terapeutico na integração de enxertos de pele total em coelhos. Dissertação (Mestrado) - Programa de Interunidades em Bioengenharia EESC/FMRP/IQSC, Universidade de Sao Paulo, São Carlos.

GONÇALVES G, PARIZOTTO NA. (1998). Fisiopatologia na reparação cutânea : Atuação da Fisioterapia. Revista Brasileira de Fisioterapia, 3(1): 5-13.

HADDAD S. (1992). Estímulo do testículo de ratos pré-púberes, púberes e adultos com ultra-som pulsado de baixa intensidade. Disertação (Mestrado) Programa de Interunidades em Bioengenharia EESC/FMRP/IQSC, Universidade de São Paulo, São Carlos.

GUIRRO R, CANCELIERI AS, SANT'ANNA IL. (2001). Avaliação dos meios intermediários utilizados na aplicação do ultra-som terapêutico. Revista Brasileira de Fisioterapia, 5(2):49-52.

HAAR G, DUCK F, STARRITT H, DANIELS S. (1989). Biophysical characterisation of diagnostic ultrasound equipment--preliminary results. Phys Med Biol., nov 34(11):1533-42. 
JETZER WE, HOU SYE, HUG AS, DURAISWAMY N, HO NH, FLYNN GL. (1988). Temperature dependency of skin permeation of waterborne organic compounds. Pharm. Acts Helv, 63:197-201.

KOEKE PU. (2003). Estudo comparativo da eficácia da fonoforese, do ultrasom terapêutico e da aplicação tópica de hidrocortisona no tratamento do tendão de rato em processo de reparo tecidual. Dissertação (Mestrado em Bioengenharia) - Escola de Engenharia de São Carlos, Faculdade de Medicina de Ribeirão Preto, Instituto de Química de São Carlos, Universidade de São Paulo.

LOW L, REED A. (2001). Eletroterapia explicada: princípios e prática. 3 ed. São Paulo, Manole.

MARZULLI FN et al. (1962). Barriers to skin penetration. J Invest. Dermatol., 39:397-93.

MITRAGOTRI S, EDWARDS DA, BLANKSCHTEIN D \& LANGER R. (1995). A mechanistic study of ultrasonically - Enhanced transdermal drug delivery. Journal of Pharmaceutical Sciences, 84:697-706.

, BLANKSTEIN D, LANGER R. Transdermal drug delivery using lowfrequency sonophoresis. Pharm. Res., 13:411-20.

MENON GK, LEE S, McAULIFFE DJ, KOLLIAS N, DOUKAS AG. (2000). J. Invest. Dermatol., 114A: 837.

NELSON RM, CURRIER DP. (1993). Clinical electrotherapy 2nd ed. Norwalk, Connecticut: Appleton \& Lange.

OHMIC INSTRUMENTS. (1988). Ultrasound power in medicine: principles os ultrasound power mensurent. Ohmic Instruments Co, St Michaels, Maryland, USA.

OKUNO E, CALDAS IL, CHOW C (1986). Física para ciências biológicas e biomédicas. São Paulo: Harbra.

ORLOWSKI S, MIR LM. (1993). Biochim. Biophys. Acta, 1154: 51-63.

PANCHAGNULA R. (1997). Transdermal Delivery of Drugs. Indian J. Pharmacol. 29:140-156.

PARIZOTO NA, KOEKE PU, MORENO BGD, LOURENCIN FTC. (2003). Utilização da fonoforese em desordens músculo-esquelética: uma metaanálise. Revista Brasileira de Fisioterapia, 7(1): 49-55.

PRAUSNITZ MR. (1999). Adv. Drug Deliv. Rev., 35:61-76.

REID DC, CUMMINGS GE. (1977). Efficiency of ultrasound counpling agents. Physiotherapy, 63(8):255-7. 
RICKEY DW, PICOT PA, CHRISTOPHER DA, FENSTER A. (1995). A wall-less vessel phantom for Doppler ultrasound studies. Ultrasound in Medicine \& Biology. 21, Issue 9, 1163-1176.

RITSCHEL WA, HUSSAIN AS. (1988). The principles of skin permeation. Meth Find Exptl Clin Pharmacol., 10:39-56.

ROSIM GC. (2003). Análise da influência do ultra-som terapêutico na penetração transcutânea de diclofenaco sódico em humanos sadios. Dissertação (Mestrado em Bioengenharia) - Escola de Engenharia de São Carlos, Faculdade de Medicina de Ribeirão Preto, Instituto de Química de São Carlos, Universidade de São Paulo.

ROSKOS KV, MAIBACH HI, GUY RH. (1989). The effect of aging on percutaneous absorption in man. J. Pharmacokinet Biopharm, 17:6174-529

SCHEUPLEIN RJ, BLANK IH. (1971). Permeability of the skin. Physiol. Rev., 51(4): 702-47.

SHAOXIA Z, ANDREIAS S, THOMAS S, YIPING L, JINSHUN Z, MAX GB. (2004). Molecular Mechanisms of Low Intensity Pulsed Ultrasound in Human Skin Fibroblasts. J. Biol. Chem., 219, Issue 52, 54463-54469.

SILVA CS. (1987). Diagnóstico e tratamento clínico In: MAFFEI, FHA. Doenças vasculares periféricas. Rio de Janeiro: MEDSI. Cap 2.

SMITH EW, MAIBACH HI. (1995). Percutaneous penetration enhancers. CRC Press, Boca Raton, FL.

TESKE, M, TRENTINI, AMM. Compêndio de fitoterapia. 3. ed. Curitiba: Herbarium Laboratório Botânico; 1997.

WARREN CG, KOBLANSKI JN, SIGELMANN RA. (1976). Ultrasound coupling media: their relative transmissivity. Arch Phys Med Rehabil. 57:218-22.

WEAVER JC. (1993). J. Cell Biochem., 51: 426-35.

WEN CL et al. (2001). A pele humana: histologia. Disponível em: http://www.saudepravc.com.br/pintanapele/histologia.htm Acesso em: $15 \mathrm{abr}$ 2005.

WU J, CHAPPELOW J, YANG J, WEIMANN L. (1998). Defects generated in human stratum corneum specimes by ultrasound. Ultrasound in Med. \& Biol. 24 (5):705-10.

ZHOU S, SCHULMEZ A, SEUFFERLEIN T, LI Y, ZHAO J, BACHEM MG. (2004). Molecular mechanims of low intensity pulsed ultrasound im human skin fibroblasts. The Journal Biologycal Chemistry 279(52) 54463-54469. 


\section{APÊNDICES}

APÊNDICE A - Microscopia das Amostras do Grupo Controle

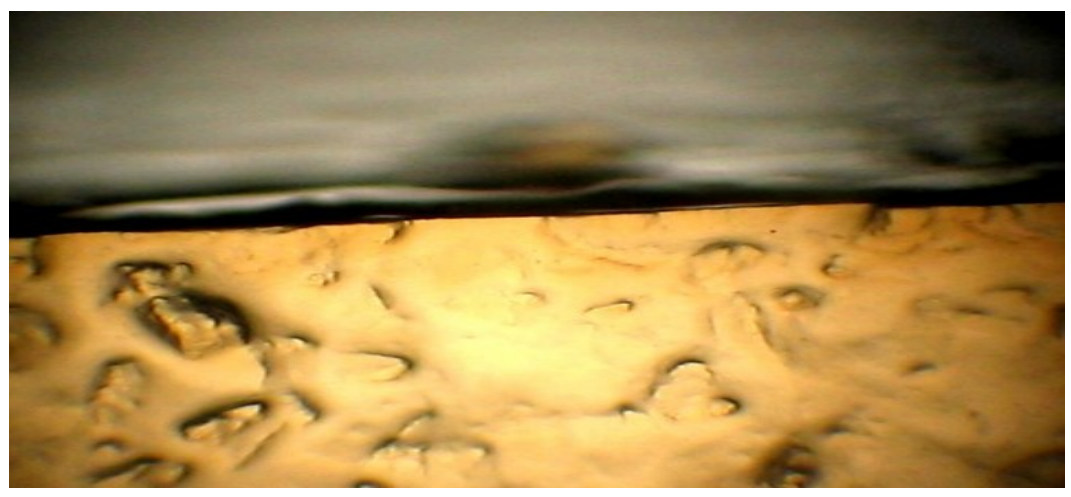

Amostra 1

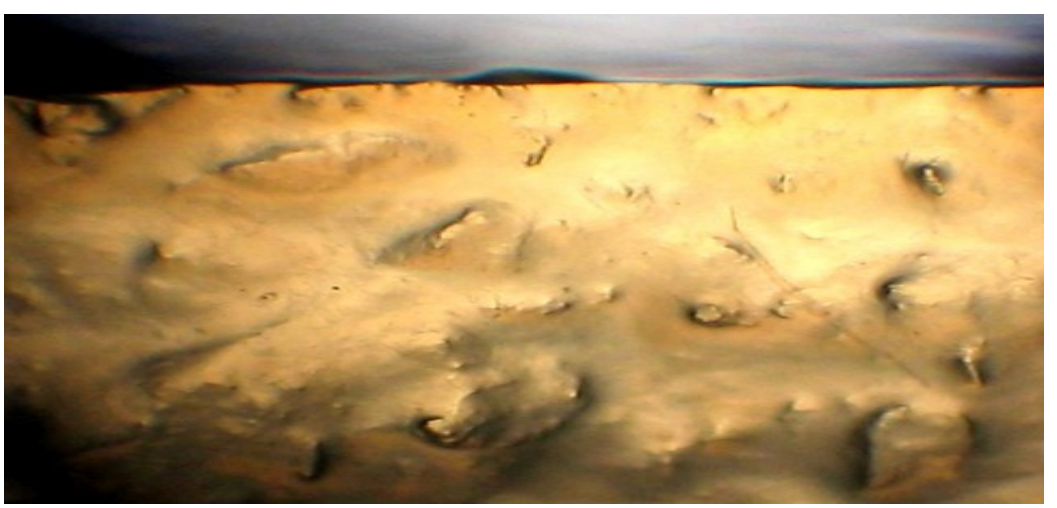

Amostra 2

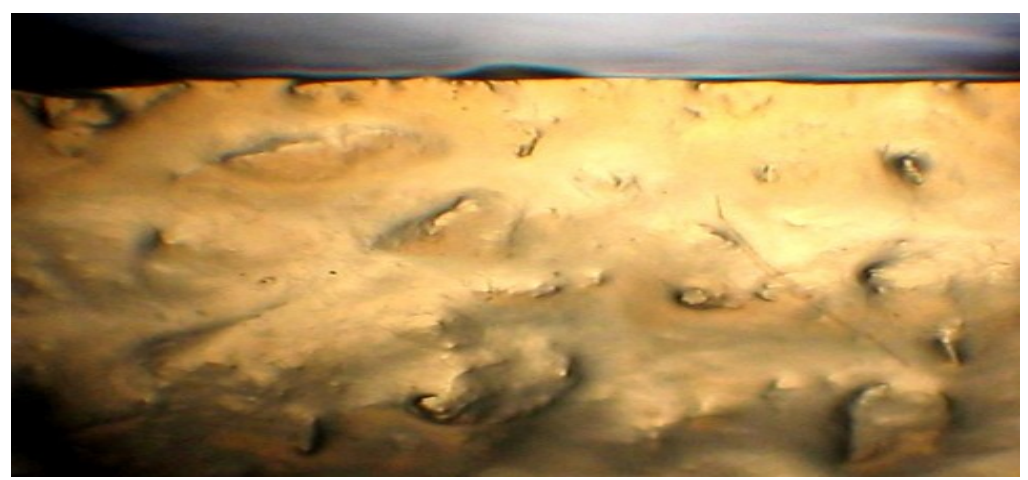

Amostra 3 


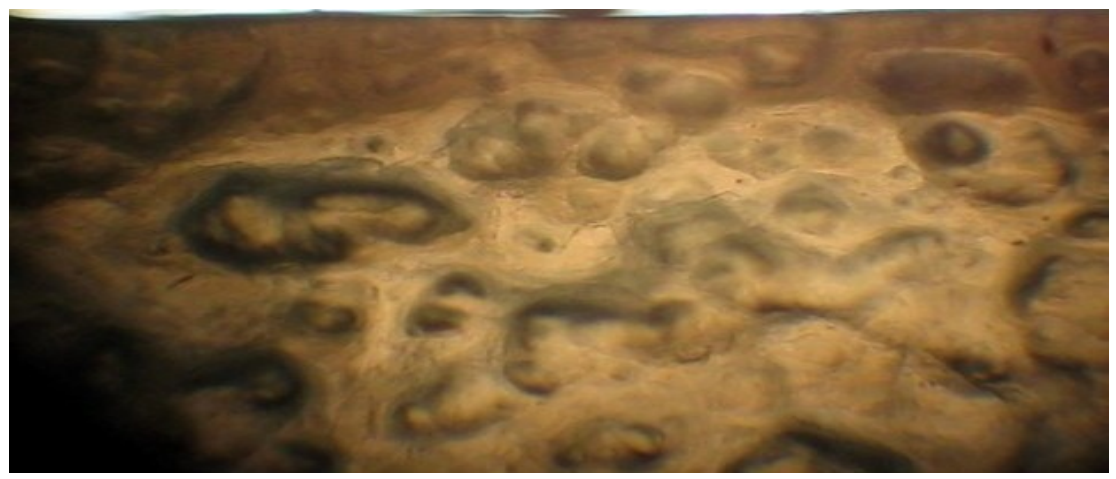

Amostra 4

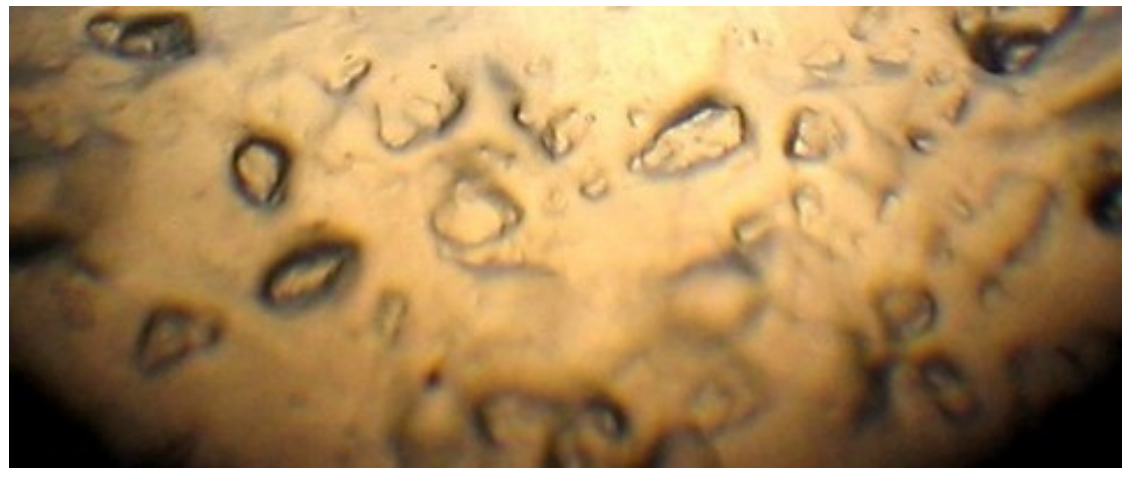

Amostra 5

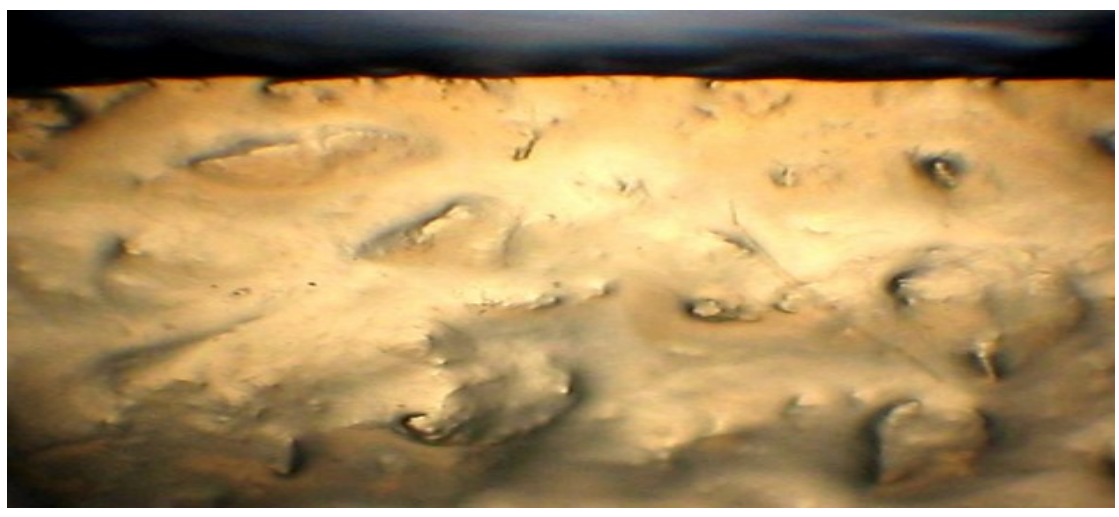

Amostra 6

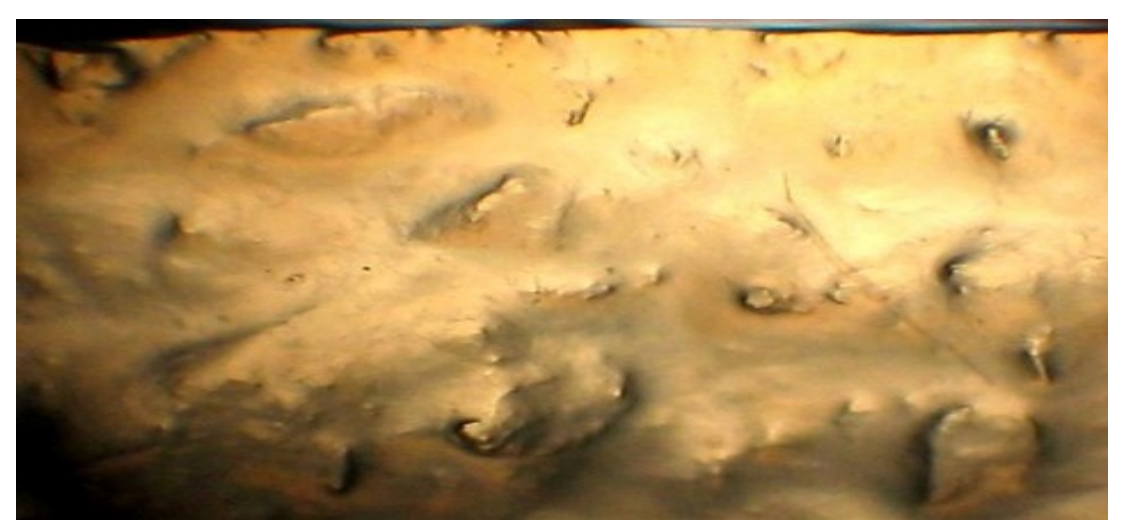




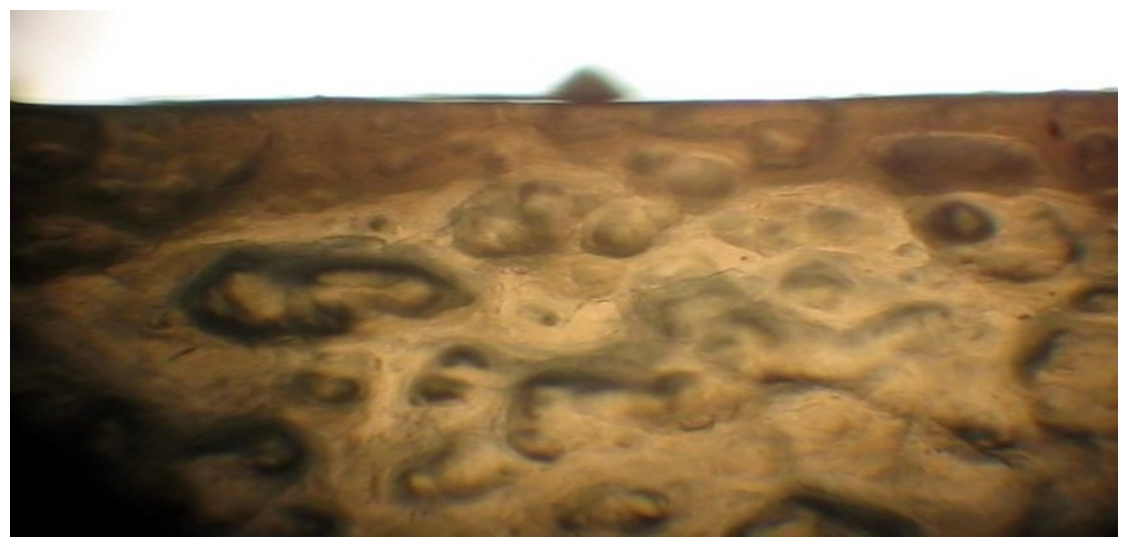

Amostra 8

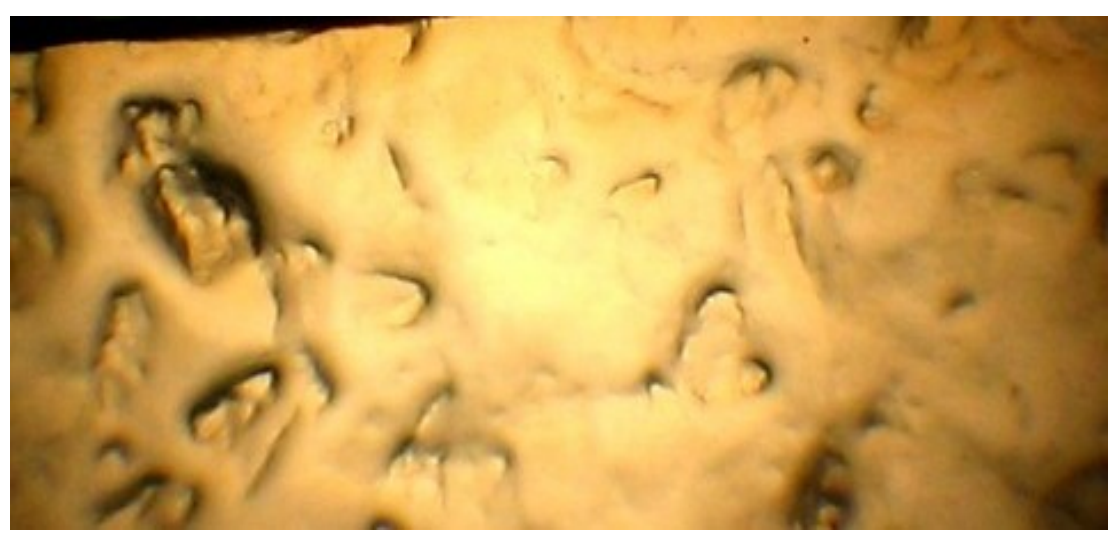

Amostra 9

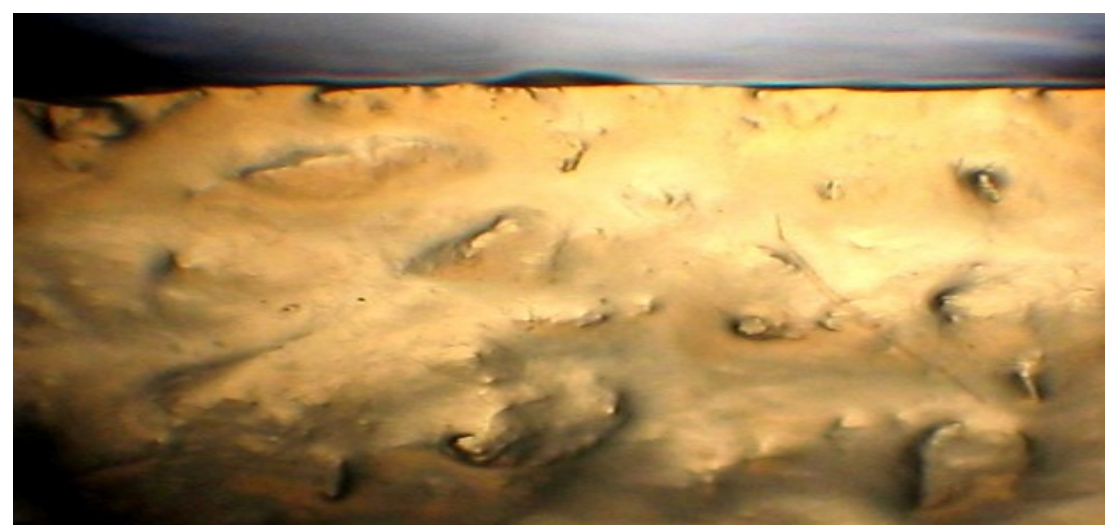

Amostra 10 
APÊNDICE B - Microscopia das Amostras Irradiadas a 1,0W/cm²

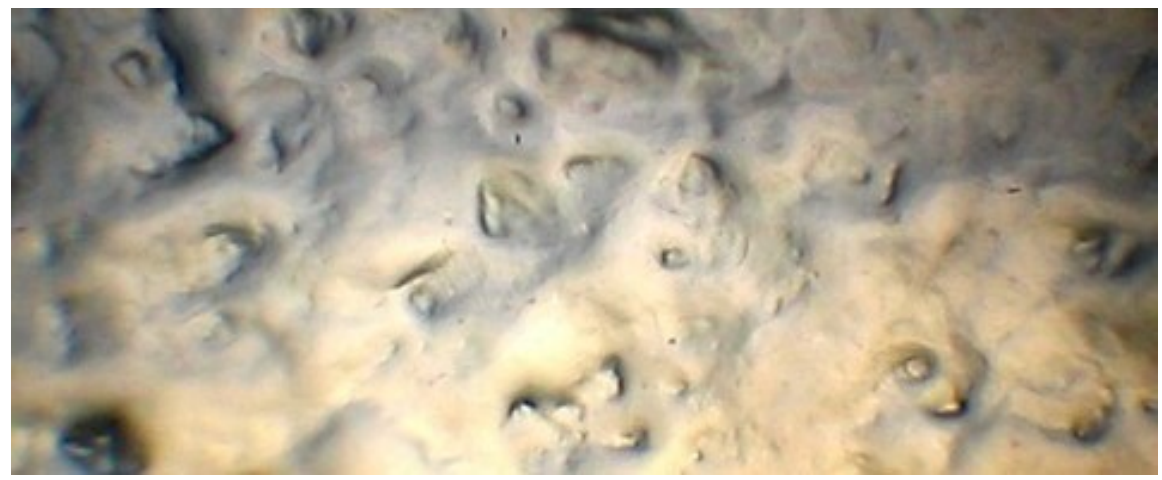

Amostra 1

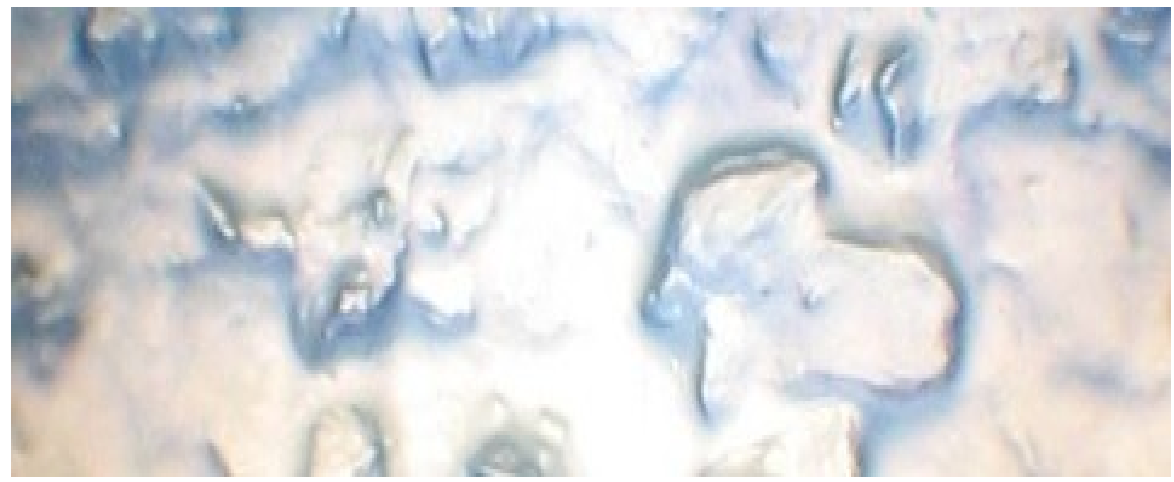

Amostra 2

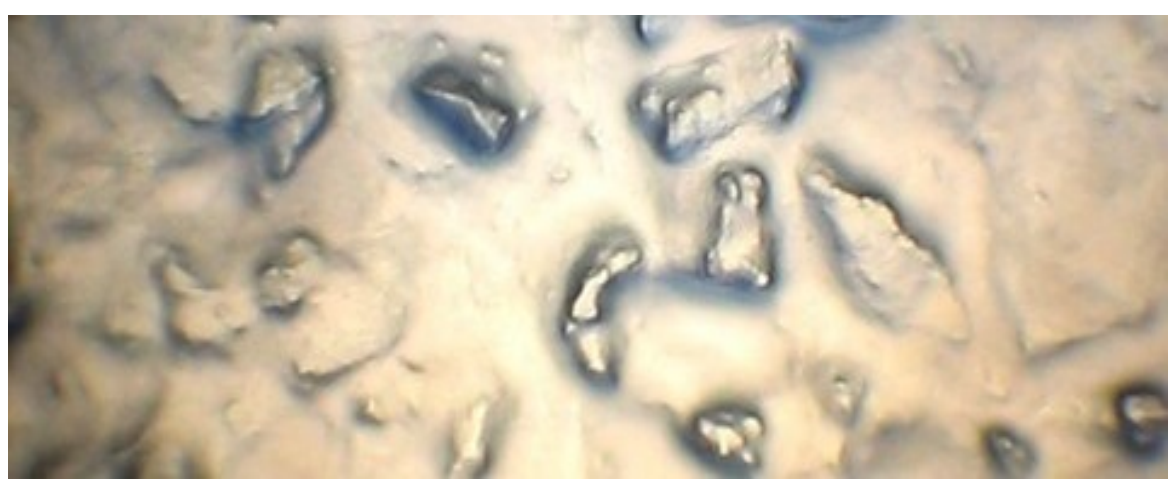

Amostra 3 


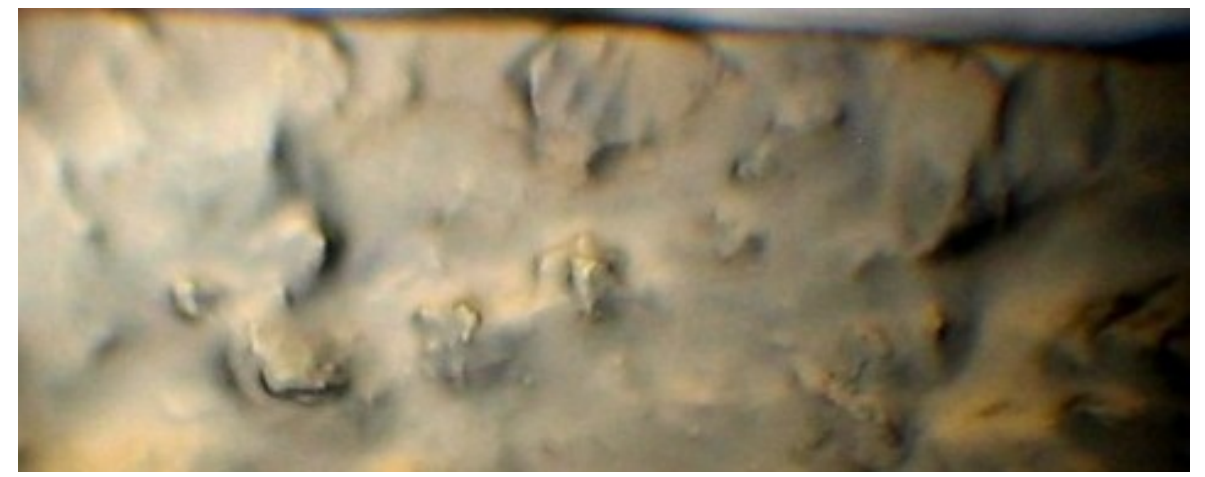

Amostra 4

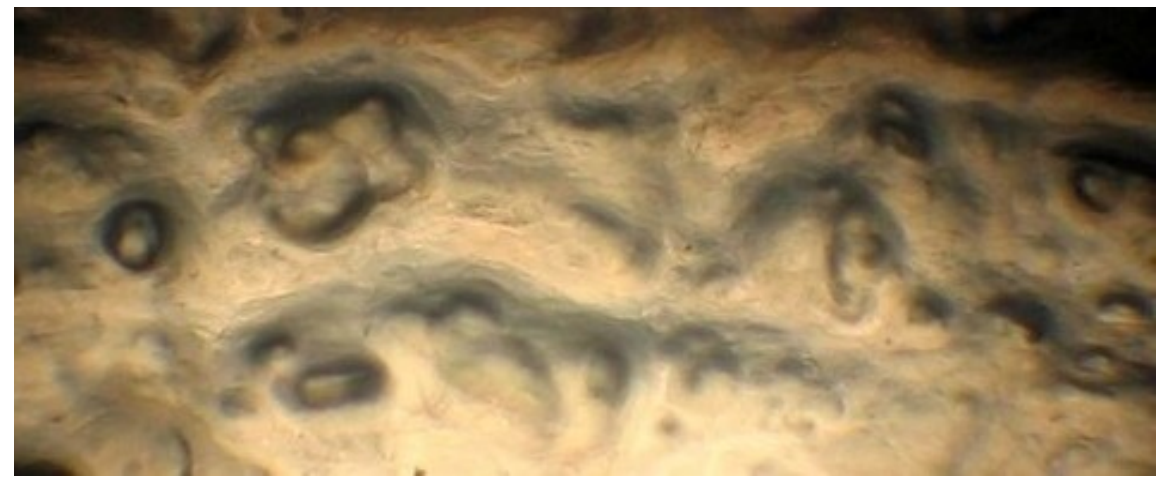

Amostra 5

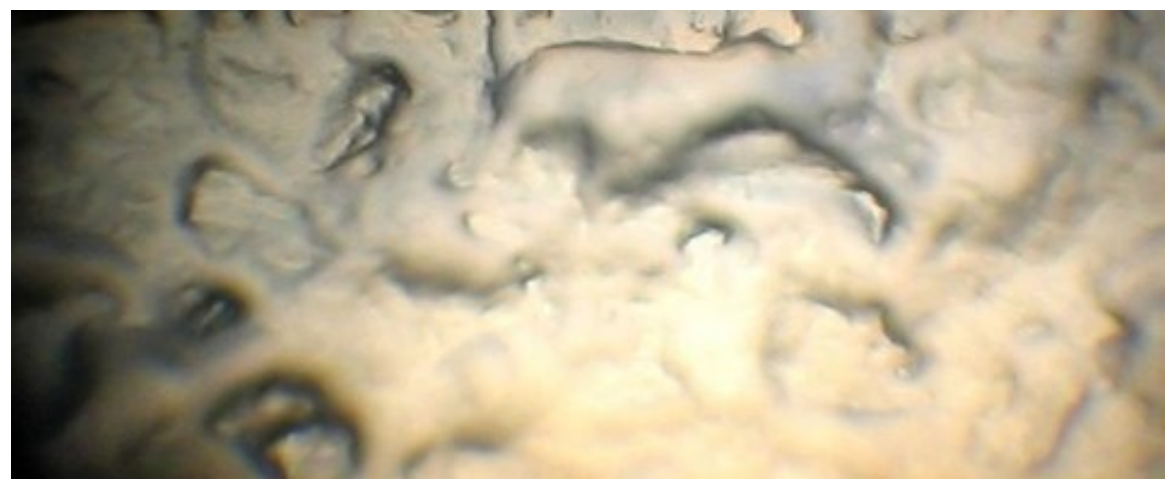

Amostra 6

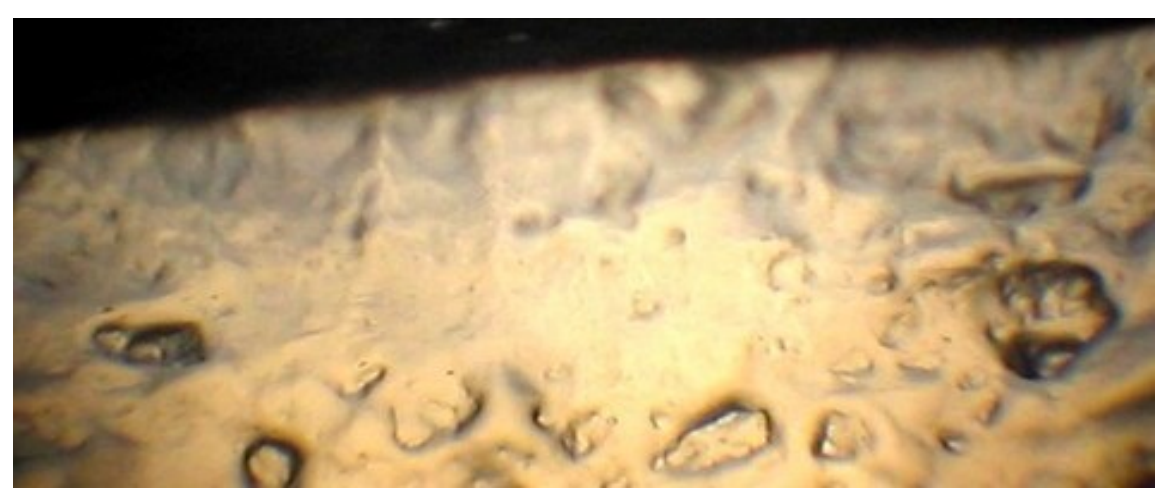

Amostra 7 


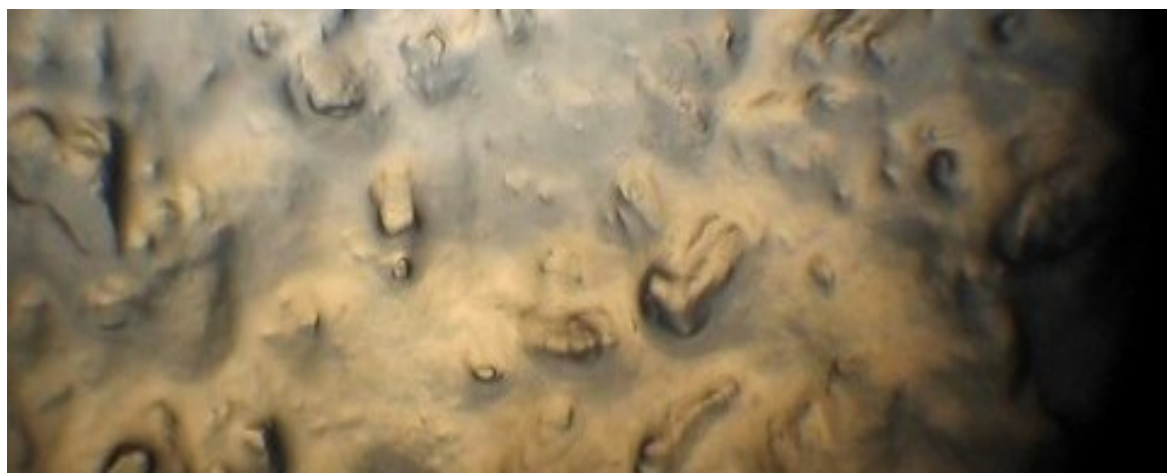

Amostra 8

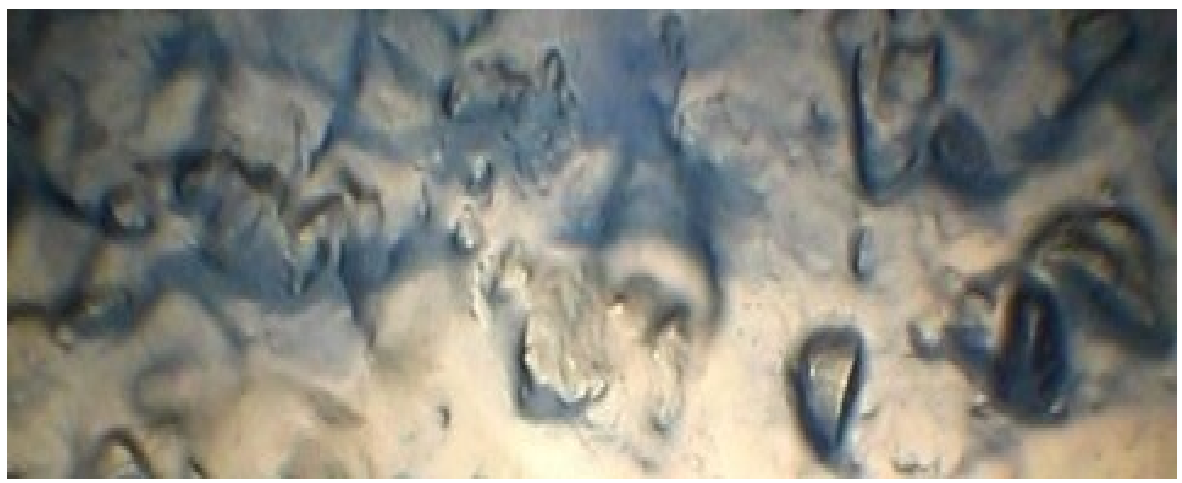

Amostra 9

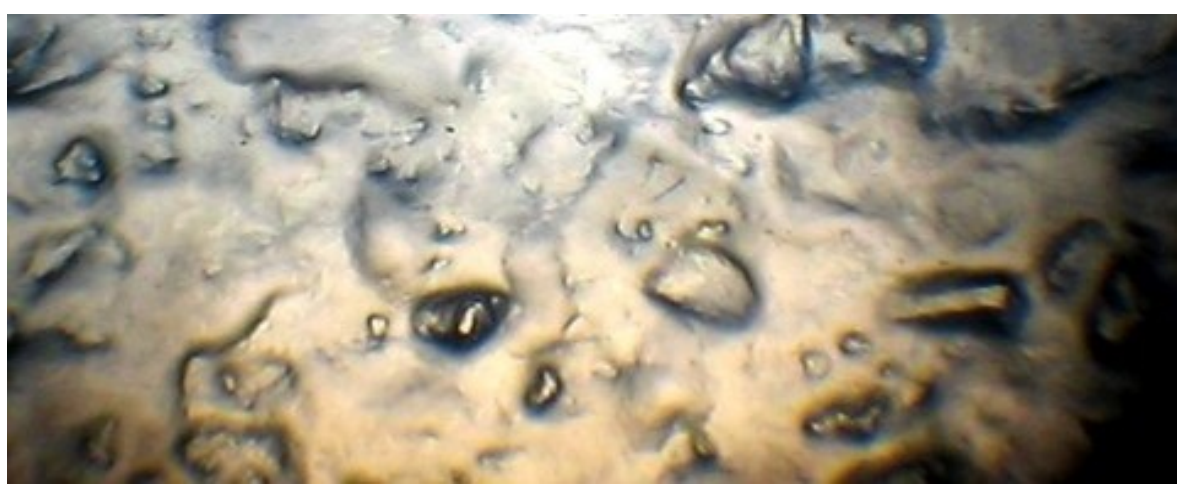

Amostra 10 
APÊNDICE C - Microscopia das Amostras Irradiadas a 1,5 W/cm²

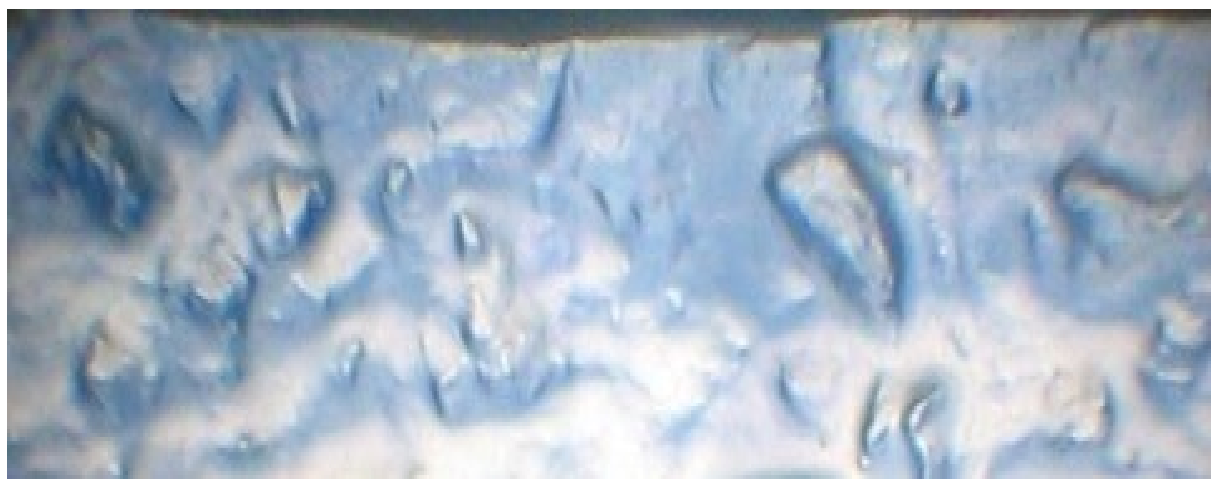

Amostra 1

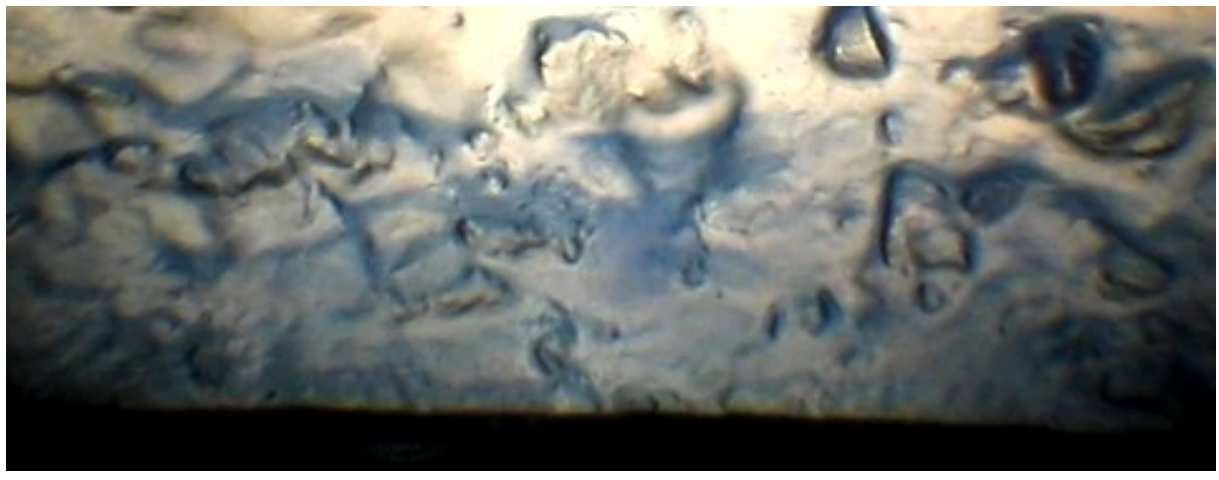

Amostra 2

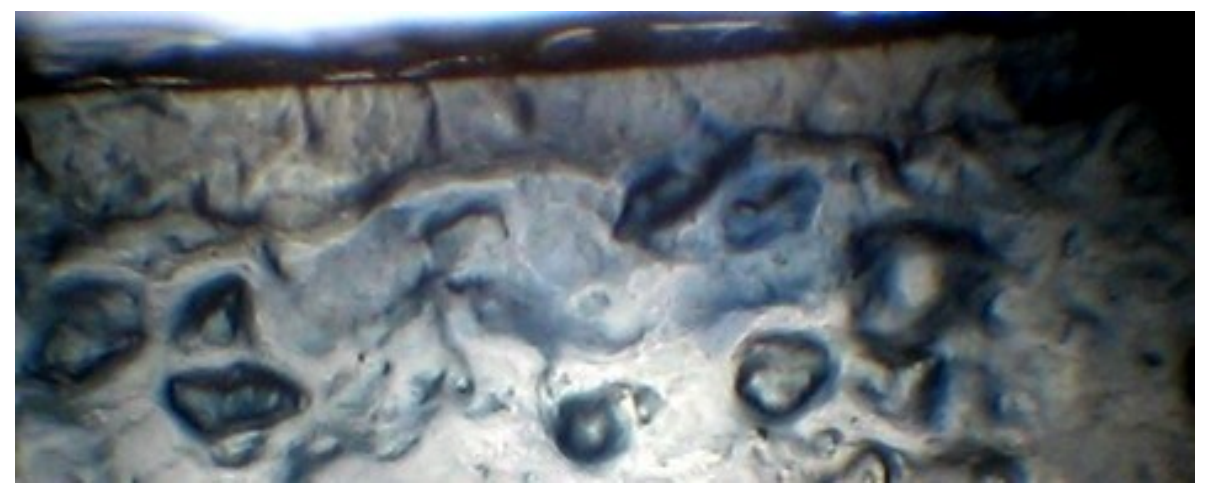

Amostra 3

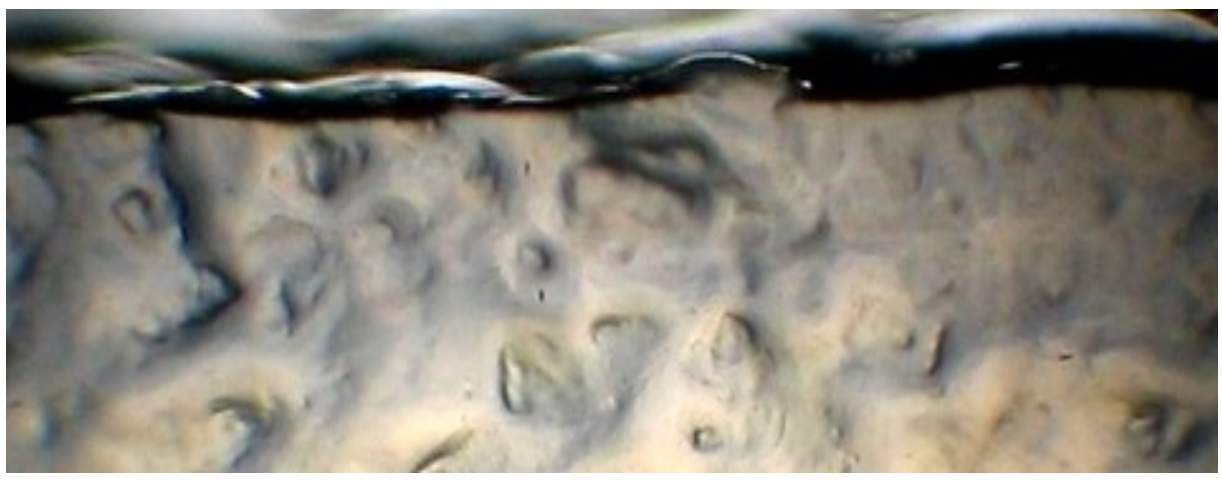




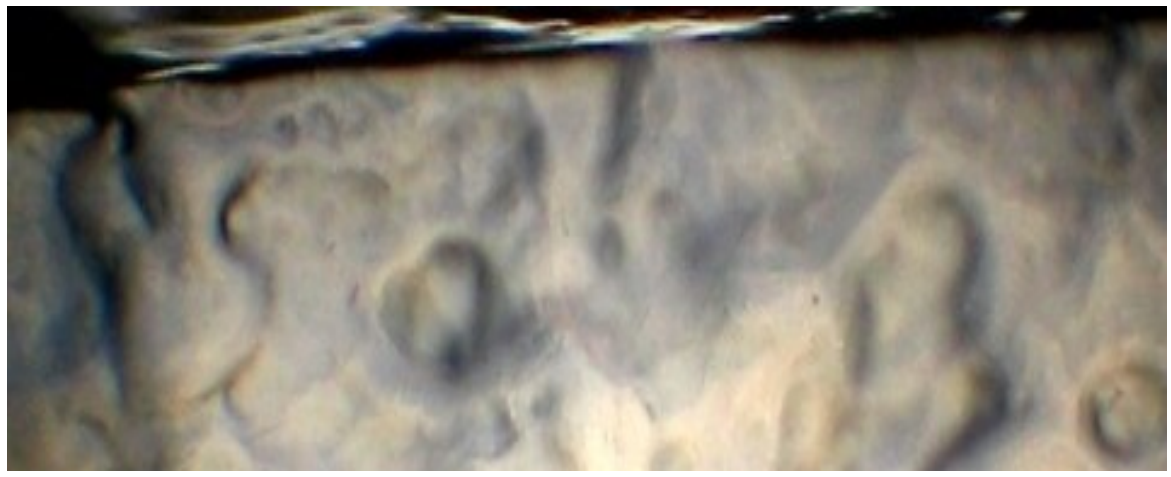

Amostra 5

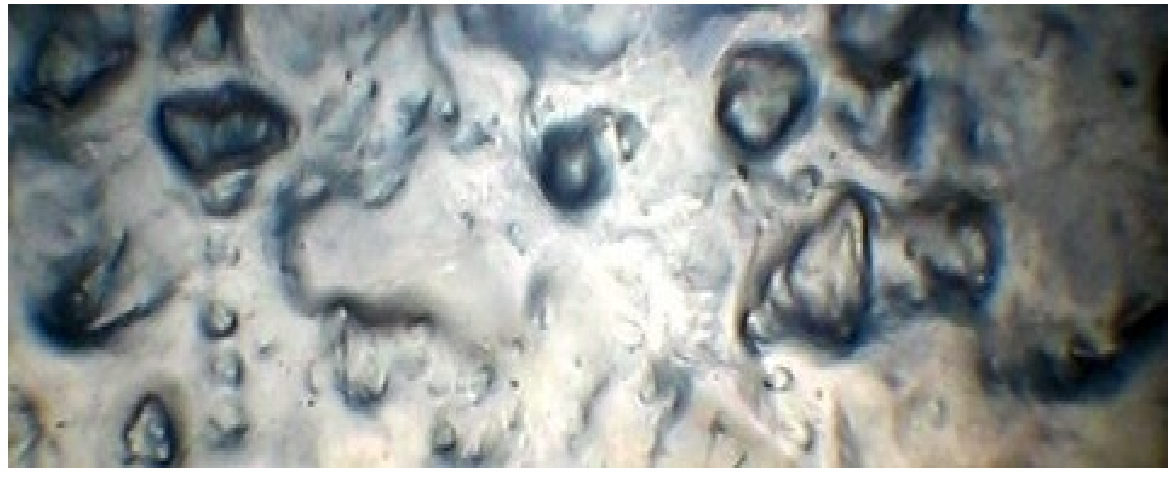

Amostra 6

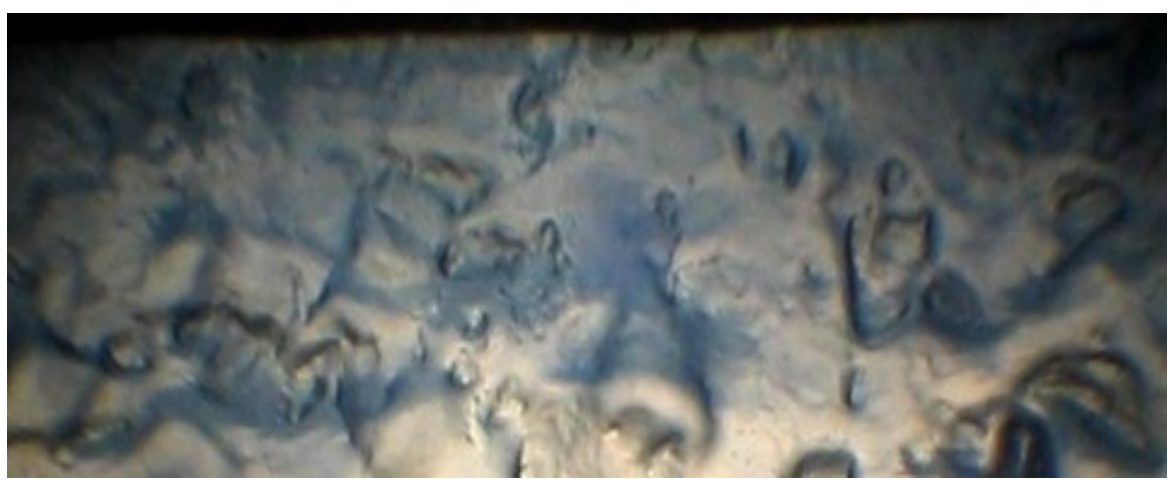

Amostra 7

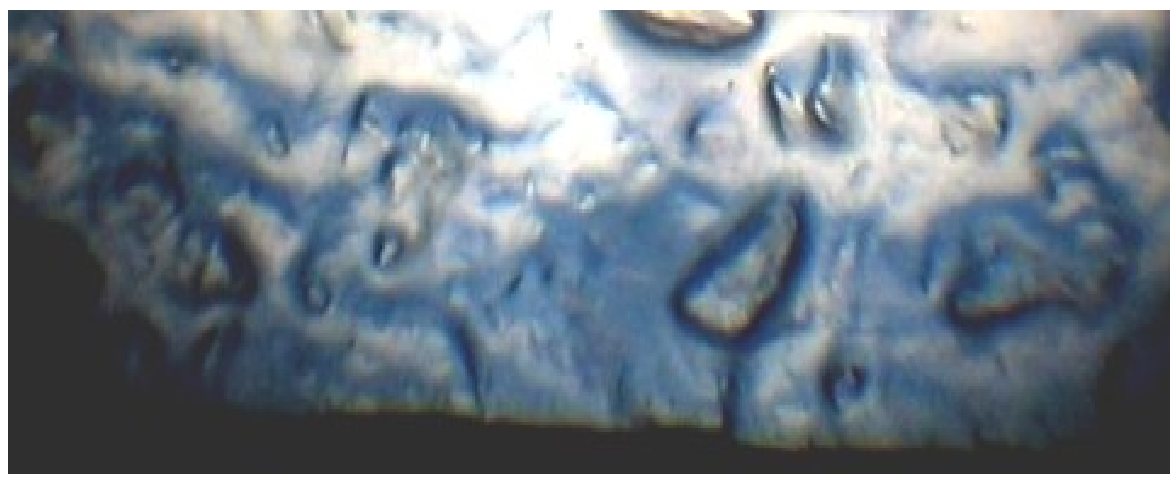




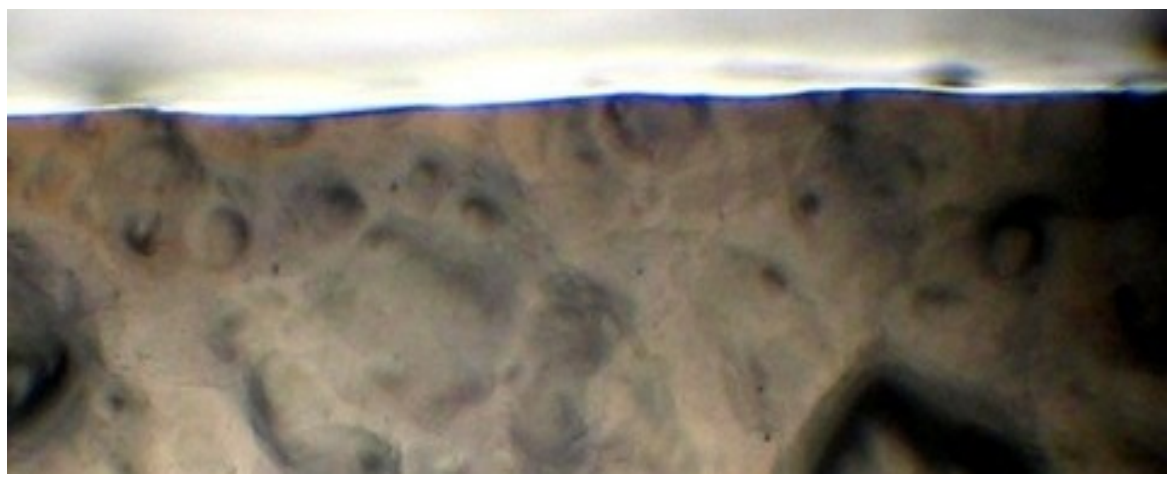

Amostra 9

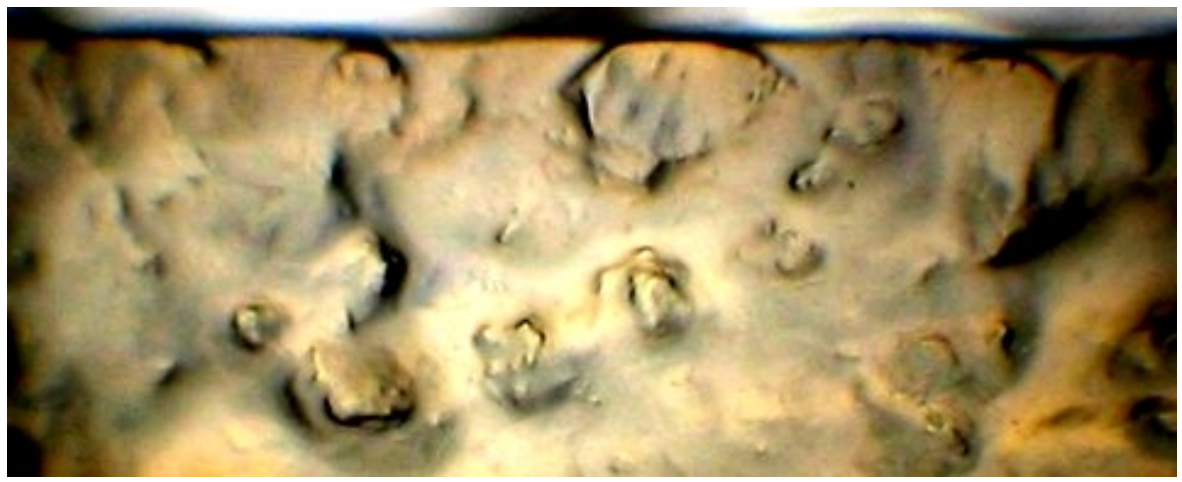

Amostra 10 
